\title{
SUPPLIERS' PERSPECTIVES ON AUTHENTIC SOUVENIR PRODUCTS: A CASE OF LUANG PRABANG, LAOS
}

\author{
BY
}

\section{BOUAVANH SOUKHATHAMMAVONG}

\author{
A thesis \\ submitted to Victoria University of Wellington in \\ fulfilment of the requirements for the degree of \\ Master of Tourism Management
}

Victoria University of Wellington 2018 


\section{Abstract}

Research on authenticity of souvenirs has been approached from the tourists' perspective given the fact that souvenirs are viewed as items functioning as a reminder or collection tool of destination experience. The heavily weighted view on authentic souvenirs from the user's view point overlooked the suppliers' role in producing and supplying authentic items, and this research aims to fill this research gap by identifying the meaning of authentic souvenirs, sources of souvenir supply/production, and the values and challenges of souvenir production from the souvenir suppliers' perspective. This research uses Laos as its case study, in particular, Luang Prabang (LPB) province which has had a rapid growth of tourists at its UNESCO World Heritage site and increased demand for authentic souvenirs accordingly.

Qualitative research was employed to generate greater meanings by using interview and participant observation as instruments to collect data. The purposive and snowball sampling were used to seek potential and appropriate key souvenir suppliers. Twenty-four souvenir suppliers were selected from four different groups, namely: souvenir producers, souvenir vendors, souvenir retailers, and middlemen. The research was conducted between July and September 2017 in various tourist hotspots in LPB, Laos, such as LPB night market, Phanom Village (Phanom Handicraft Centre), Royal Palace Museum, Kuangsi waterfall and OCK POP TOK. These attractions were selected because they attracted both suppliers and tourists. The raw data was analysed through thematic analysis manually. Major themes derived from interview sections have been combined with participant observation data to certify/confirm the validity.

In general, the key findings in this research indicate that LPB souvenir suppliers view authentic souvenir products as crucial because of their historical and cultural representation, including the significance of place identity. Major souvenir suppliers agree that authentic souvenirs should be related to the handicrafts and produced by local craftsmen. The products should represent LPB's authenticity and Lao culture. Souvenir suppliers believe that a good authentic souvenir can establish a great image for the tourism industry in LPB as well as Laos. This research newly finds that attitudes toward, and willingness to sell, imported and mass-produced souvenirs are more typical of souvenir vendors as they have less resources including 
financial limitation. On one hand, this research identifies three key values perceived by the suppliers: economic, symbolic and artisan. On the other hand, one issue with which souvenir suppliers are confronted relate to lack of raw materials.

This research presents important implications for both academia and practitioners. For academia, this research contributes to the tourism product research from the souvenir supplier's view point where the literature in tourism research is not yet fully developed. Academic researchers can adopt the conceptual framework proposed in this thesis and refer to the findings as their reference for further studies. Practitioners and souvenir sectors in tourist destinations, including marketers and government agencies, should acknowledge and consider issues addressed by various suppliers. Further solutions should be implemented in collaboration with tourism stakeholders to sustain and improve souvenir businesses.

Key words: authenticity, souvenir, values, supplier, World Heritage Site. 


\section{Acknowledgement}

I would like to use this opportunity to express my sincere thanks to organisations and people who have given me great assistance and excellent support to my academic life in New Zealand. First, my appreciative thanks to New Zealand Aid for providing the scholarship which has allowed me to pursue my study. Thanks to Victoria International Student Organisation and Student Learning Centre for your great services.

Most importantly, I would like to express my special appreciation and thanks to my fabulous supervisor, Dr Eerang Park. I greatly appreciate your excellent support, your time and immediate feedback that you have devoted to encourage my academic endeavour. With this great support, I am the first Masters student under the New Zealand Aid scholarship to have had the opportunity to present a research paper in the international conference and be the first Masters student in the School of Management to attend the overseas conference. This is one of my unforgettable events in my academic life; without you, I would not have gotten so far and received this opportunity. I would also like to thank the Tourism Group staff and lecturers at Victoria University of Wellington (VUW), the School of Management staff, and Student Learning Support for their kindness and assistance during my research at Wellington. Thanks to Kathryn Lawrence for proofreading my paper.

My appreciation to people at my work place, Institute of Mass Media Culture and Tourism, Ministry of Information, Culture and Tourism; Department of Luang Prabang Information Culture and Tourism, and Luang Prabang Handicraft Association for their consistent support and assistance. I am very grateful to these organisations for giving me the time to meet and discuss my research, and for offering the permission letter to conduct the survey in Luang Prabang province. Special thanks to respondents who sacrificed their time to be involved in this study.

At a personal level, I would like to thank to my lovely parents, Bounthong and Bounyang Soukhathammavong for their support since I was young. You are my inspiration and I love you both very much. Thanks to my husband who is always beside me and is a wonderful partner. Your love, care and time devoted to supporting our family, has allowed me to fully focus on my study. I am really appreciative. To all these people, thank you very much. 


\section{Table of Contents}

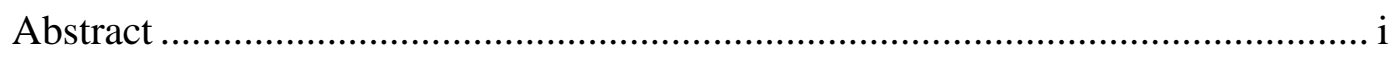

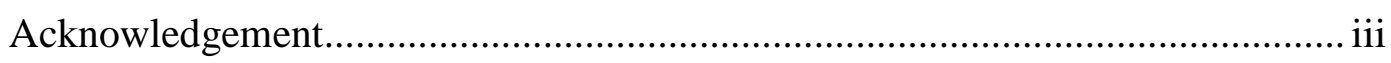

List of Figures ............................................................................................ vii

List of Tables................................................................................... viii

List of abbreviation and used terms ............................................................ ix

CHAPTER 1: BACKGROUND AND RESEARCH FOCUS ............................. 1

1.1 Study background .............................................................................. 1

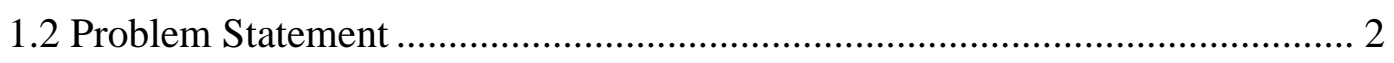

1.3 Aim of research and objectives ................................................................. 3

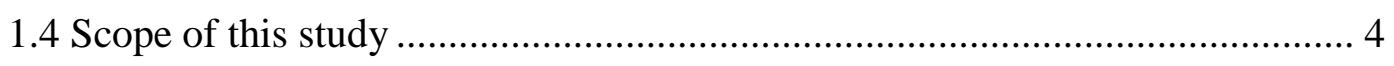

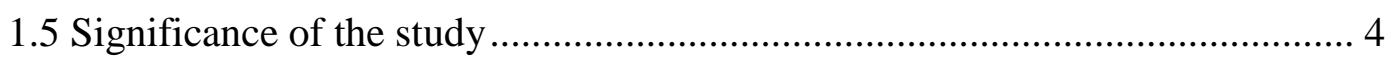

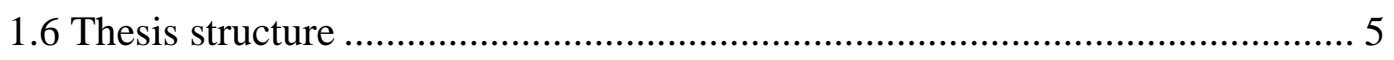

CHAPTER 2: LITERATURE REVIEW …................................................... 7

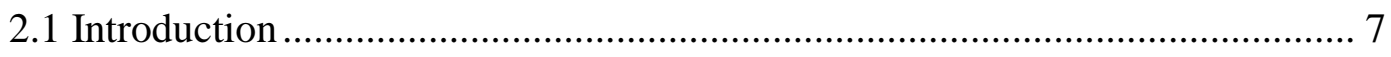

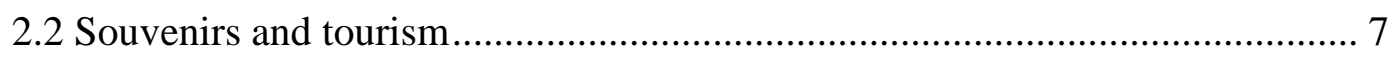

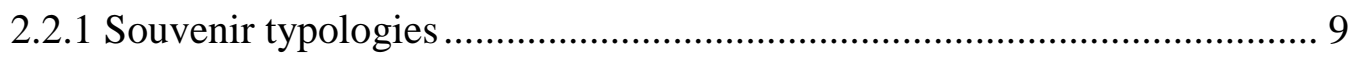

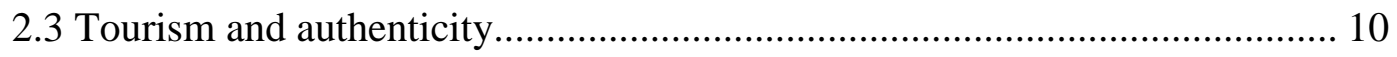

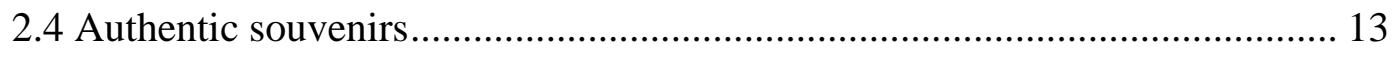

2.4.1 Tourist perceived authentic souvenirs .................................................. 13

2.4.2 Supplier perceived authentic souvenirs .............................................. 16

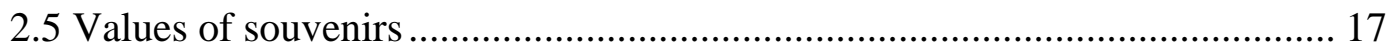

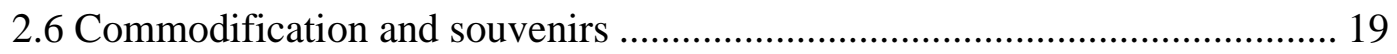

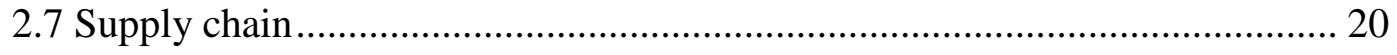

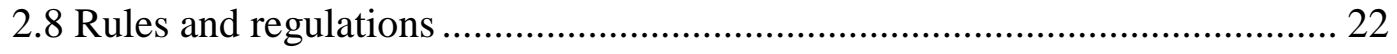

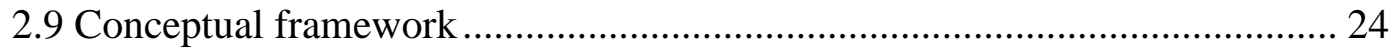

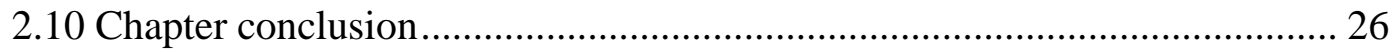

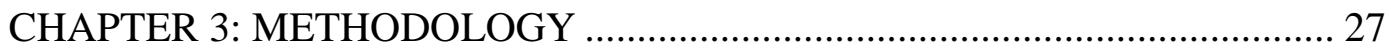

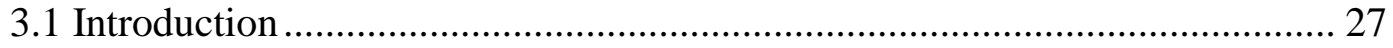

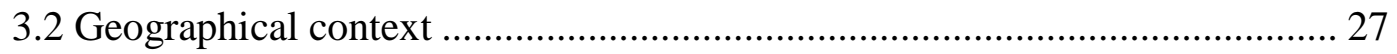

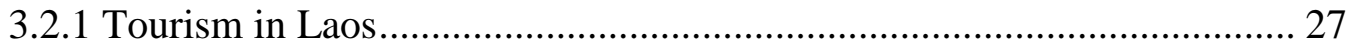

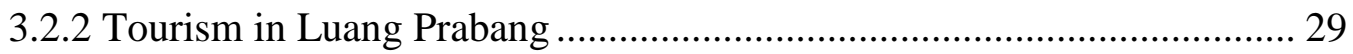

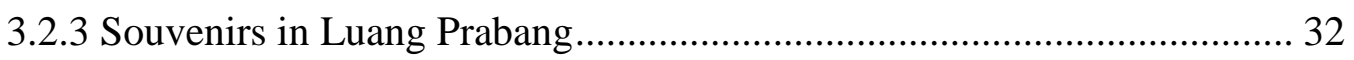

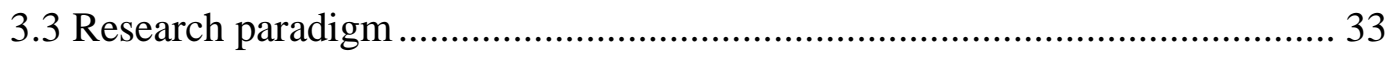




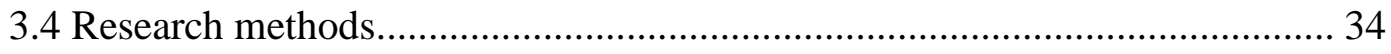

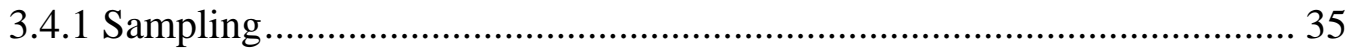

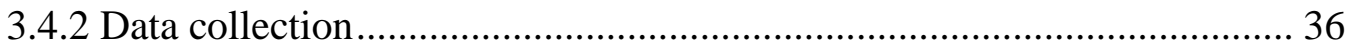

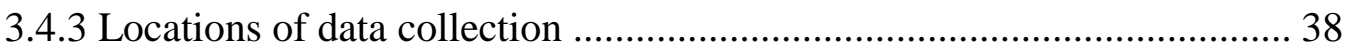

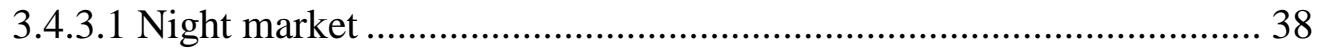

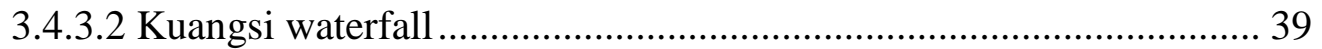

3.4.3.3 Phanom Handicraft centre ................................................................ 39

3.4.3.4 The Royal Palace Museum ............................................................... 40

3.4.3.5 Ock Pop Tok Living Crafts............................................................... 41

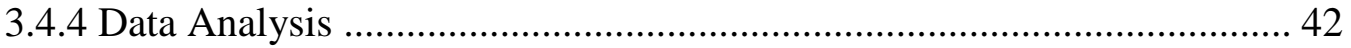

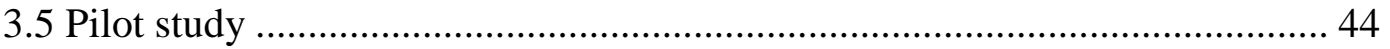

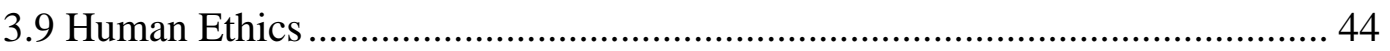

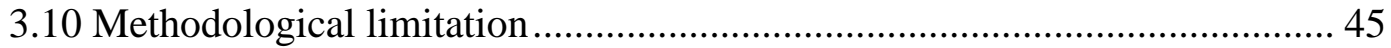

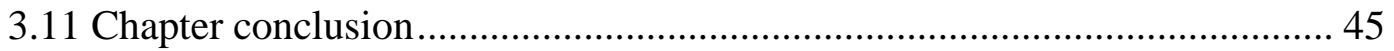

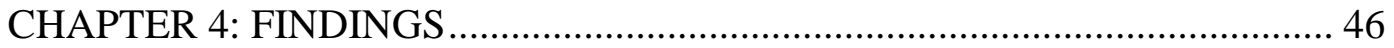

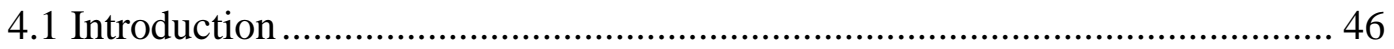

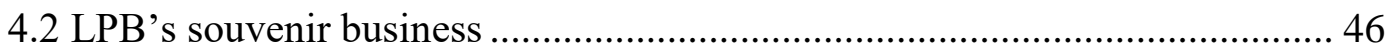

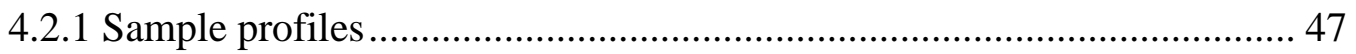

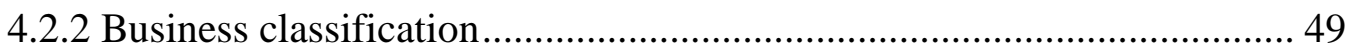

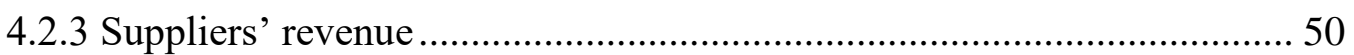

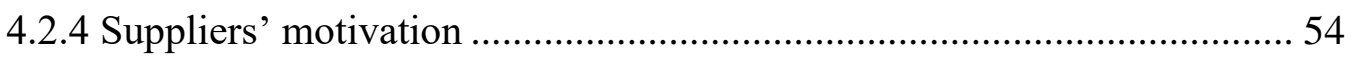

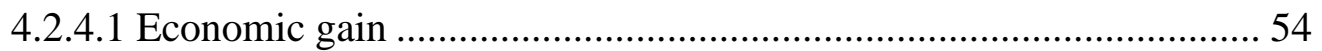

4.2.4.2 Family inheritance/family business ............................................... 56

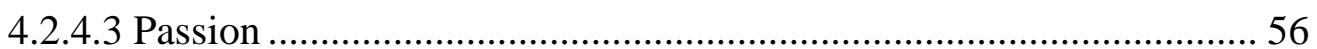

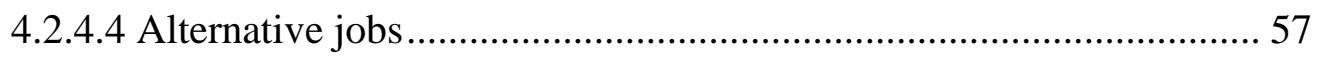

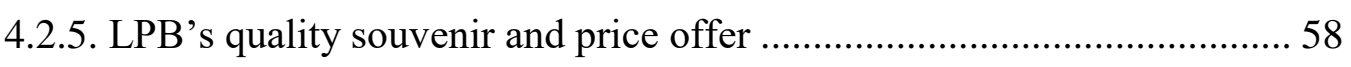

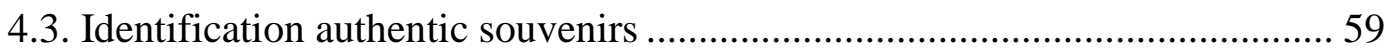

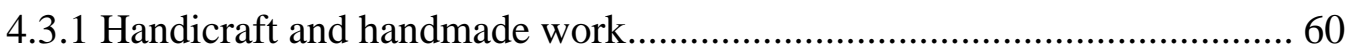

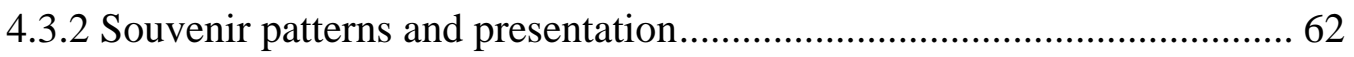

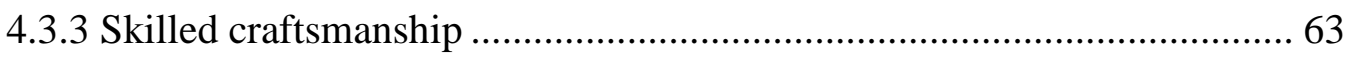

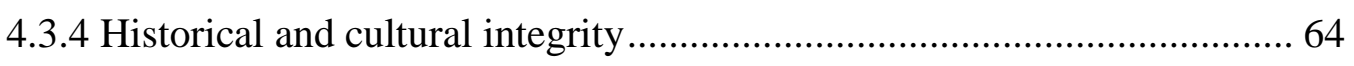

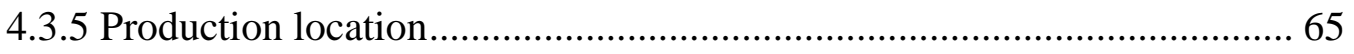

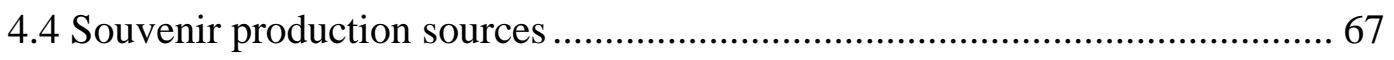

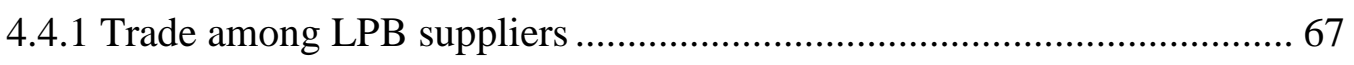

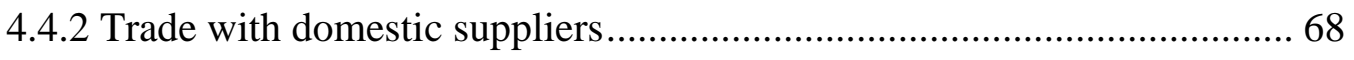

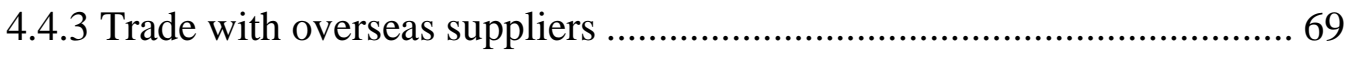




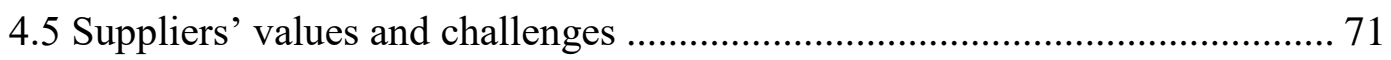

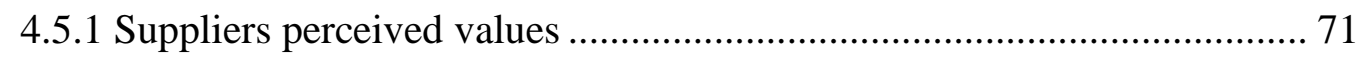

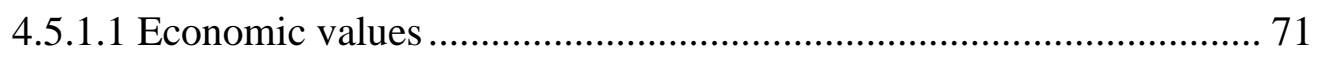

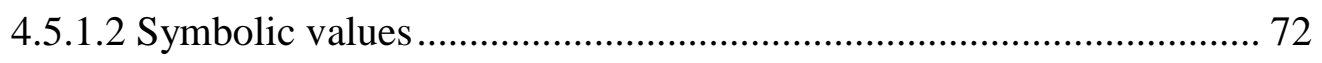

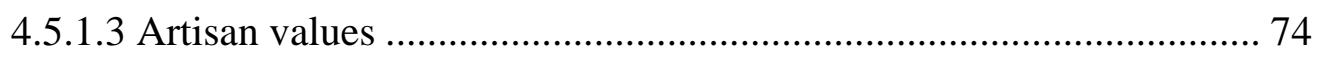

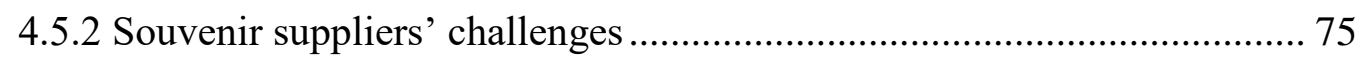

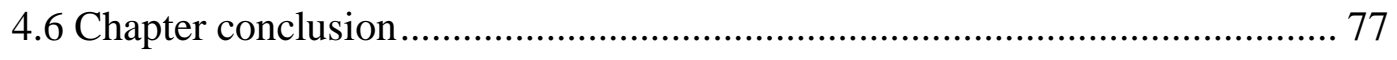

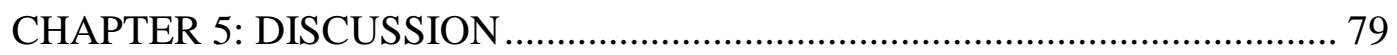

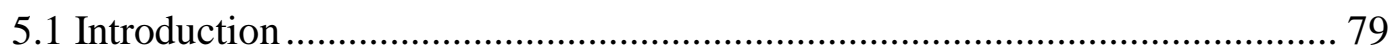

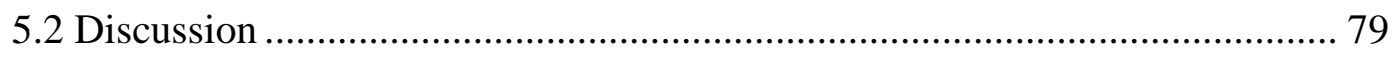

5.2.1 Suppliers and authentic souvenirs ................................................... 79

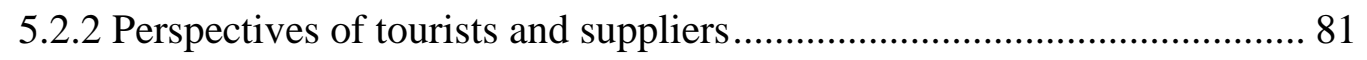

5.2.3 Reflection of suppliers' values and challenges ..................................... 81

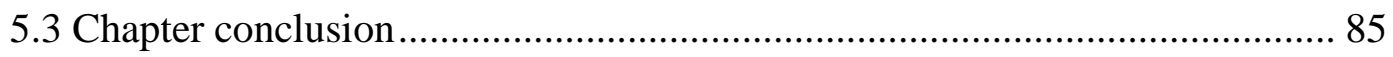

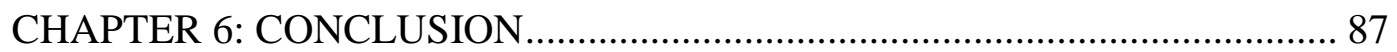

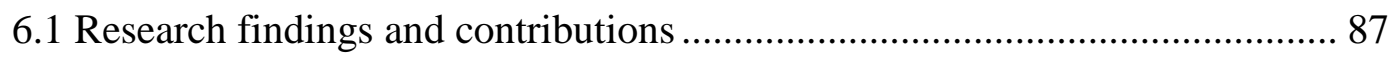

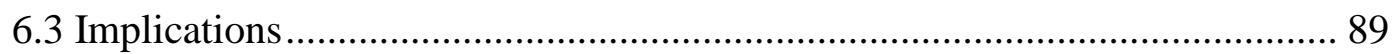

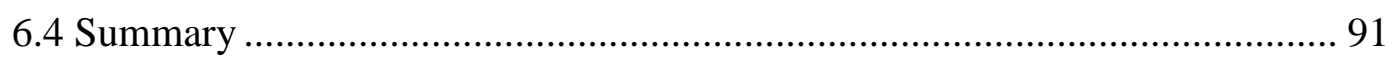

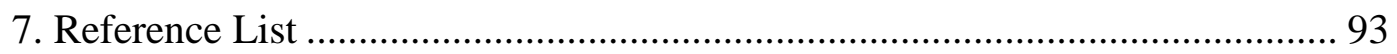

8. Appendix A: Interview Section Guideline ................................................. 101

9. Appendix B: Participant Consent Form .................................................... 103

10. Appendix C: Participant Information Sheet ............................................... 104

12. Appendix D1: Research Approval Letter (English version) ........................ 105

13. Appendix E2: Research Approval Letter (Lao version) .............................. 106 


\section{List of Figures}

Figure 2.1: Souvenir supply chain structure and suppliers' relationships 21

Figure 2.2: Conceptual framework of souvenirs and its relationship with the supply and demand side ............................................................................. 25

Figure 3.1: Laos's location and the area of research........................................ 28

Figure 3.2 Traditional morning alms giving in LPB city ................................. 30

Figure 3.3: Laos New year or Pi Mai water festivals in LPB city ...................... 31

Figure 3.4. Handmade and authentic souvenirs at Phanom Centre...................... 39

Figure 3.5: Lao female performs the textile weaving at the Phanom Centre......40

Figure 3.6. Handmade textiles clothes at Phanom Centre, LPB................40

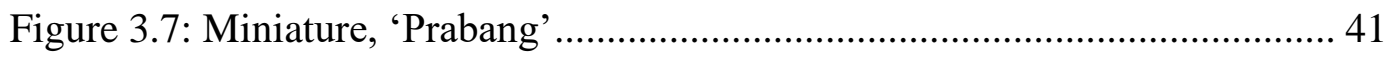

Figure 3.8: Dining area ........................................... 41

Figure 3.9: Accommodation...............................................41

Figure 3.10: Free one-on-one or group tour at the Ock Pop Tok Living Crafts ... 42

Figure 3.11: Data analysis process....................................43

Figure 4.1: Authentic souvenir stall in LPB international airport....................... 51

Figure 4.2: Authentic textiles souvenir and Buddha painting ........................... 52

Figure 4.3: LPB suppliers' perception toward authentic ................................... 60

Figure 4.4: LPB pictorial souvenirs of Luang Prabang...................................... 73

Figure 4.5: Lady perform the stage authenticity at crafst centre.................74

Figure 4.6: Artisan value perceived by LPB suppliers ................................... 75 


\section{List of Tables}

Table 2.1: Souvenir values perceived by tourists............................................. 18

Table 3.1: Revenue from tourism and major exports between 2013 and 2015.... 29

Table 4.1: Snapshot of LPB suppliers profiles ............................................... 47

Table 4.2: LPB souvenir suppliers' role profiles ............................................. 48

Table 4.3: Suppliers' motives for working in souvenir business in LPB ............ 54 


\section{List of abbreviation and used terms}

$\begin{array}{ll}\text { ADB } & =\text { Asian Development Bank } \\ \text { ASEAN } & \text { Association of South East Asian Nation } \\ \text { Domestic suppliers }= & \text { Suppliers who reside outside LPB but trade with LPB } \\ & \text { suppliers } \\ \text { GMS countries } & =\text { Greater Mekong Sub-region countries } \\ \text { International suppliers = Suppliers who reside outside Laos } & =\text { Lao Handicrafts Association } \\ \text { LHA } & =\text { Lao National Chamber of Commerce and Industry } \\ \text { LNCCI } & =\text { Lao National Tourism Association } \\ \text { LNTA } & =\text { Luang Prabang } \\ \text { LPB } & =\text { Suppliers who reside and work on the business within } \\ \text { Local Suppliers } & \text { LPB } \\ \text { ODOP } & \text { One district one product } \\ \text { MICT } & \text { Ministry of Information Culture and Tourism } \\ \text { SMEs } & =\text { Small and Medium Enterprises } \\ \text { SNV } & =\text { Netherland Development Agency } \\ \text { SPs } & =\text { Souvenir Producers } \\ \text { SRs } & =\text { Souvenir Retailers } \\ \text { SVs } & \text { Souvenir Vendors } \\ \text { UNESCO } & \text { Organization } \\ & \end{array}$




\section{CHAPTER 1: BACKGROUND AND RESEARCH FOCUS}

\subsection{Study background}

Tourism has been recommended as a way to drive social economic development (Telfer \& Sharpley, 2015). According to the United Nations Educational, Scientific and Culture Organization or UNWTO (2017), worldwide global destinations received 1.1 billion international tourists between January and October 2017, approximately a $7 \%$ increase on the same period as last year and approximately a 70-million increase of international arrivals. This impacts on the overall world economic upswing across the regions. Souvenirs are a part of tourism activities that bring significant value to the tourist destination (Cave, Baum and Jolliffe, 2013). Souvenirs can strengthen and improve a destination's economy (Lacher and Nepal 2011). Millions of workers around the world are hired in the souvenir production, distribution and selling process, and that brings a huge economic contribution to the destinations (Moscardo, 2008).

The study of Littrell, Baizerman, Kean, and Gahring (1994) revealed that one in three, or approximately $33 \%$, of tourist expenditure is devoted to purchasing souvenirs. In addition, souvenirs have become a major source of income and offer possible benefits for host destinations (Brennan \& Savage, 2012) and this can alleviate poverty, especially for souvenir producers who live in far distant and/or rural areas, particularly in developing countries such as Vietnam, Malaysia, Thailand, and Laos (Lacher and Nepal, 2011; Thirumaran, Dam, \& Thirumaran, 2014; Tourism Development Department (TDD), 2015; UNDP, 2013). Because of these benefits, many destinations attempt to pursue a strategy, in fact a number of destination developments aim to create authentic souvenirs that look appealing to tourists in order to engage tourists' interests in those destinations and increase their purchasing.

Swanson and Timothy (2012) identify two main components of souvenir industry: demand (i.e. tourists) and supply (i.e. suppliers: souvenir sellers/producers/middlemen). However, tourism research has focused more on the demand side such as tourists' purchasing behaviour (Altintzoglou, Heide, \& Borch,, 2016; Anuar, Yulia, Hamden, Abdul \& Edruce, 2017; Putachote, 2013; Wilkins, 2011), souvenir and travel motivations (Swanson and Horridge, 2006), conceptualising of objects and the meaning of souvenirs (Wang, 1999), and tourists' 
views on souvenirs and authenticity (Peters, 2011; Torabian and Arai, 2016), but it is still limited on the supplier side. To explore and preserve the values and strengthen the local souvenir products as well as gaining profit for host destinations, it is essential to understand suppliers' views on the souvenir sector, especially how suppliers perceive authenticity of the souvenir products they produce, deliver, and/or sell that may enhance or reduce the quality of tourists' experiences.

Research in souvenirs and the issue of authentic souvenirs, particularly in cultural heritage destinations such as Laos, where natural and cultural attributes are the competitive edge of tourism, is needed for destination management, engaging especially with supplier-side stakeholders. But, because of the paucity of research with reference to the local context, the souvenir sector in Laos hardly accesses references and industry frameworks for its businesses. While visitors seek authentic souvenirs, distributing a high volume of unknown souvenirs leads to the loss of the sense of authenticity (Charters, 2012; Nazariadli, Morais, Barbieri, \& Smith, 2017). The aim of this study is thus to explore and examine the souvenir suppliers' perceptions of, and attitudes toward, authentic souvenirs. This research assumes that souvenir suppliers are associated with the quality of authentic souvenirs produced, delivered, and/or sold to tourists, especially in the World Heritage context. Understanding the suppliers' perspective will assist to provide better information and diminish the negative impacts by presenting better solutions. This research uses Laos as the case study, particularly Luang Prabang (LPB) province, where there has been a rapid growth of tourist arrivals at its UNESCO World Heritage site.

\subsection{Problem Statement}

The research on authenticity regarding souvenirs has made progress in tourism studies, but this thesis identifies research gaps in twofold. First, previous academic literature has explored the souvenir and its authenticity from the tourists' perspective but rarely from the suppliers', which is needed for destination management. It should engage equally with the supplier-side stakeholders' perspective. Failing to address this may create an incomplete picture of the souvenir sector and its involvement in tourists' experiences and consumption in a heritage destination.

Second, research in the area of souvenirs and the issue of authentic souvenirs, particularly in cultural heritage destinations, is needed for destination management. It should engage with supplier-side stakeholders. In the chosen research context, Laos, 
where natural and cultural attributes are the competitive edge of tourism, the government has focused more on basic infrastructure development for tourism growth and less on destination management with souvenir production and sales. Although Laos' handicrafts are one of the nine main income sources (GMS, 2014), most of the support is limited and inconsistent for souvenirs in general. In fact, the key support for this industry is from entrepreneurs, small businesses and foreign aid, and these groups work independently. Because of the paucity of research with reference to the local context, the souvenir sector in Laos rarely accesses references and industry frameworks for its businesses.

The souvenir suppliers' practical issues are not limited to the lack of references but extend to wider 'tug-of-war' issues. The commodification of souvenirs has accelerated the importing of goods from other countries such as China. There is increased media attention on the opportunities and challenges of the souvenir sector in Laos. The media reports that local souvenir producers cannot provide large volumes, consistent quality, and have limited patterns, whereas overseas souvenir producers can provide large volumes, consistent quality and more varied patterns; they can even offer low prices (Vientiane Times, 2017). While visitors seek authentic souvenirs, distributing a high volume of souvenirs tends to lose the sense of authenticity (Charters, 2012). Recently, research also revealed that tourists tend to avoid fake souvenir products that are, in their view, unappealing in presentation and lacking authenticity even though the prices are cheaper (Thirumara et al., 2014). To preserve the values and strengthen the local souvenir products as well as gaining profit for host destinations, it is essential to understand how suppliers perceive the souvenir products they produce and deliver.

\subsection{Aim of research and objectives}

In order to fill the research gaps identified, this research aims to explore and examine the souvenir suppliers' perceptions of, and attitudes toward, authentic souvenirs. This research uses Laos for a case study, in particular Luang Prabang (LPB) province which has had a rapid growth of tourist arrivals at its UNESCO World Heritage site. To achieve the purpose of this research, the following four objectives are proposed:

- to explore the souvenir business in LPB from the suppliers' point of view;

- to identify the meaning of authentic souvenirs from the suppliers' perspective; 
- to investigate the sources of souvenir production and supply in LPB;

- to investigate the values and the challenges of authentic souvenir supply in LPB from the suppliers' perspective.

\subsection{Scope of this study}

This research mainly focuses on the souvenir suppliers. It excludes the demand side (tourists). The scope of this research will focus on the target suppliers from four groups that have been identified by literature, namely: producers, retailers, vendors, and middlemen. This study does not include the view of government agencies. The reason to exclude the government in this research is because the researcher attempts to focus on the souvenir suppliers' perspective on the view of business side only. Thus, no government staff have been recruited. However, the potential interview participants are recommended by key tourism and souvenir industry authorities such as LPB Department of Information Culture and Tourism and LPB Handicrafts Association.

\subsection{Significance of the study}

This study aims to explore souvenir suppliers' perception and contribute to the existing gap from which other scholars can, especially in the World Heritage Site like LPB. The outcome of this study will have both academic and practical benefit. For the academic contribution, this research will fill the existing gap in the areas of tourism and souvenirs. The current research will provide a holistic understanding of souvenir suppliers' views on authentic souvenirs. This will fill the gap in tourism research with reference to souvenirs, which is heavily focused on the demand-side only. Future research can refer to the framework and findings of this research as a means to further investigate the souvenir suppliers. In terms of the practical contribution, the results of this research will inform key stakeholders - souvenir providers and souvenir authorities such as private businesses and public - of the current views of souvenir suppliers. Key authorities could capitalise on the findings of this research. Although only conducted in one location as a case study, these findings would also benefit other provinces and other areas with similar characteristics. The findings will be crucial for LPB souvenir suppliers. This research, in general, can also be considered as ground-breaking in this area in LPB, Laos, as well as in the context of developing countries. 


\subsection{Thesis structure}

This thesis has broken into six chapters:

Chapter 1 presents the needs of this research, the research background and the problem statement. In addition, it covers the research aim and four objectives to explore the perspectives of souvenirs' suppliers in authentic souvenirs in LPB province, Laos. It presents the limitation of this study's scope and the significance of this study. Lastly, the chapter presents the overview of the whole thesis structure.

Chapter 2 presents a literature review. This chapter starts with the importance of souvenirs to the tourism industry. This includes the impact of souvenirs on the destination image, businesses and tourists' experience. It presents the five souvenir typologies, and the expansion of souvenir research topics in various areas. The chapter has elaborated the interconnection of souvenir, tourism and authenticity concepts. It highlights the importance of souvenir product authenticity and identifies the three approaches to the authenticity concept (e.g. objective, construct, and existential authenticity) and these concepts will be used to investigate the perspectives of souvenir suppliers. It also discusses the authentic souvenir from the demand side (e.g. tourists) and the supply side (producers, vendors, retailers, and middlemen). It will extend and highlight the need for rules and regulations in souvenirs' management in this era. Finally, the chapter presents the conceptual framework.

Chapter 3 presents the research methodology. First, it revisits the aim of the research, which is to explore the suppliers' perspective on authentic souvenirs. The chapter justifies the reasons for choosing the research paradigm and research design. It explains the geographical context, including tourism in Laos, tourism in LPB and souvenirs in LPB. Further, it elaborates sampling, data collection methods, and data collection areas. It also presents the data analysis procedure and states the human ethics considerations. Finally, this chapter concludes with methodological limitations.

Chapter 4 presents the findings. The representation of findings follows the four research objectives. First, it presents the overview of the souvenir industry in LPB, including suppliers' personal information. This is followed by the motives of involving the souvenir business, and the overall souvenir market situation in LPB 
addressed by suppliers. This research also identifies the authentic souvenirs, highlights the souvenir production in LPB and the values and challenges of authentic souvenir supply from the suppliers' perspective. The immediate discussion on findings will synthesise and link these research findings back to the previous study.

Chapter 5 presents in-depth discussion on the research findings based on the facts presented and discussed in chapter 4 and makes the connection to the theoretical background and information in chapter 2, which supports the research finding the key considerations and implications must be scrutinised.

Chapter 6 concludes the overall research findings through summarising the key issues and results from the discussions. It takes an advance by presenting the key solutions and implications for improvement. Last, this chapter identifies the limitations of this study and suggests future research directions. 


\section{CHAPTER 2: LITERATURE REVIEW}

\subsection{Introduction}

Chapter 1 presents the research overview of souvenirs and rationales why this research is needed. This chapter revisits the previous relevant theories that related to souvenirs and authentic concepts. First, it starts with the importance of souvenirs in the tourism industry and identifies five souvenir typologies of Gordon (1986). It further elaborates the interconnection of tourism and authentic concepts. This includes the identification of the three authenticity concepts (e.g. objective, construct, and existential authenticity). In addition, it defines the authentic souvenir and reviews some perspectives of tourists and suppliers. It also examines the souvenir values that they perceived. Next, it explains the link of commodification and souvenirs in the tourism industry, followed by the supply chain explanation. The need for rules and regulations in souvenirs' management is expanded and highlights their importance to better development of souvenir businesses. Finally, a conceptual framework synthesises the literature review and is used to advance this study.

\subsection{Souvenirs and tourism}

A number of scholars defined souvenirs as objects that carry the place and culture orientation with tourists' associations. The word souvenir means 'Remembers' (Gordon, 1986). Commonly, souvenirs refer to gifts or products that are produced locally and are related to the significant culture and history of destinations (Dougoud, 2000; Trinh, Ryan, \& Cave, 2014; Waitt, 2000). Cave et al., (2013) state that recent study defines the souvenir as any item that can be used as a reminder or collection tool. Trinh et al., (2014) further assert that souvenirs not only represent the story of the destination but also place, image and sometimes even the brand of destination uniqueness. Souvenirs also represent a social interaction and are one of the easiest ways that tourists can experience the cultural and historical destination (Chhabra, 2005; Cave et al., 2013). In short, souvenirs can be any items that are linked to the place that tourists visited. 
Souvenirs can be seen as a crucial part of travel experiences and tourism activities (Elomba and Yun, 2017). Brennan and Savage (2012) and Shen (2011) assert that souvenirs mostly represent the images of regions and cultural icons and thus they create the sense of holding meanings. Swanson and Timothy (2012) indicate that a souvenir can be used as a tool to promote a destination's image as souvenirs carry the significance of countries. Thus, authentic souvenir provision is important to the destination in terms of presentation of its own uniqueness of culture, place and interaction with tourists through selling authentic items.

Souvenir production can contribute to the host's economy and the destination's overall image (Elomba \& Yun, 2017). Gordon (1986) claims tourists who are traveling afar purchase souvenirs as part of traveling to keep tangible memories/items as physical evidence of their travel between locations and are, perhaps, icons of national interaction. Thus, tourists are likely to seek authenticity and quality of souvenirs. The business survey claims that seven out of ten travellers perceive purchasing souvenirs as a central part of their holiday and only one in five travellers leave their holiday destinations without taking anything home (Holiday Inn, 2015). While tourists view souvenir items are pivotal to them, souvenirs also make the significant contributions to host economy.

In addition, souvenirs have become a significant contributor to the major sources of income and this alleviates poverty for souvenir suppliers', particularly producers in rural areas in developing countries. For example, $40 \%$ of people who live in a rural village in Vietnam rely on income from souvenir selling (Thirumaran et al., 2014). In Malaysia, some villages in outskirt towns have additional income from producing and selling souvenir products (UNDP, 2013). Many young residents in rural areas of Thailand and Cambodia are trained to be skilled craftsman so that they can generate income from making souvenirs (Lacher \& Nepal, 2011; UNWTO, 2012). In Laos, particularly in LPB, people from ethnic groups who live in the higher land, such as Hmong people, receive their main income from producing and selling souvenirs to support their families (TDD, 2015). It seems that in developing countries, souvenirs can be seen as a way to generate employment and create income and benefiting people in the destination widely. Thus, several destinations are attempting to effect souvenir development as a way to promote souvenir villages as tourist attractions to receive economic benefits.

In fact, souvenirs have been produced by integrating the destination's culture and uniqueness (Cave et al., 2013; Thirumaran et al., 2014). For instance, 
the Japanese government has used the concept of Green Tourism Souvenirs as a way to rejuvenate the decrease of agriculture products in off-peak season and create job opportunities for females (Hashimoto \& Telfer, 2013). However, there are also many examples of destinations that have spoiled or diminished the values of the destinations (Hume, 2013), when the demand and supply do not match in the destination, resulting in popularity yet lacking proper management/control. As a result, some destinations need to replace local souvenir products with imported items. According to Lacher and Nepal (2011), the imported souvenir products seem not to contribute to, or provide the economic value for, the local craftsmen. In fact, in the words of Cohen (1988), when local craft products or local souvenirs receive attention as commodification and trade, such souvenirs will eventually be imitated by non-original producers or even imported products.

\subsubsection{Souvenir typologies}

Souvenirs sold all over the world vary in the different areas. Gordon (1986) classified souvenirs into five typologies, namely: pictorial, piece-of-rock, symbolic, marker, and local products. (1) Pictorial souvenirs refer to image items such as postcards, photographs, and posters. Various destinations use the authentic feeling through photos. Capitalising on this, shooting photos at tourist attractions is still making money. (2) Piece-of-rock souvenirs refer to natural items that come from the destination's environment, such as stones from the beach and seashells. (3) Symbolic souvenirs are items that are mostly mass-produced objects rather than natural. The items represent place identity. There are basic items such as a miniature Eiffel Tower from France, a miniature Merlion from Singapore and a miniature That Luang stupa from Laos. (4) Marker souvenirs refer to items that can be increased in terms of value by adding specific words, locations, events or signs such as T-shirts and keychains. In fact, this type of souvenir typology is a world component of the travelling experience (Swanson \&Timothy, 2012) and the most duplicated items. 5) Local product souvenirs refer to various things such as local food/production that are made locally and represent a place and a destination (e.g. Sushi from Japan, Kimchi from Korea, TumYum soup from Thailand, Larb salad from Laos, and Manuka honey from New Zealand), alcohol items (e.g. vodka from Poland, Whisky from Scotland), local cloths and local crafts.

According to Gordon's (1986) proposed five souvenir types elaborated on earlier, the nature of this paper is to provide conceptual understanding. This 
research thus picks up her classification that serves as a systematic approach to advance by employing four out of five souvenir typologies to investigate the suppliers' perspectives and excludes piece-of-rock souvenirs because Laos is a landlocked country and strong on preserving its natural resources.

\subsection{Tourism and authenticity}

Authenticity is a crucial component of tourism products. The theme of authenticity has been interwoven with tourism research for more than four decades, when it was first introduced by McConnell (1976). It is used in various areas of tourism such as rituals, events, food, accommodation and even costumes (Steiner \& Reisinger, 2006). Authenticity is recognised as a crucial motivating force that inspires the tourism industry through products, services and tourist activities (Cohen \& Cohen, 2012; Kolar \& Zabkar, 2010; Mkono, 2011; Yeoman, Brass, \& McMahonBeattie, 2007). Yeoman et al (2007) stress that authenticity is a key driver for tourism products and it is one of the main attributes that tourists seek to enhance their travelling experiences. Despite the fact that authenticity is a pivotal criterion for tourism products, understanding of how this concept is constructed is worth investigating.

Many scholars define the term 'authenticity' as 'real', 'unique' and 'genuine' (Cohen, 1988; Gordon, 1986; Hashimoto \& Telfer, 2007). In the words of Sharpley (1994), authenticity in a tourism context refers to traditional values and its originality, the reality, and the uniqueness. In the tourism industry, especially when it is related to souvenir products, authenticity is not a standalone concept. In fact, there are other influential factors such as tourists' behaviour, and tourists' demography (Wang, 1999). Tourists seem to seek authentic souvenirs to keep mementos of their trip and experiences because souvenirs can represent place and people (Love \& Sheldon, 1998; Cave et al., 2013). Elomba and Yun (2017) examine the local and international tourists' perspectives toward authenticity in souvenir items but suggest the important perspectives of souvenir suppliers. Souvenirs capture the unique quality of destination and transport this quality home as a reminder of what made the place special (Swanson \& Timothy, 2012). Tourism research has discussed the relationships such as souvenir objects, visited place and distinct tourists (Cave et al., 2013). Thus, there are needs to further explain what authenticity means in a tourism context. 
To understand authenticity better, different scholars investigate various approaches. For example, Wang (1999) categorised authenticity into three types namely: objective, constructive and existential. Objective authenticity can be defined as object realism or it can refer to authentic items that can be tested and confirmed by the experts (Boorstin, 1961; MacCannell, 1973) when there is a need to make judgements about whether the item is real, true, correct, and authentic (Steiner \& Reisinger, 2006). In the Objective authenticity, MacCannell (1976) introduced Stage authenticity defined as offering tourists a particular performance as the stage of reference (MacCannell, 1973). Constructive authenticity depends on tourists' perceived experiences. For example, shopping in the copycat souvenir shop is perceived as authentic to tourists due to market uniqueness such as location, fun and the ability to negotiate the price ( $\mathrm{Wu}$, Wall, \& Pearce, 2014). In short, constructive authenticity can be constructed from people in the society. Existential authenticity refers to the person/individual who feels authentic because the experience they receive, or object they see, is not common in their daily life.

In addition, Silver (1993) projects authenticity as travellers' own trusts, outlooks and favourites, and this concept is similar to Constructive authenticity proposed by Wang (1999). Cohen (1979) distinguished authenticity into 'true or false'. However, he argued that tourists' views on authentic souvenirs can be changed from time-to-time. Among the wider assumption of authentic concepts, Wang (1999) suggests the most comprehensive conceptual frameworks of authentic concepts. Objective authenticity refers to authenticity as independently judged by professionals rather than perceived by tourists (Torabian \& Arai, 2016). For example, objective authenticity can be provided where products are made from local craftsman or from local natural materials. Objective authenticity is often judged by experts' standard rather than tourists, and the suppliers (e.g. producers, artisans) are the main people who can determine objective authenticity (Chhabra, 2005).

Some researchers believe that authenticity can be constructed (e.g. Cohen, 1988, Wang, 1999) especially in terms of stage authenticity. Cohen (1988) and Littrell et al. (1993) argue whether tourists can enjoy authentic ambience/items also depends on the tourists' style, character, and travel repetitions. MacCannell (1976) strongly disagrees and he perceived a different view with a further elaboration of 'Staged authenticity'. He introduced two concepts: 'Front' and 'Back' stage. Where Front stage refers to the place for welcoming and greeting the tourists, it is the place where the shows should display. Back stage is the area that is mostly closed to the 
outsiders, but tourists are keen to explore it (MacCannell, 1976). He argues that both Back and Front seem not to present the authenticity because the events/products are already organised to serve the spectators. In fact, the events/products are being set. To him, the authenticity is primitive/real and can only be found from places where there is very little discovered, or they are far distance/rural areas. For this critical point, understanding of how authenticity can be constructed would serve souvenir suppliers well when seeking authentic ideas.

Constructive authenticity refers to the social influence and depends on tourists' perceived experiences. Constructive authenticity can be set based on tourists' judgement rather the reality (Peach \& Moscardo, 1986). For instance, shopping in Copycat market can be seen by tourists as an authentic experience because of the market's uniqueness: location/environment, fun, and the ability to bargain on the price (Wu et al., 2014). In other words, constructive authenticity is social and personal (Mkono, 2012). Some tourists might be influenced by their friends and the media about what they knew or saw so through constructive authenticity. Constructive authenticity can be described as cool authenticity in which tourists make judgements about the authenticity of tour objects (Smith \& Duffy, 2003). The factors influencing constructive authenticity include frequency of travel, educational background, socio-economic and demographic characteristics, and consumer behaviour (Shen, 2011).

Existential authenticity refers to the person/individual who feels an experience is authentic because the experience they receive, or object they see, is not common in their daily life (Wang, 1999). Existential authenticity entails more effort and consideration for both host and the visitor in constructing an authentic encounter (Cohen \& Cohen, 2012). According to Yi, Lin, Jin, and Luo (2016), tourists' existential authenticity depends on their experiences of particular items/objects, environments, or activities as well as their experiences of engaging with local residents. Because of these, scholars suggest destinations' marketers need to enable suppliers to arrange attractive outlets to suit customers' needs.

Many researchers attempt to explore the influence of existential authenticity on consumers/tourists and confirm that existential authenticity tends to show positive impacts on building tourists' loyalty (Kolar \& Zabkar, 2010; Steiner \& Reisinger, 2006). Souvenirs can also be linked to the ideas of holy journeys and religion (Graburn, 1977). The original ideas of souvenir consumption come from the holy environment when people travel to the place and make a different 
experience. In other words, it also means that it is the activity that breaks the daily routine (Hitchcock \& Teague, 2000). Existential authenticity covers individual feeling inspired by the liminal procedures of tourist actions with the liminal spaces and experiences rather than particular objects (Wang, 1999). Liminal space can be defined as the particular places or zones that allow tourists to be themselves. For instance, the festival organisers have set the liminal space that allow festival goers to enjoy themselves by drinking and dancing at festivals (Kim \& Jamal, 2007). Tourists may not feel authentic if they are out of this zone. Thus, their existential authenticity occurs because they engage in activities that are excluded from their routines. In the heritage context, liminal space and souvenirs might be the place that limited the authentic souvenirs that represent the zones or cultural and historical integrity.

Cohen (1993) and Adams (1996) assert that the authenticity concept in tourism products may need to compromise between souvenir products and consumer preferences. Chhabra (2005) delimits and concludes the meaning of authenticity as the negotiated process. Kozak and Kozak (2013) claims souvenirs are the objects that bring meaning closer to place attachment, this also includes the tourist involvement. To sum up, authenticity has underpinned tourism activities, especially souvenir products. Understanding the perception of both consumers and providers would satisfy both consumers and suppliers needs. Tourism products and authenticity are associated and interwoven with each other and rarely separated. Authenticity plays a key role in tourism products, especially the souvenir items. Because of that, tourists and suppliers perceive authenticity in souvenir products are worth examining.

\subsection{Authentic souvenirs 2.4.1 Tourist perceived authentic souvenirs}

Gordon (1986) asserts that tourists carry souvenirs home as part of the evidence that shows they visited the destination or to remind them of a trip and add a desirable trip to their network. Authentic souvenir refers to the objects founded on culture, heritage, place identity and uniqueness of particular events or activities (Durko \& James, 2016). Cohen (1988) indicates that authentic souvenir products become a significant mark of destination ethnicity or cultural identity. Authentic souvenirs can enhance consumers' feelings or make the tourists feel special, 
creating the novelty feeling of owning the souvenirs (Wang, 1999). It is found that tourists feel more satisfied if they feel that the souvenir products are authentic.

The tourists' perspective in research on tourism souvenirs is substantial and addressed by several researchers (e.g. Anur et al., 2017; Lin \& Mao, 2014; Wilkins, 2011). Brennan and Savage (2012) indicate that souvenirs typically signify the images of regions in which Shen (2011) agrees that souvenirs represent cultural icons and create the sense of holding meanings. Many researchers assert that tourists are likely to seek authenticity and quality of souvenirs. Elomba and Yun, (2017), Littrell et al. (1993), Swanson and Horridege (2004), and Thirumaran et al. (2014) agree that tourists look for authentic souvenir products with some characteristics requirement such as hand-made, high quality, and appealing presentation. Torabian and Arai (2016) analyse the souvenir authenticity through the perspectives of tourists, identifying four important themes which are similar to Littrell et al.'s (1993) study, such as using local materials, produced by local artisans and handmade, demonstrating signature or symbols, preferring the higher quality and appealing design with premium price. With several repeated criteria mentioned above, tourists seem to value uniqueness and originality, workmanship, handmade, cultural and historic integrity as criteria to evaluate souvenir authenticity.

Littrell et al. (1994) and Thompson and Cutler (1997) concentrate on tourists' purchasing behaviour. Meanwhile, Cohen (1979) argues that tourists' views on authentic souvenirs can be changed from time-to-time depending on tourists' personalities. In fact, Andriotis (2011) asserts that tourists do not care much if whether the souvenir that they brought home is made with either local or imported materials. However, Shen (2011) point out that tourists feel dissatisfied when they know that the souvenir that they purchased is imported. Anderson and Littrell (1995) argue that souvenir-buying behaviour is not determined by one single component; in fact, it comprises various attributes such as product design, travel experience, sellers' interaction (Anderson \& Littrell, 1995).

Scholars also advance their study on the authentic souvenirs criteria into local labour involvement and production location. While Asplet and Copper (2000) assert that local labour becomes the main element that impacts on authentic souvenir creation, Thirumaran et al. (2014) confirm that souvenir products presenting craftsmanship seem to gain attention from tourists compared to the ones that do not. In fact, several researchers assert that the reactions or the interaction of 
retailers with tourists are addressed as one of the major motivations to souvenir purchasers (e.g. Chhabra, 2005; Damrongpipat \& Hirunraks, 2009).; Littrell et al., 1994; Thompson \& Cutler, 1997).

Heitmann (2011) considers authentic items as being created or attached with local traditional cultures and pattern styles. In other words, the item's presentation or performance has an association with traditional culture and original sense of the genuine, real or unique, made by local hand (Heitmann, 2011). While many researchers assert that indigenous or original pattern seems to convey to tourists an authentic souvenir, Xie, $\mathrm{Wu}$ and Hsieh's (2012) study argues that tourists' perception authenticity of souvenirs is toward the contemporary design rather than original markers or indigenous pattern. In fact, Xie et al. (2012) argue that tourists view authentic souvenir products as items that comprise modern patterns. In addition, the patterns on souvenirs can influence the level of purchasing, for example, styles, decoration, and types of souvenir chosen (Littrell et al.,1994); Thompson \& Cutler, 1997).

Lacher and Nepal (2011), summarise the traits of souvenirs demanded by tourists relate to production places. These souvenir items should be appropriately priced, and be of skilled-craftsmnship, have appealing presentation and a cultural connection, be symbolic and memorable of places of travel, and be portable. Lin and Wang (2012) have suggested that authentic souvenirs can be perceived in three determinations: traditional presentation, indigenous making and functional use. Their study seems to be in line with Littrell et al. (1993). It is interesting to note that Littrell et al.'s (1993) study is one that extends knowledge of tourists' perceptions by integrating suppliers' perspectives to the current literature, which is worth pursuing. Thus, the factors that support authenticity are worth exploring, especially in souvenir products. Tourists perceive authentic products include the location of where souvenirs have been produced and seems to be one criterion that they look for in the authentic souvenir items.

Summarising souvenir items from the tourists' perception of authentic souvenirs has highlighted various authenticity values. However, most papers seem to imply and identify similar cultural and historical integrity, including product uniqueness, handmade, label and aesthetics, functional use, product identification. However, some elements that influence tourists' perceived quality of the authentic experience are related to suppliers and the role of suppliers in souvenir distribution. 


\subsubsection{Supplier perceived authentic souvenirs}

Some research attempts to explore suppliers' perspectives with specific interests in souvenirs and suppliers (Chhabra, 2005; Thirumaran et al., 2014; Trinh et al., 2014). Thirumaran et al. (2014) studied the development of souvenir products by only focusing on selective stakeholders such as public authorities, tour operators and tourists on authentic souvenir products. However, they leave out souvenir suppliers (e.g. producers, sellers, and middle men) - the people who influence the concept of authenticity, especially souvenir producers. Trinh et al (2014) studied only retailers but their findings implied a significant relationship between producers and distributors in selecting and selling items at the customer contact line. Even though not enough of this area references souvenir suppliers' perspective of authentic souvenirs, authentic souvenirs enhance tourist quality experience, and show positive attitudes to souvenir purchasing (Ramkissoon \& Uysal, 2011).

Several studies have examined the backward linkages associated with the purchase of souvenirs to their original production (Timothy \& Wall, 1997, Swanson \&Timothy, 2012). According to Chhabra (2005), authenticity from the souvenir vendors' perspective, is the representation of original traditions, location of production, connection to the past, consumer demand, impression, and negotiation process. This study also reveals that through souvenir suppliers, participants agree that souvenir producers are crucial to delivering authenticity (Chhabra, 2005). Brennan and Savage (2012) suggest that souvenir consumers tend to have less access to souvenir information. In fact, they relied on suppliers such as retailers or producers to inform them. Chhabra (2005) asserts that souvenir vendors also act as the middleman to assist the flow-of-supply system.

Meanwhile, Lin and Mao (2015) report that souvenir suppliers have substituted authentic local products with imported goods from other areas. This action may have been taken when local souvenir makers were unable to provide large quantities, and thus, local souvenir suppliers are requested to work with other suppliers to sustain their businesses. For example, Scottish souvenir suppliers must import and repack souvenir products with a logo and trademark of Scotland to sustain the consumers' need caused by mass tourism (Chhabra, 2005). On one hand, some destinations produce souvenir products based on their culture and traditional values. On the other hand, suppliers may need to deliver the products that they presume tourists are willing to pay for. In the words of Adams (1996) and Cohen 
(1993), authenticity can be perceived as being suppliers need to adjust their souvenir products to suit their potential consumer. Despite these suppliers' importance toward constructing of authenticity, understanding their viewpoint is crucial to enhancing souvenir consumption.

Many studies concentrate more on consumers' perspectives with less focus on suppliers' perceptions. Elomba and Yun (2017), addresses this; although their study examines the tourist perspectives on souvenirs' authenticity, their results suggest that souvenir suppliers have emphasised the overall presentation and souvenir images. Many researchers are calling for more research investigating from the souvenir suppliers (e.g. Chhabra, 2005; Trinh et al., 2014), exploring suppliers' perspectives toward authenticity and the value of souvenirs.

\subsection{Values of souvenirs}

Tourists' perceptions of souvenirs can be categorised into several values, namely: use, exchange, sign, and spiritual (Lin \& Wang, 2012; Paraskevaidis \& Andriotis, 2015). Collins-Kreiner and Zins (2013) argue that any object can be a souvenir depending on whether souvenirs are used or the use values are related to the tourist. According to Lin and Wang (2012) and Paraskevaidis and Andriotis (2015), use value souvenirs refer to items that tourists can use to remind them of the places they visited. Meanwhile, those souvenir items can also be used in daily life when they return home. The souvenir items include the coffee cup, T-shirt, pen that are marked with letters of locations, places or events.

Tourists' perceive an exchange value in souvenirs as items that they have traded with suppliers as part of dollar-in-return (Cohen, 1998). Examples of exchange value in souvenirs include entrance fee, and photo services where tourists received pictorial souvenirs. The sign value of souvenirs refers to the tourist's purchase as part of gaining social status (Paraskevaidis \& Andriotis, 2015). Generally, these souvenir products are luxury items, limited editions or rare products. Spiritual value in souvenir items means an interconnection with the empowerment of religious faith, particularly where the powers of certain religious souvenirs are supernatural, such as healing and protecting identities. For example, miniature Buddha stupa. The summary of four types of values perceived by the souvenir consumers/tourists is shown in Table 2.1. 
Table 2.1 Souvenir values perceived by tourists

\section{Value}

types

\section{Tourist value to hold souvenir items}

\begin{tabular}{|c|c|}
\hline $\begin{array}{c}\text { Use } \\
\text { value }\end{array}$ & $\begin{array}{l}>\text { To utilise as a reminder of travelling experience } \\
\text { May use in daily life after returning from vacation e.g. coffee } \\
\text { cup, pen, shirt }\end{array}$ \\
\hline $\begin{array}{c}\text { Exchange } \\
\text { value }\end{array}$ & $\begin{array}{l}>\text { It can be cheap or expensive for exchange } \\
>\text { Might gain a higher value as time passes }\end{array}$ \\
\hline $\begin{array}{l}\text { Sign } \\
\text { value }\end{array}$ & $\begin{array}{l}>\text { Social position gain and prestigious feeling } \\
>\text { The unique and novelty souvenirs, usually authentic items }\end{array}$ \\
\hline $\begin{array}{l}\text { Spiritual } \\
\text { value }\end{array}$ & $\begin{array}{l}\text { Related to religious faith and the belief that religious souvenirs } \\
\text { have magical powers such as caring and bringing luck (e.g. } \\
\text { 'Prabang' or miniature Buddha stupa }\end{array}$ \\
\hline
\end{tabular}

Sources: Adapted from Cohen (1988); Lin\&Wang (2012); Paraskevaidis \& Andriotis (2015)

Each value is associated with the place, sense of novelty and social constructivism. But the value of souvenirs to suppliers are not consistent with the categories in Table 2.1. Steward (1984) argues that souvenirs have a value linked to historical objects as they represent the period of past to the future, but he claims that suppliers' perceived value of souvenirs should be different because of a different purpose. According to Kong and Chang (2012) and Thirumaran et al. (2014), souvenirs should be developed as part of tourism development. This is because it can enhance the tourist experience as well as generate alternative incomes. Economy gain seems to be a key value that has been identified and mentioned from different researchers.

Souvenir suppliers' perceived values mainly focus on economy but include destination uniqueness. According to Lacher and Nepal (2011), although imported souvenir products bring smart profits to the souvenir vendors, there is not much economic incomes to other suppliers especially for souvenir producers when compared with local souvenir products. This is because the production of souvenirs generates jobs and opportunity for local residents and increases the ability to secure the raw materials. In addition, it is one of the tools that the destination uses to brand or represent the destination image. This includes the cultural representation and 
place identity or 'symbolic' values. Symbolic values can be perceived not only from the material itself but an actual person for certain objects (Kleine \& Kernan, 1991). It is about the social constructive to give the meaning (Wang, 1999) as an artisan value may relate to the concept of authenticity as a key to attracting the attention of consumers because of its novelty for them.

According to Wei, Zhan and Zhang (2010), souvenir products carry symbolic values through attraction and destination uniqueness. Their studies also exemplify tourist liminal space, particularly places or zones, and the influence also links to social class (Wei et al., 2010). This can be linked to the tourist's enjoyment of local cultural activities or local souvenir products and the tourist's pleasure of memorable trips. In the process of authentic souvenir development, souvenir suppliers, in particular, souvenir producers, should consider and integrate the local culture in order to create novelty and authentic souvenirs to increase their value and this could increase the tourists' loyalty (Lee, Lee \& Yoon, 2009). In addition, a story behind the item can be seen as a crucial factor. Some travellers might decide to buy souvenir items because of core values or to remind them of something or the item impresses them in some way.

Local producers might think of using local raw materials with regard to environmental friendliness and promoting their local materials as a way to create the authentic souvenir. By doing this, the tourist can listen to the 'behind-the-scene' story, which is the objective of the activities associated with place and environment. This creates the authentic experience for authentic-souvenir holders. It also generates incomes for the communities. With this in mind, government agencies and relevant authorities might need to collaborate to supply local raw materials that local souvenir producers can afford. This could be done by turning some rice field areas, especially during the dry season when they do not grow rice, to plant local ingredients. Moreover, assistance is needed for local suppliers to find a market with some price guarantee.

\subsection{Commodification and souvenirs}

Commodification, in the context of tourism, refers to the utilisation of the destination's culture and the cultural pieces to make a large enough profit to support part of the area's economy (MacLeod, 2006). Commodification is associated with converting the intangible and tangible elements of culture into souvenirs to be 
traded and this generates commercialisation for souvenir suppliers/stakeholders in the destinations. In return, consumers also receive tangible items that represent their trip and moments of their experience at the place or destination visited. According to Derrett (2003), creating the authentic souvenir products allows the host and the guests to interconnect. On one hand, the host can present their culture, heritage and significant uniqueness of the place to the guests or tourists with a return in dollar. On the other hand, tourists who seek to explore or learn other cultures are willing to pay for something that they feel is appealing and authentic or novel to them, a uniqueness that they may not see or experience anywhere else in the world. Thus, profits can be generated by commodifying the destination's signature.

However, the problem of commodification is that it alters the tourists' abilities to have an authentic experience and introduces the false culture into the indigenous one. In fact, the earlier paper of Boorstin (1964) shows some concerns on the concept of commodification as products or services become more touristoriented. Thus, the traditional patterns, styles or uniqueness might be influenced and adapted to the consumers/tourists taste, which will later reduce and diminish authenticity. Cohen (1988) claims that commodification does not necessarily destroy the meaning of cultural products, in fact, it may change or add new meanings to the old ones. Cohen (1988) and Thirumaran et al. (2014) determined that art and craft souvenir items may be altered from large models to the portable souvenir items for the purpose of comfortability for far-distance consumers/tourists.

Some tourism scholars assert issues of commodification in souvenir products. Destination needs to commodify their significant culture, uniqueness, and authenticity to enhance tourists' experiences, while such commodification in itself is a way for destination marketers to promote their locations. In return, tourism stakeholders can improve local economy. To sum up, developing the commodification of souvenir products is needed to improve economy of destination and intensify consumer consumption.

\subsection{Supply chain}

An effective supply chain management facilitates the flow of business from producers to buyers or it makes souvenir products accessible at the sites, at the right time and appropriate amount, with the lowest time and cost in relation to the supply (Cheng, Law, Bjornsson, Jones, \& Sriram, 2010). It should be noted though that 
transparency among the suppliers is important to the construction of the supply chain management (Cheng et al., 2010).

The souvenir supply chain includes producers, middlemen, retailers, and vendors. Basically, producers are those people who convert raw materials into souvenir products. Lin and Mao (2015) have identified souvenir producers as people who have constructed and influenced the authenticity in the production process. Retailers and vendors are those who sell products to consumers/tourists, generating personal benefits from the objects and the experiences they represent (Healy, 1994; Swanson \& Timothy, 2012). Middlemen refers to people who take provide a bridge between producers and vendors/retailers; sometimes the middlemen and the wholesalers can be the same group of people, depending on the types of business and financial availability. According to Chhabra (2005), the roles of souvenir retailers and vendors are also crucial as they can disseminate the authentic belief to the consumers.

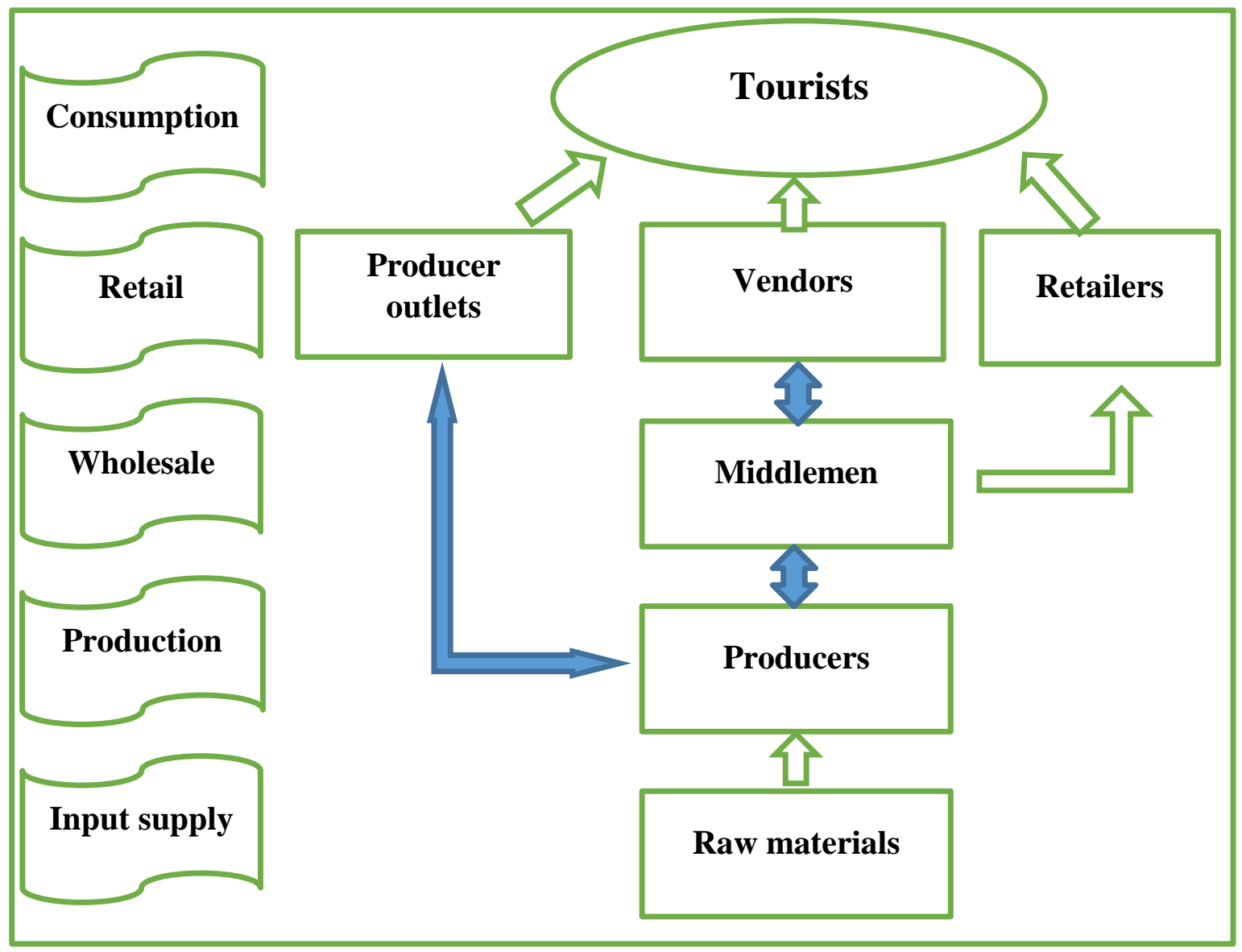

Figure 2.1 Souvenir supply chain structure and suppliers' relationships (Source: Adapted from Ashley, 2006; Healy, 1994; International Trade) 
Figure 2.1 depicts the souvenir supply chain's structure and suppliers' relationships. There are five steps in the process ranking from input supply to consumption, with the involvement of four main souvenir suppliers. At the Input Supply stage, producers take the role to gather materials and deliver for the Production stage, where they are tasked to produce souvenir products. In this figure, the role of wholesale is taken by the middleman, where the middleman may also act as distributor to disseminate products to the vendors and retailers. The middlemen are also tasked with ensuring the souvenir supply chain does not break down. At the Retail stage, apart from vendors and retailers, producers are also another group of players who take an initiative to offer their products at their own outlets. Lastly, at the Consumption stage, tourists consume souvenir products from three main sources: producer outlets, vendors, and retailers.

To sum up, the main players who take distinctive roles in souvenir production, distribution and selling process are mainly souvenir producers, middlemen, vendors and retailers. Thus, this study will consider these four groups as the souvenir suppliers, to investigate their standpoints on authentic souvenirs.

\subsection{Rules and regulations}

Effective rules and regulations can be a great source of direction to create the Fairtrade environment. This could improve the souvenir strategy and souvenir industry management especially in the context of heritage culture. Thirumaran et al. (2014) suggested adding souvenir development as a category in policy because it potentially ensures the full contribution of craftsmen and sustainable practical traditions. Part of the rules and regulations could reduce and diminish inauthentic souvenir products (e.g. low-quality products imported). The legislation could direct and establish a basic and fair situation among suppliers.

The formal rules and regulations can also be the primary effort to engage various stakeholders, constructing the policies in order to guide and discourse the need of stakeholders (Thirumaran et al., 2014). It can bring stakeholders together with a single purpose of integrating livelihoods in tourism, incorporating environmental resources in a sustainable way and a continuity in culture and presentations. Constructing the policies in order to guide and discourse the need of stakeholders (Thirumaran et al., 2014), key stakeholders can assist by taking part, 
for example, marketing promotions, local infrastructure and local event organisation.

However, the ineffectiveness of rules and regulations from relevant authorities can diminish an opportunity or create an unpleasant environment within and among souvenir suppliers and the souvenir industry. Many studies identify that authentic creation, which is from indigenous craft makers, and material usage, is the main component of authentic souvenirs (Littrell et al., 1993; Xie et al., 2012). In addition, customers tend to purchase souvenir products or view them as authentic items when those objects present together with craftsmen or local artisans on sites (Littrell et al., 1993). Importantly, authentic souvenirs are heavily dependent on craftsman skill and it is time consuming in the production process. Without rules and regulations, minor souvenir producers may not have rights to bargain or raise their voices (Rogersons \& Sithole, 2001). In addition, souvenir price tags can be seen as basic of fair price practice from suppliers to consumers.

In particular, in the research context like Laos, mainly LPB, the joining of ASEAN's free trade agreement can impact on various industries such as tourism and this includes souvenir products. According to ASEAN Tourism Strategic Plan 2016-2025, the agreement allows the shipment of products/goods to another market/place easily (ASEAN, 2015). The manufactured trend is continuing to improve products in order to serve the large market. Because of this, if massproduction replaces the local craftsman and without the authorities control, authentic souvenirs may vanish in time. Thus, the rules and regulations are needed to sustain souvenir industry, expand and maintain authentic souvenirs and destination uniqueness.

The exact rules and regulations also push industry to improve their product quality and assist the way for small or medium enterprises to grow. For example, the Thai government is trying to promote and sell each province's local souvenirs to tourists by securing a commitment from Thai airlines to provide a space in its catalogue. The catalogue has to include the local Thai souvenirs (ODOP products) that are made within the country. In Lao, the establishment of rules and regulations under the current Prime Minister, Dr. Thongloun Sisoulith, to promote local products, includes one with specific regard to gift-giving to the government's guests; when giving souvenirs, as a priority, the main consideration should be local souvenir products produced within the country (Idsala, 2017). Under this rule and regulation, not only can the local souvenir products be promoted to potential 
premium customers, but souvenir industry also needs to put more effort into assuring the products' quality and developing appealing souvenir products.

According to ASEAN Tourism Strategic Plan 2016-2025, a major goal for this region is "enhanced competitiveness of ASEAN as a single destination: Connectivity and destination infrastructure, joint marketing, product diversification, HRD, regional standards and travel facilitation." It focuses more on "sustainable and inclusive tourism public-private-community partnerships, investment promotions, safety \& security, heritage protection, environmental sustainability and responsiveness to climate change" (ASEAN, 2015). There are a number of concerns regarding souvenir products that cannot be ignored in developing countries, in particular, the lack of capital and knowledge for souvenir providers (Lacher \& Slocum, 2013). If there are supportive policies, it can motivate local souvenir producers to create new and more innovative souvenir products while enhancing tourists' experiences and increasing their spending.

\subsection{Conceptual framework}

To fulfil the gap and advance knowledge on how souvenir suppliers view the issue of authentic souvenirs, this research adapts some authentic souvenir attributes suggested by Littrell et al. (1993) and utilises four out of five types of Gordon's souvenir classification (1976).

Figure 2.2 synthesises the overall literature associated with three main concepts of souvenir products, namely commodification, authenticity and values. Souvenir business has been divided into two different parts, demand (tourists) and supply (suppliers). There are seven attributes of authentic souvenirs perceived by tourists, which are: uniqueness and originality, workmanship (handmade), aesthetics, function and use, cultural and historic integrity, craftsmen and materials appealing, and product identification (Littrell et al., 1993). Conversely, suppliers perceive authentic souvenirs differently from those viewed by tourists, which have been classified into four criteria, namely: representation of original traditions, location of production, history connection, and appealing to consumer demand. Surprisingly, the perception by suppliers has not yet gained enough attention by researchers and scholars. The resulting framework is presented in Figure 2.2 below. 


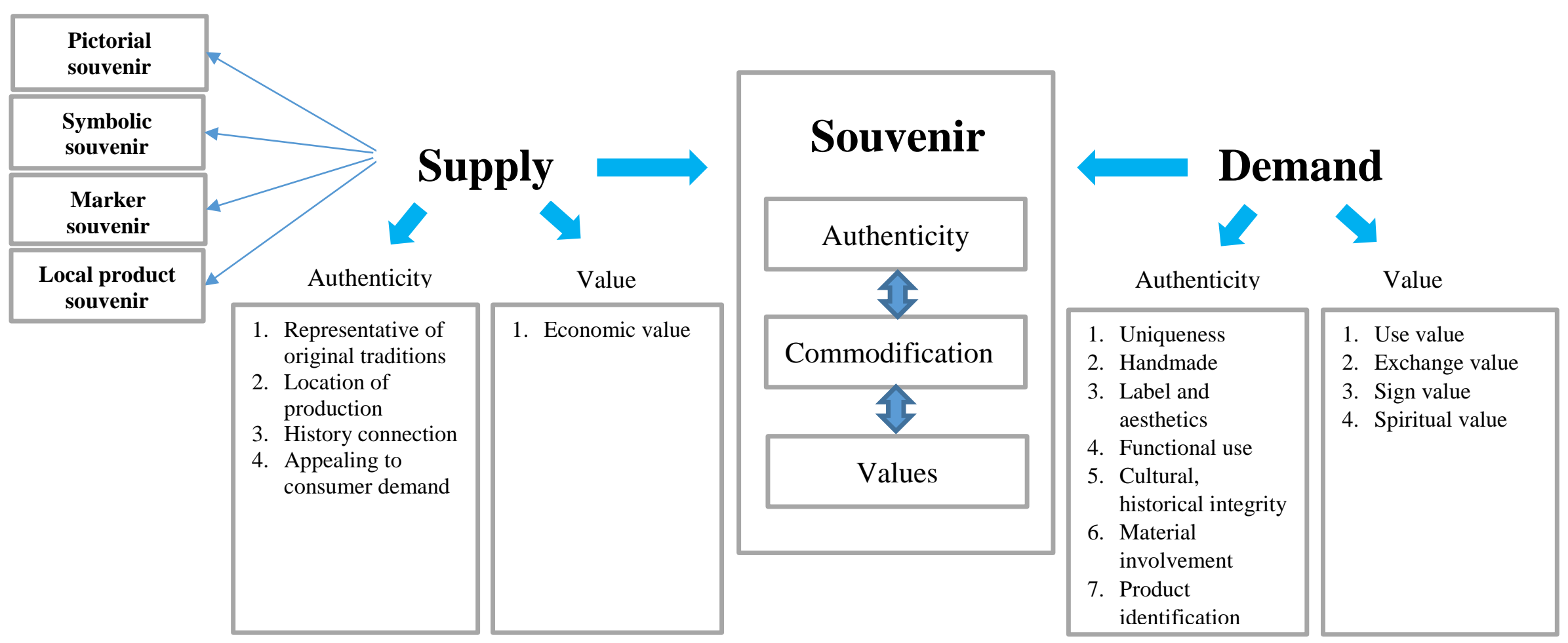

Figure 2.2: Conceptual framework of souvenirs and its relationship with the supply and demand side 
Although the souvenir research on authenticity is being developed, it focuses heavily on authentic souvenirs from the tourists' view point, and overlooks the suppliers' role in producing and supplying authentic items. Thus, this research aims to fill this research gap by determining the meaning of authentic souvenirs, sources of souvenir supply/production, and the values of souvenir products from the souvenir suppliers' perspective. Souvenir research in the context of World Heritage is still needed in order to improve the souvenir industry, especially in the competitive era. Therefore, light can be shed on souvenir suppliers (e.g. producers, middlemen, retailers and vendors) an area still largely unknown and underinvestigated.

This model of conceptual framework will be used as a basis to investigate the research question: suppliers' perceptions of, and attitudes toward, authentic souvenirs. This study investigates the suppliers' point of view which has not been explored adequately, by considering Gordon's (1976) souvenir types classification, namely: pictorial, symbolic, maker, and local product. This research does not include piece-of-rock souvenirs due to limitation of the research geography, which is a landlocked country, where there is no access to any sea or ocean. Thus, pieceof-rock souvenirs is not applicable.

\subsection{Chapter conclusion}

Chapter 2 revisits various concepts of souvenir and tourism, tourism and authenticity, and authentic souvenirs. This includes the standpoints of tourists and suppliers regarding their unique perceived authenticity in the case of souvenir products. This research presents three components underlining the study, namely authenticity, commodification and values. It highlights the key players in the supply chain process for this study, which are souvenir producers, souvenir vendors, souvenir retailers, and middlemen. Furthermore, rules and regulations are inspected for potential future souvenir regulation improvement. The conceptual framework concludes and synthesises the overall concepts and identifies the research gap which will help to define further research questions. 


\section{CHAPTER 3: METHODOLOGY}

\subsection{Introduction}

The previous chapter explained and illustrated the need for this research by identifying the research gaps. This chapter presents the research methodology. First, it introduces the research paradigm. This includes the researcher's point of view, research instrument, and procedures. Next, it presents and justifies the research location, sampling, research method and describes the five data collections areas that present the key tourism and souvenir significance in LPB. The overview of location areas and the souvenir industry situation are explained. The third section presents the methodology for this research. The fourth section provides the method and technique for data collection. This section also elaborates on the technique for data analysis. The final section discusses the legitimacy and trustworthiness of the results, human ethics and methodological limitations.

\subsection{Geographical context 3.2.1 Tourism in Laos}

Laos, the official name is Laos People Democratic Republic (Lao PDR), is a landlocked country located in South East Asia with an area of 236,800 square kilometres in which rivers and mountains cover approximately $70 \%$ (Yamachi \& Lee, 1999). There are almost seven million residents (Parameswaran, 2016). Laos is surrounded by five countries: Myanmar at the north west, China at the north east, Vietnam at the east, Cambodia at the south and Thailand at the west (see Figure 3.1). It is believed that over $80 \%$ of the population is still living in the rural areas and the majority of them have preserved the original culture and traditions.

Tourism has brought the significant improvement to Laos in many areas. Laos first opened the door to tourism in 1989 (Yamachi \& Lee, 1999). Since then, the tourism industry has speedily developed and become one of the main revenues and a key earner of the overseas currency (Yamachi \& Lee, 1999). Laos' official tourist slogan is "Simply beautiful. Laos was awarded the "World Best Destination in 2013" (Laovoices, 2013) by the European Council on Tourism and Trade. 


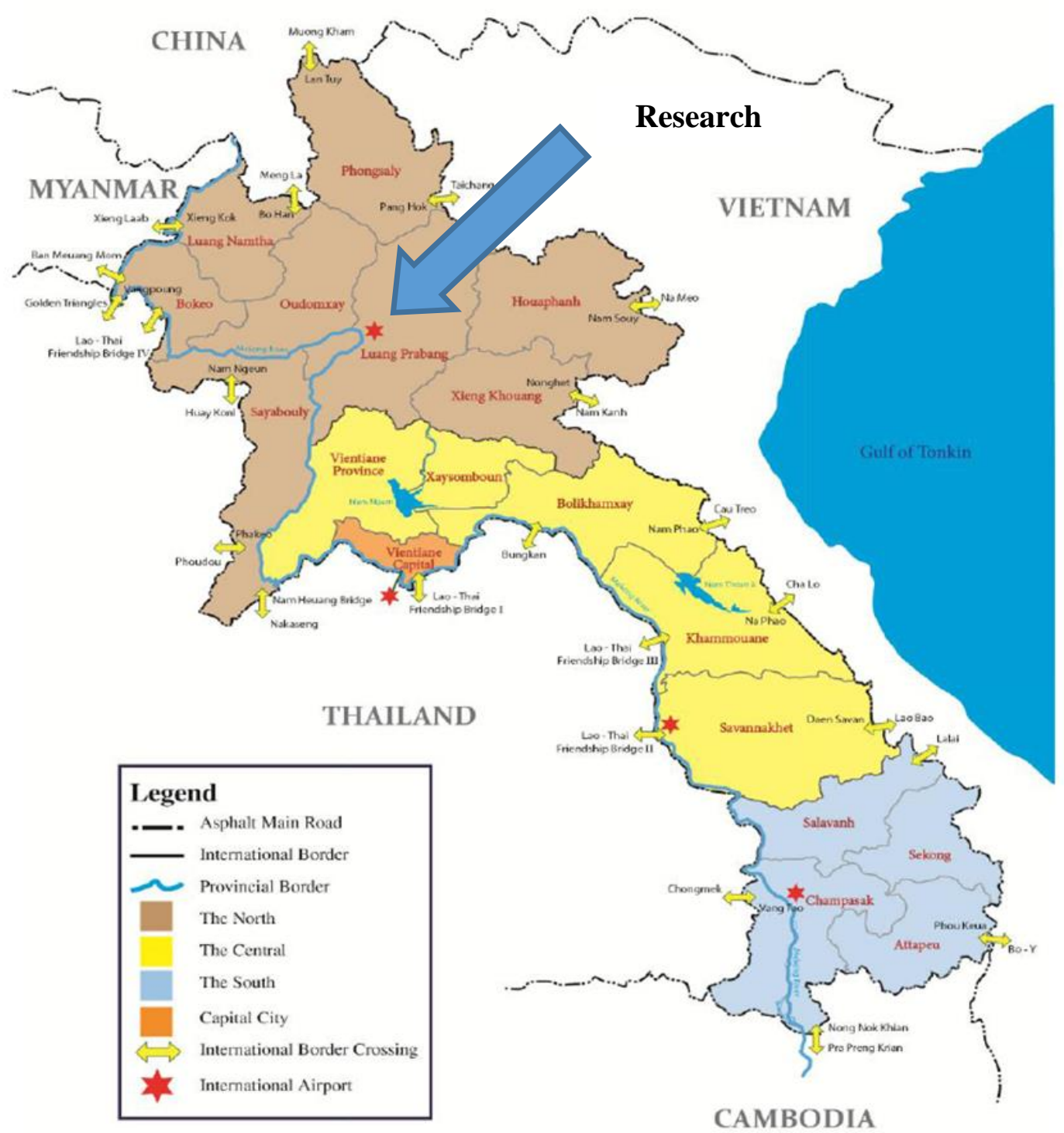

Figure 3.1: Laos's location and the area of research

(Source:TDD, 2015)

The tourism industry reinforces the basic infrastructure and facilities, and improves the quality of service, which in the country are developed to welcome the tourists, as well as tourism suppliers' investment such as accommodation and tourism facilities. Local residents enjoy the improvement. The tourism industry generates jobs and opportunities and increases the flow of foreign exchange. Laos has many World Heritage sites of which LPB is one of the tourists' favorite destinations. According to the information from the Tourism Development Department [TDD] (2015), the tourism industry was ranked as the second main contributor to Lao economy between 2013 and 2014 and third in 2015, where 
handicraft can be seen as one of the nine tourism products that could generate huge income for Laos' economy.

Table 3.1: Revenue from tourism and major exports between 2013 and 2015

\begin{tabular}{|l|c|c|c|c|c|c|}
\hline \multirow{2}{*}{ Products } & \multicolumn{2}{|c|}{$\mathbf{2 0 1 5}$} & \multicolumn{2}{c|}{$\mathbf{2 0 1 4}$} & \multicolumn{2}{c|}{$\mathbf{2 0 1 3}$} \\
\cline { 2 - 7 } & Revenue & Rank & Revenue & Rank & Revenue & Rank \\
\hline Minerals & $1,292.4$ & 1 & $1,325.2$ & 1 & $1,982.0$ & 1 \\
\hline $\begin{array}{l}\text { Other } \\
\text { Industries }\end{array}$ & 917.2 & 2 & 237.6 & 5 & 133.0 & 6 \\
\hline Tourism & 725.3 & 3 & 641.6 & 2 & 595.9 & 2 \\
\hline Electricity & 495.5 & 4 & 586.1 & 3 & 592.3 & 3 \\
\hline $\begin{array}{l}\text { Agricultural } \\
\text { Product }\end{array}$ & 319.8 & 5 & 238.2 & 4 & 290.1 & 4 \\
\hline Garments & 199.3 & 6 & 219.5 & 6 & 232.7 & 5 \\
\hline $\begin{array}{l}\text { Wood } \\
\text { Products }\end{array}$ & 144.6 & 7 & 159.9 & 7 & 83.5 & 7 \\
\hline Coffee & 54.7 & 8 & 48.4 & 8 & 79.7 & 8 \\
\hline Handicrafts & 2.1 & 9 & 5.3 & 9 & 0.94 & 9 \\
\hline
\end{tabular}

(Source: Adapted from the Department of Tourism Marketing in Laos, 2015)

In the past, the Laos government has taken this sector as the main priority to improve social economy and continuous emerging tourism is one of the main development priorities. Recently, in the press conference on $16^{\text {th }}$ October 2017, Mr. Sonexay Siphandone, the Deputy Prime Minister of Laos, announced the "Visit Laos Year 2018" campaign. The special features of Visiting Laos Year 2018 are mainly to engage not only overseas tourists but also to engage domestic tourists (KPL news, 2017). There are various activities that have been created to suit domestic and international tourists.

Despite the geographic advantage and condition of the country, this might be the key motivation for authentic experience among travellers. Thus, Laos is always the country that many tourists consider as a stopover, to explore its culture and natural resources as well as experience local lifestyles.

\subsubsection{Tourism in Luang Prabang}

The LPB is the largest province in the northern part of Laos with an area of 16.875 square meters and a population of 450,000 (Tourism Development Department, 2015). It was recognised as a World Heritage site by UNESCO in 1995 due to its preservation of a mixture of traditional architecture by the European colonial 
authorities between the $19^{\text {th }}$ and $20^{\text {th }}$ centuries, culture and heritage, religious and spiritual uniqueness, stunning nature and townscape (GMS, 2015).

According to Laos National Tourism Association (LNTA, n.d), the tourism strategy development plan between 2011 and 2020, LPB, has prioritised tourism as a means to develop the provinces' social economy; this was stated at the sixth LPB party congress conference. This plan has supported and accelerated the tourism sector in LPB province and it is fundamental to development in many areas. A number of basic infrastructures have been developed; this includes the basic transport mode such as better road and air transport in Laos. Although Laos has 17 provinces and one capital city, there are only two international airports, one in Vientiane Capital city and one in LPB province.

LPB city has been recognised as the one of the best tourist destinations in the world by several organisations. According to a recent report of LBP Department of Information Culture and Tourism[LPBDICT], LPB is one of the top ten tourist destinations awarded by Wanderlust Travel magazine of England, 2006 to 2012 consecutively, and in 2014 to 2016 consecutively. Further, it received the best destination in South East Asia from trip advisors in 2013, and LPB city is so called the best green city and smoke-free city (LPBDICT, 2017).

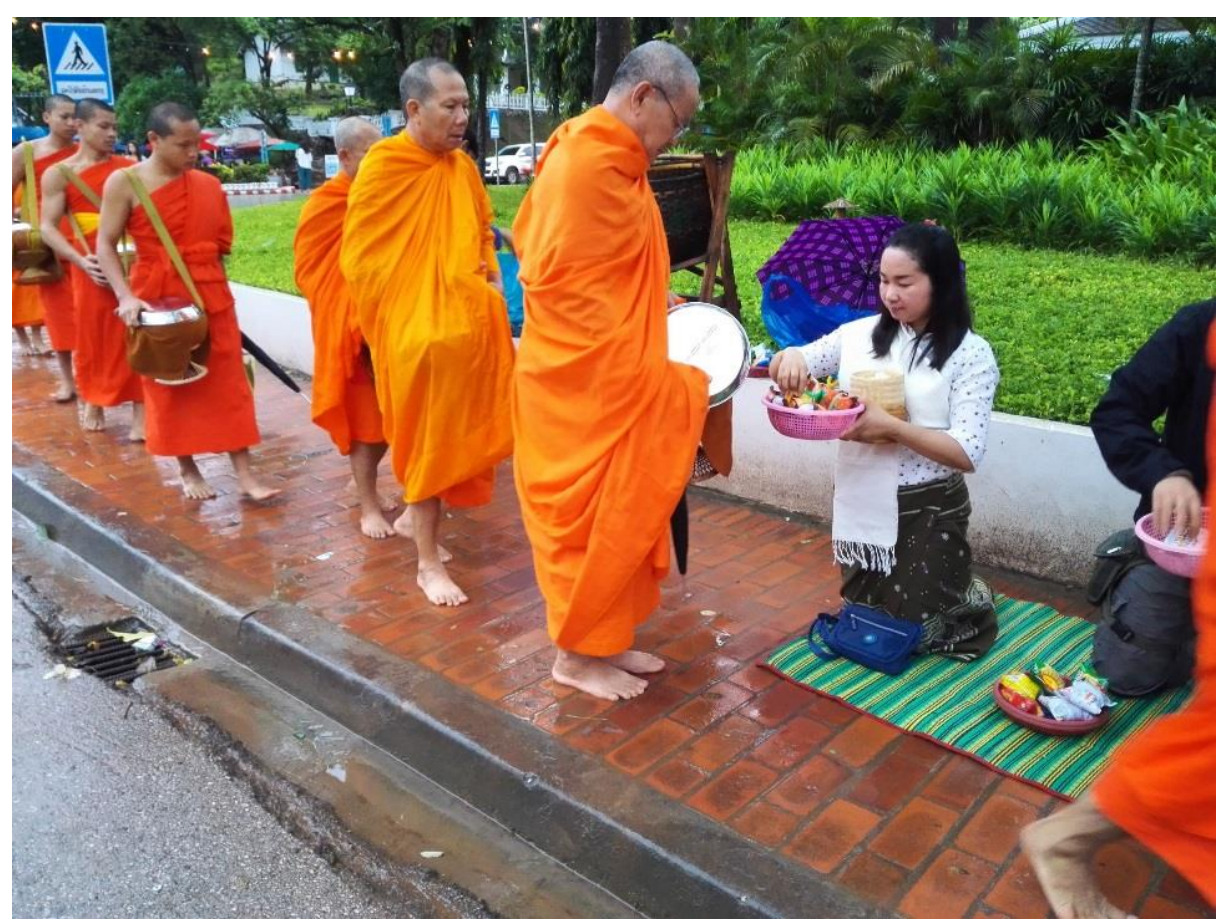

Figure 3.2 Traditional morning alms giving in LPB city

(Sources: author, 2018) 
According to Guardian Newspaper (2018), LPB city is one of 52 cities that should be visited in year 2018. LPB retains the significance of the city's combination of unspoiled natural resources as well as each traditions and annual festivals. It can be seen as a city that has preserved its culture and way of traditional king, French-style architecture of its buildings, and contemporary lifestyles of local tradition. For example, traditional morning daily alms giving (see Figure 3.2) and Pi Mai Laos or watering festivals (see Figure 3.3)

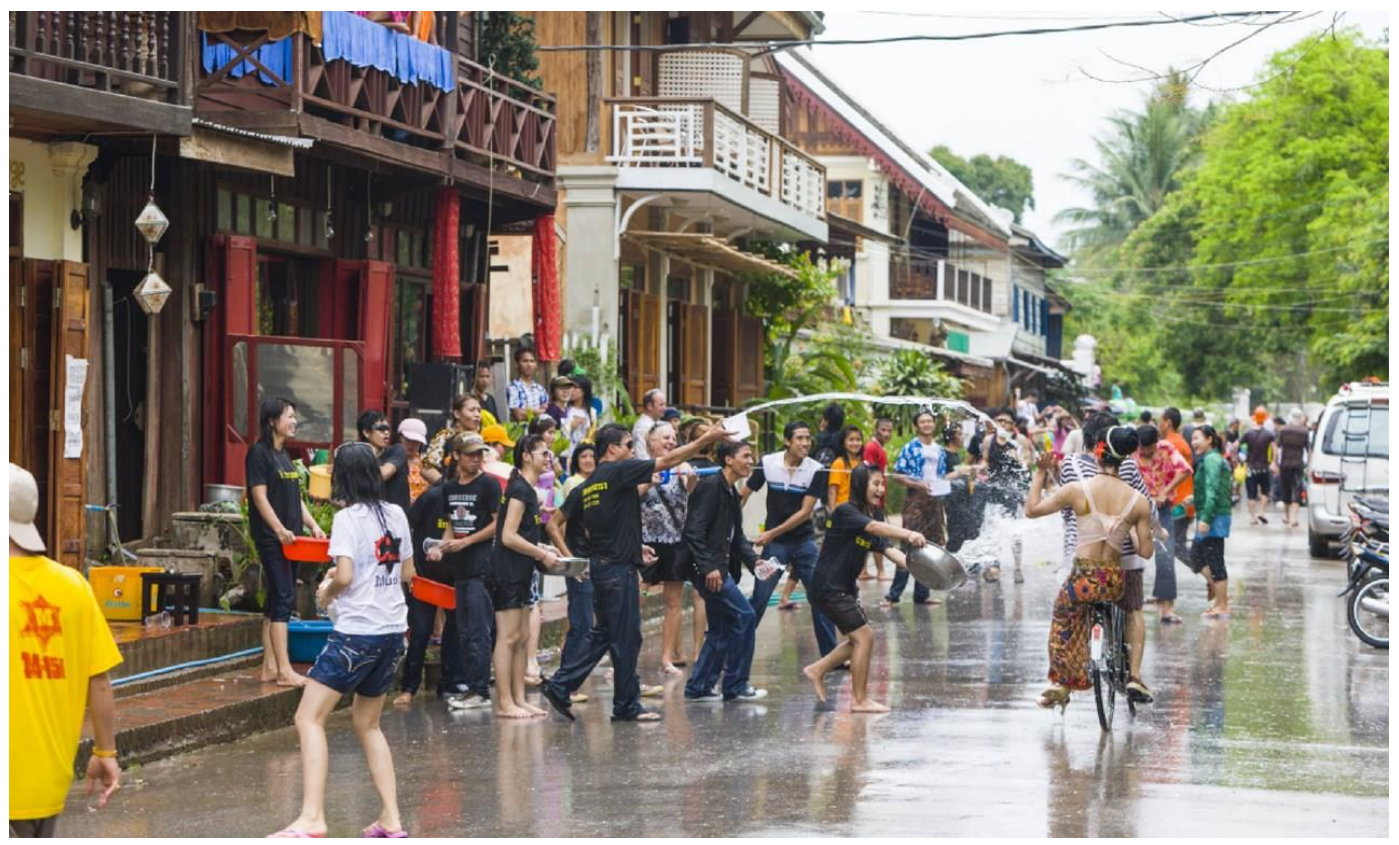

Figure 3.3: Laos New Year or Pi Mai water festivals in LPB city (Source: Wanderlust Travel Magazine, 2017)

LPB's tourism industry is substantially developed and has received higher tourist volumes to the sites. In 2014, LPB itself served over 150,000 domestic tourists and welcomed 380,000 international visitors (MICT, 2014). In 2015, LPB welcomed over 490.000 international tourists. The increase in tourists to the province is a crucial point for LPB authorities in developing tourism products to enhance tourist experience. It consequently boosts other tourism sectors' need to expand. There are 228 tourist attractions in which natural attractions cover 108 (equivalent to $47.36 \%$ ), cultural attractions have 86 (equivalent to $37.71 \%$ ), and historical attractions cover 34 (equivalent to 14.91\%). It is predicted that the tourism facilities will be expanded with the aims to meet tourist demand, and many facilities have already been developed to welcome tourists to visitor Lao in Year in 2018. 


\subsubsection{Souvenirs in Luang Prabang}

The geographical focus of this research is LPB province, the major tourist destination in Laos. According to Tourism Development Department (2015), LPB ranked second highest for international visitors next to Vientiane Capital, approximately over $70 \%$ during April to December 2015. Because of this, the souvenir industry in LPB can grow significantly compared to other provinces in the northern part of Laos (Laos Handicraft Association, 2016). Souvenirs in LPB can be seen as the main source of income, especially for people who live in rural areas or Hmong people or people who have lived in highland areas (mountainous area). LPB is also the most desired souvenir market for not only domestic suppliers, but also international suppliers.

It has been asserted that souvenir products in LPB can represent the place identity and the integrity of culture and customs, and gain attention from tourists and tourists' experiences. LPB souvenir businesses are nominated by handicraft products and LPB traditional food and local handicraft work are called as great souvenirs and are well-known souvenirs among local and domestic visitors. In fact, it is known by this region as the night market with the best handicraft in this region. However, there is not much documentation. The documentation of overall souvenir industry is rarely found in public news/journals. At most, there are a few shallow reports from the local associations. In fact, souvenir industry is not well documented.

LPB sells a large variety of traditional goods and souvenirs. It is also wellknown for its exclusive textiles, particularly the lady costume such as 'Sinh' (Sinh is a traditional Laos skirt, usually worn long over the knee), mulberry paper or $S a$ paper, and Cha numkeng (a traditional LPB basket made of local raw materials). Some traditional foods include Jaew Bong (a sweet and spicy sauce with buffalo skin); Khai Pan (dried river weed lightly fried with sesame seeds and garlic), and Kaonom Kinou (a crispy sweet snack made from flour and sugar cane). LPB souvenir items related to traditional textiles such as cotton and silk are well-known among international and domestic tourists, especially Lao people who have lived overseas, while local food types of souvenirs are much appreciated by local and domestic tourists. 


\subsection{Research paradigm}

A research paradigm is a global perspective on a way of thinking and making sense of the complexities of the real world (Guba \& Lincoln, 1994; Patton, 1990). Guba (1990, p.17) states that paradigm is "a basic set of beliefs that guide action". It indicates, precisely, how the research should be completed including the designation of methodology. Thus, a paradigm can be used to direct the overall research process. Guba (1990) and Bryman (2015) emphasise that there are various paradigms that can be used to guide the research. However, two main paradigms that are used widely are positivism, and interpretivism. Positivism is based on the belief of reality (Guba, 1990), sometimes referred to as rationalistic belief which shows the cause and effect outcomes (Mackenzie \& Knipe, 2006). Interpretivism refers to the perspective of individuals who believe that the inquiries can be explained and constructed (Guba, 1990).

These paradigms have been directed by three basic queries, which can be classified into ontology, epistemology, and methodology (Guba \& Lincoln, 1994; Morrison, 2012; Saunders et al., 2012). Ontological stance refers to the individual elementary norms about fact (Tronvoll, Brown, Gremler, \& Edvardsson, 2011) or 'what is the nature of reality' (Guba, 1990, p.18). It is concerned with what creates a sense of being (Gupta \& Awasthy, 2015). Thus, it is crucial for researchers to take their stance according to researchers' personal perceptions of truth (Gupta \& Awasthy, 2015). Epistemological stance can be defined as the apprehension of the validity of knowledge formulation (Scotland, 2012). The researcher has a responsibility to examine the truth by bringing up the questions involving knowledge. These queries examine how to recognise the reality, and how this knowledge can be taken to other people (Guba, 1990; Morrison, 2012). The methodology refers to the researcher's procedure of finding out the inquiry of knowledge or the way to answer the research questions. Thus, research methodologies are informed and supported by ontological stance and epistemological stance.

Under the ontological stance, positivism paradigm refers to the view of realities on what is available in the world and reality (Guba, 1990). When committed with the ontological stance, the positivists will pose questions to generate the answers. Under the epistemological stance, positivism paradigm views or believes that researchers attempt to find out inquiries but minimise the influence 
on the research by excluding human biases. They emphasise minor communication involvement with participants in their research or called positivists (Wilson, 2010). Thus, the methodology used in the group of positivism researchers is a quantitative approach. This is because the quantitative research is more straightforward and objective (Cavana, Delahaye, \& Sekaran, 2001). Quantitative research focuses on numeral, mathematical, computational, or statistical outcomes of observation phenomena. This also informs the method of data collection such as survey, testing and research conducted through a logical approach (Gupta \& Awasthy, 2015)

Under the ontological stance, interpretivism paradigm refers to the perception of realities that can be generated from multiple inquiries and social interactions. The epistemological stance from interpretivists can be constructed subjectively (Gupta \& Awasthy, 2015). This group of individuals is interdependent on their research because they believe that the researchers can gain knowledge about reality by interacting with social actors. Consequently, the researchers can understand the research respondents' social world through varied knowledge, experiences and difference of social perspectives (Scotland, 2012; Wilson, 2010). Thus, such researchers pay attention to the meaning of social behaviour and adopt a qualitative technique to collect data to understand the social aspects of phenomena which are too complex to measure based on the same nature of sciences (Gupta \& Awasthy, 2015; Wilson, 2010). Generally, qualitative research explores human thoughts and behaviour under constructivism (Cavana et al., 2001). By doing it this way, researchers can communicate with respondents to get an in-depth understanding about their perception (Saunders et al., 2012).

To approach the study of suppliers' perspective toward souvenir authenticity, the researcher employs interpretivism paradigm. This paradigm is chosen because it can broaden and construct information, knowledge and phenomena through the interaction between examiners/researchers and examinees/participants (Guba \& Lincoln, 1994; Pickard, 2013). This paradigm also assists the research by providing appropriate research design, which is a qualitative approach for examining the research perceptions in this study.

\subsection{Research methods}

According to the research paradigm mentioned above, this study has employed the qualitative research as a tool for data collection and data analysis. 
This is because qualitative research seeks to attain a rich, thoughtful understanding of souvenir suppliers' perspectives toward authenticity and understanding the suppliers view point. It can be used to generate greater meaning rather than statistics (Cavana et al., 2001; Walliman, 2010). Qualitative inquiry is particularly wordoriented toward investigation, finding, and inductive logic (Patton, 1990). Under interpretivist or constructivist epistemology, methodology is set for qualitative research informing ways to collect data in the form of in-depth interviews which is the most appropriate technique to study such complicated issues and difficult to measure. Denzin and Lincoln (2011) also state that qualitative research captures personal perspective and investigates the concerns on daily life. Finally, it is also useful when the research issues cannot be identified due to the limited or existing literature. The qualitative research through interview and field observation can allow a researcher to interpret various information and construct the overall themes (Patton, 1990). Therefore, a qualitative approach is the best application for this study.

\subsubsection{Sampling}

Sampling is the process of selecting the unit to analyse the data. According to Leavy (2017), the sample design should consider the research aims and the available resources (e.g. personnel, the certain characteristics of populations, restriction of time and cost). It is also needed to maximise the reliability and validity of data (Patton, 1990). In this study, the researcher used the purposive sampling. Purposive sampling is essential strategically and entails an attempt to establish a good correlation between research aims and sampling (Bryman, 2015). In short, the researcher's samples, are based on wanting to interview people who are relevant.

To be eligible for this study, it is important that the sample has experience in supply souvenir products in LPB and has worked in this industry for at least two years and in line with four categories. These are: 1) souvenir producers (SPs); 2) souvenir vendors (SVs), which in this context refer to sellers who own stalls in flexible locations such as a street market; 3 ) souvenir retailers (SRs), which in this context refer to people who own shops in fixed locations; and 4) middlemen (MM). They were selected because they are the main suppliers who can influence the souvenir products, and they have the experience and knowledge that this research requires. They are directly involved with supplying souvenir products. They are groups who can influence the level of authenticity in souvenir products. 
Characteristics, knowledge and experience of these people are significant in fitting with the research objectives. Thus, this study can answer the research question.

Twenty-four respondents were approached by using purposive and snowball sampling. Four groups of participants include: 1) souvenir producers (SPs); 2) souvenir vendors (SVs), which in this context refer to sellers who own stalls in flexible locations such as a street market; 3) souvenir retailers (SRs), which in this context, refer to people who own shops in fixed locations; and 4) middlemen(MM). First, the key informant is the LPB Handicrafts Association director, who acts as a souvenir retailer for four souvenir suppliers. He was recommended by the LPB Information, Culture and Tourism Department and did the interview, and then the snowball sampling was used to identify the potential participants introduced by the interviewee (Cavana et al, 2001). To meet the eligibility of participant, the screening questions to secure the right participants for this study, such as persons who have worked in the industry for at least two years. They then needed to be categorised into the four types of supplier as highlighted above, and once verified, the interview was conducted.

\subsubsection{Data collection}

Three types of data were collected for this research: in-depth interview, participant observation and secondary data. The in-depth interview sections were conducted between July and September 2017 in LPB. With the aim of exploring suppliers' perspectives toward souvenir authenticity. The semi-structured in-depth interview is used to collect data as it can provide a great opportunity to discover rich and multifaceted information personally, especially through one-on-one interaction (Jennings, 2010). The semi-structured interview and the face-to-face interview can encourage interviewees to express their opinions, and questions can be asked to clarify information (Cavana et al., 2001).

The semi-structured interview comprises five sections. The first section collects participants' personal information. The questions include working experience, suppliers' categories, resident status, and net incomes. The next section examines the suppliers' perspectives of souvenir business in LPB. This section consists of business motivation, the ability to offer quality products at reasonable prices as well as the ability to offer local souvenir products aims to explore the souvenir business in LPB from the suppliers' point of view. 
The full set of semi-structured questions are used as a guide for this study. First, the interview section started with the researcher explaining the main objectives to the participants who were screened with two screening questions. Taylor (2005) states the main reason for this type of interview is that the researcher can examine and generate greater information from the respondents' perspectives. After that, potential interviewees were informed of overall interview sections with researcher reading out the interview guideline (see Appendix A). To proceed to the interview section, all participants were requested to sign the consent form. Interview sections were digitally recorded, and the researcher also made notes, to ensure all data was captured. The interviews were conducted in Lao language and took about 45-60 minutes. It was conducted during working hours and real commercial time.

Participant observation has been utilised as a tool for data collection in qualitative research together with other ways (for instance, interview and focus group) as an instrument and to add more data validity. Participants were encouraged to give their views and express their ideas, thoughts and intentions. It provides firsthand and particular knowledge of some events that allows the researcher to understand the dynamics of reality (Smith, 2010). Participant observation was used to gain any points that the researcher may not have gathered in the interview sections.

Participant observation is employed in this study to obtain data for analysis and collect straightforward data in a natural setting and real situation (Brunt, 1997). This method is useful as it provides the tool to double check for nonverbal feelings, regulate the conversation from who to whom, capture the way of participants' communication with each other in a non-setting environment and this could generate some information that may be limited or not covered in the interview section (Schmuck, 2006). The researcher joined a souvenir tour as a tourist. She also visited the LPB night market and some tourist attractions such as Kouangsi waterfall, Phanom Villages, Royal Palace Museum to have a casual conversation and experience with souvenir sellers.

The field observation was recoded through note taking with small field notebook which researcher carried it on during the trip. The recorded notebook was date/time and location observation and key person interaction or conversation (e.g. souvenir supplier types, producers, vendors, or tourists). The researcher focused more on the significant event like tourists interact with souvenir sellers. Time 
sampling, researcher more focus on the time in tourism attraction. In addition, many photos were taken during the trip to use as references with information that has been recorded from the interview sections.

Secondary data refers to information collected by other persons rather than the researcher (Cavana et al., 2001). To ensure validity and reliability, this study employed secondary data to gain wider knowledge and statistic figure. Such information could assist the author to. The secondary data used in this study is from non-profit organisations and the authorities' annual report. These include annual reports from the regions such as ASEAN community, report of Greater Mekong Sub-regions (GMS) countries, Asian Development Bank (ADB) report, the working paper of Netherland Development Agency (SNV), and it also includes an annual report from Laos Handicraft Association (LHA).

Attempts were also made to seek information from government sites. This includes the annual report of LPB Information, Culture and Tourism Department. It is also the official website of the Tourism Marketing Department, Ministry of Information, Culture and Tourism in Laos. This is useful in terms of gaining the official statistics, current situations. However, there is not much documentation relating to souvenirs alone available. In fact, the information about LPB souvenirs has been integrated with handicraft products. To sum up, the secondary data were used to compare and support the results from this study.

\subsubsection{Locations of data collection}

Various locations, attractions and villages are considered as research areas for both in-depth interviews and field observations, but the main focus is on the LPB city centre. The research areas include the following five locations: LPB night market, Kuangsi waterfall, Phanom Handricraft Centre, Royal Palace Museum and Ock Pop Tok Living Crafts. The more detail will be elaborated shortly in the next sections.

\subsubsection{Night market}

LPB's night market is one of the most appealing handicraft markets for tourists and suppliers. According to the world travel guide, Lonely Planet, LPB night market is one of the best handicraft markets in South East Asia and one it is one zone for souvenir vendors in LPB. It is where the local handicraft products are sold in particular, the local handicraft made by Hmong people (minority ethnic groups who live in higher land, their handicraft products are really authentic and rarely found in 
other places). LPB night market includes 400 souvenir stalls (Ashley, 2006) The LPB night market is located in the main city starting from LPB Information Centre, Sisavangvong Road and along to the end of the Royal Palace Museum, approximately one kilometre. The market is officially open daily from $5 \mathrm{pm}$ to 10 pm.

\subsubsection{Kuangsi waterfall}

Kuangsi waterfall or Tad Kuangsi is about $30 \mathrm{~km}$ away from the LPB city town. The waterfall is approximately 650 feet, or around 50 metres, in height. It is one of the must-see attractions. The waterfall is the biggest in LPB and the most beautiful ever in this area. This is a year-round tourism attraction. It is one of the crowded attractions and many souvenir suppliers have located their stalls here.

\subsubsection{Phanom Handicraft centre}

Ban Phanom is a village located six kilometres east of LPB, it is well-known for its cotton textile and silk weaving (Benson, 2011). The centre is called "Phanom Handicraft Centre" that displays the local handmade textile products and offers the 'staged authenticity' or 'gives visitors a particular performance as the point of reference' (MacCannell, 1976) such as a weaving performance on sites (see Figure 3.4).

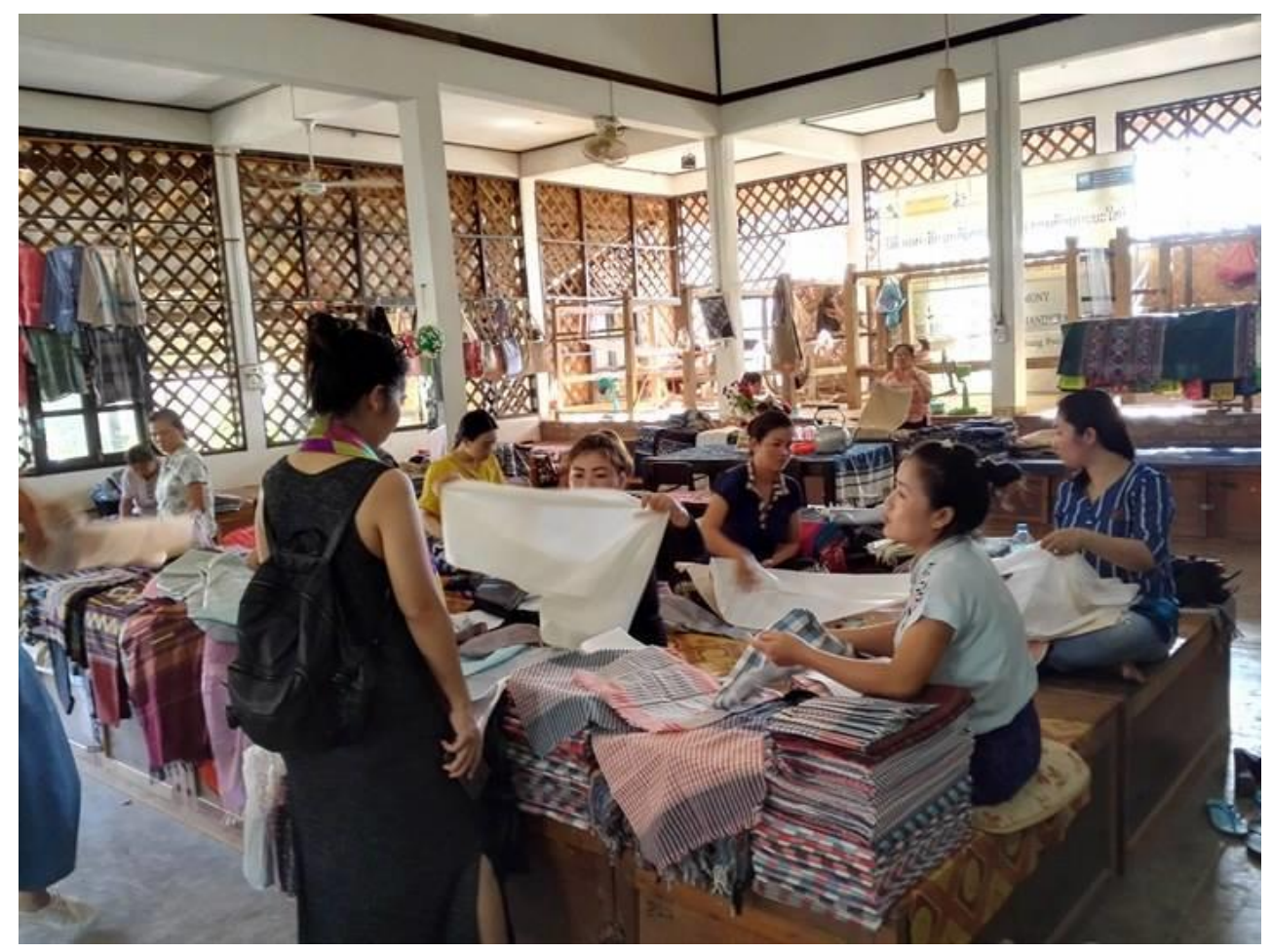

Figure 3.4: Handmade and authentic souvenir stalls at Phanom Handicraft Centre (Source: author, 2018) 
The majority of textiles are made here and the centre is the best-known tourism and commercial attraction among both tourists and sellers. It is believed that this centre sells only handmade and local souvenirs made by local craftspeople. The popular souvenir products include Sinh (Lao skirts), scarves, decorated textiles, and ladies' cotton clothing (see to Figure 3.6). The centre is also where souvenir shops are located together, and tourists can explore and sit down to chat and ask/negotiate the price with local retailers. When there are no customers, the souvenir suppliers take the role of the producer, producing the handmade textiles or Sinh (see to Figure 3.5)

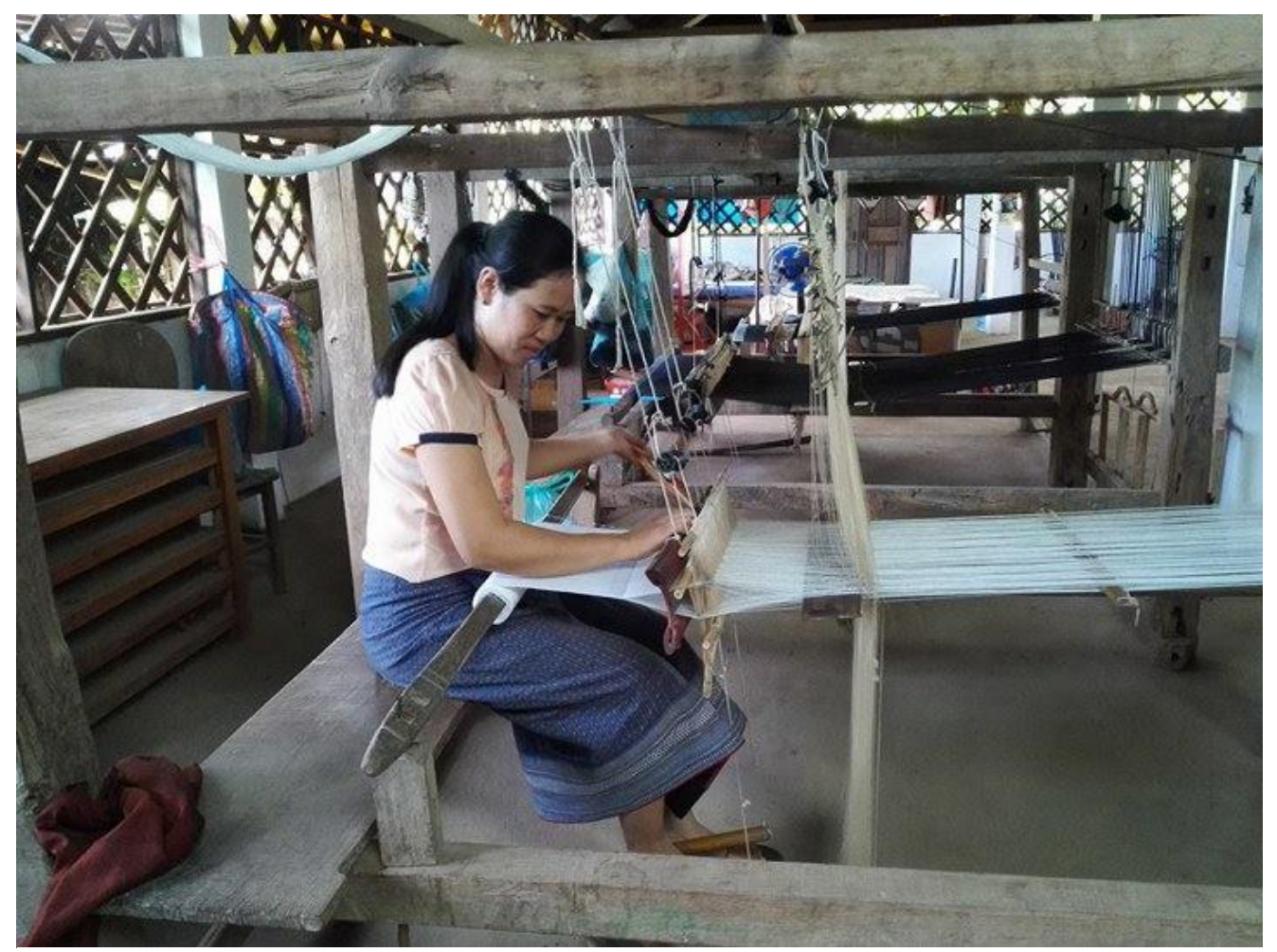

Figure 3.5: Lao female performs the textile weaving at the Phanom Centre

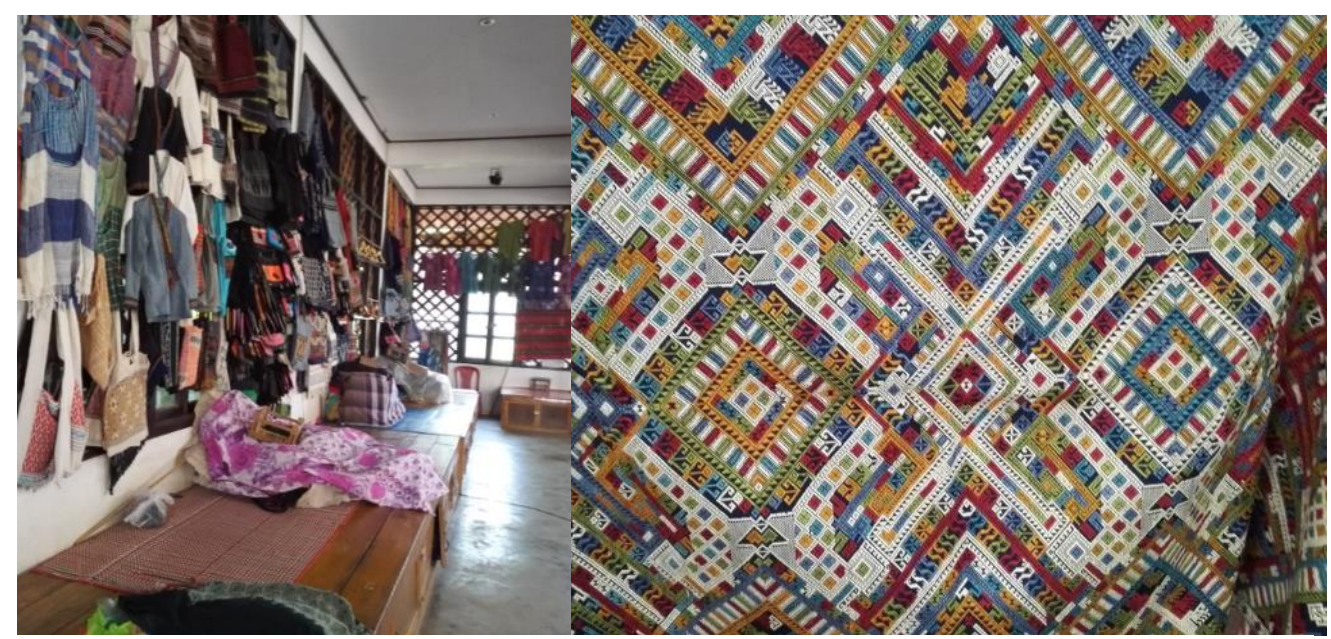

Figure 3.6: Handmade textiles clothes at Phanom Centre, LPB 


\subsubsection{The Royal Palace Museum}

The Royal Palace Museum is a well-known attraction in LPB. It is located in

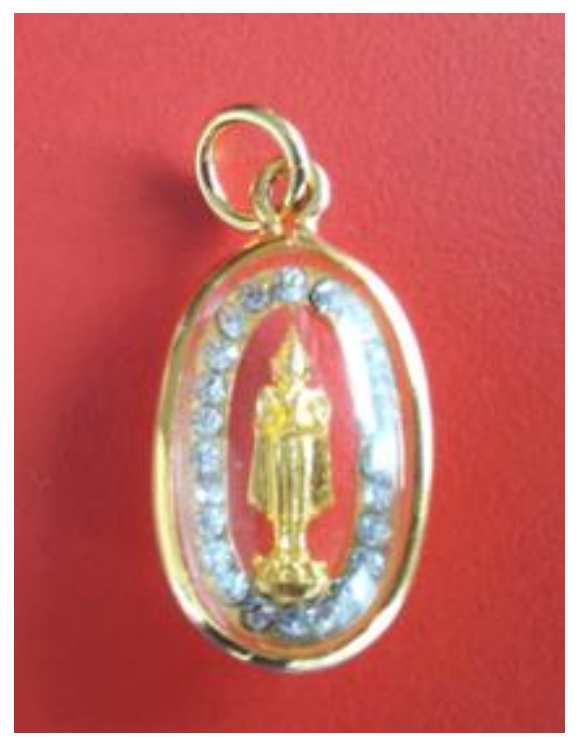

Figure 3.7: Miniature, 'Prabang'

Sisavangvong Road in the city centre. There is a souvenir stall in the museum that offers special or rare souvenirs or 'offers for sacrifice' or sells the authentic souvenirs related to spiritual signs and LPB signature. These include manicure Prabang or a traditional LPB Buddha stupa, called 'Prabang' (see Figure 3.7). The souvenir stall is well-organised and provides information about authentic souvenirs that represent the LPB uniqueness and its cultural and historical heritage.

(Sources: author, 2018)

\subsubsection{Ock Pop Tok Living Crafts}

Ock Pop Tok Living Crafts is the weaving centre located two kilometres south of LPB centre. The centre provides food and beverage (see Figure 3.8), accommodation (see Figure 3.9) and offers weaving and dying classes to both international and domestic visitors as well as souvenir tours (see Figure 3.10). This centre is well-organised and directed by the owner, a Lao lady, and her overseas friend.

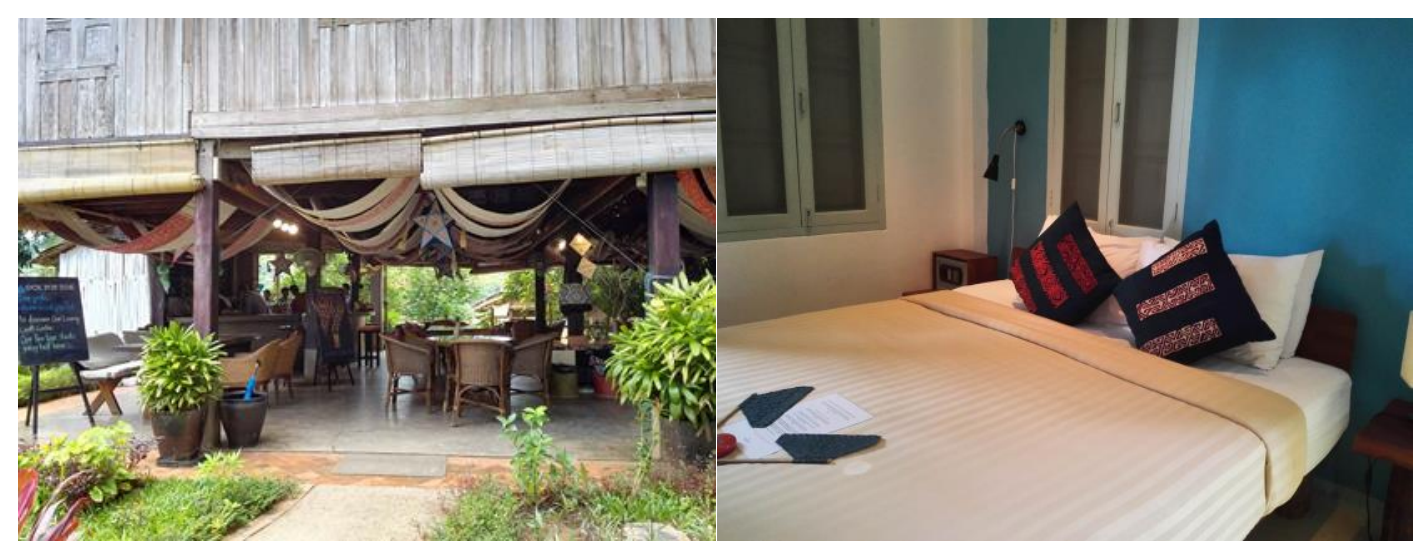

Figure 3.8: Dining areas

(Source: author, 2018)
Figure 3.9: Accommodation

(Source: author, 2018) 


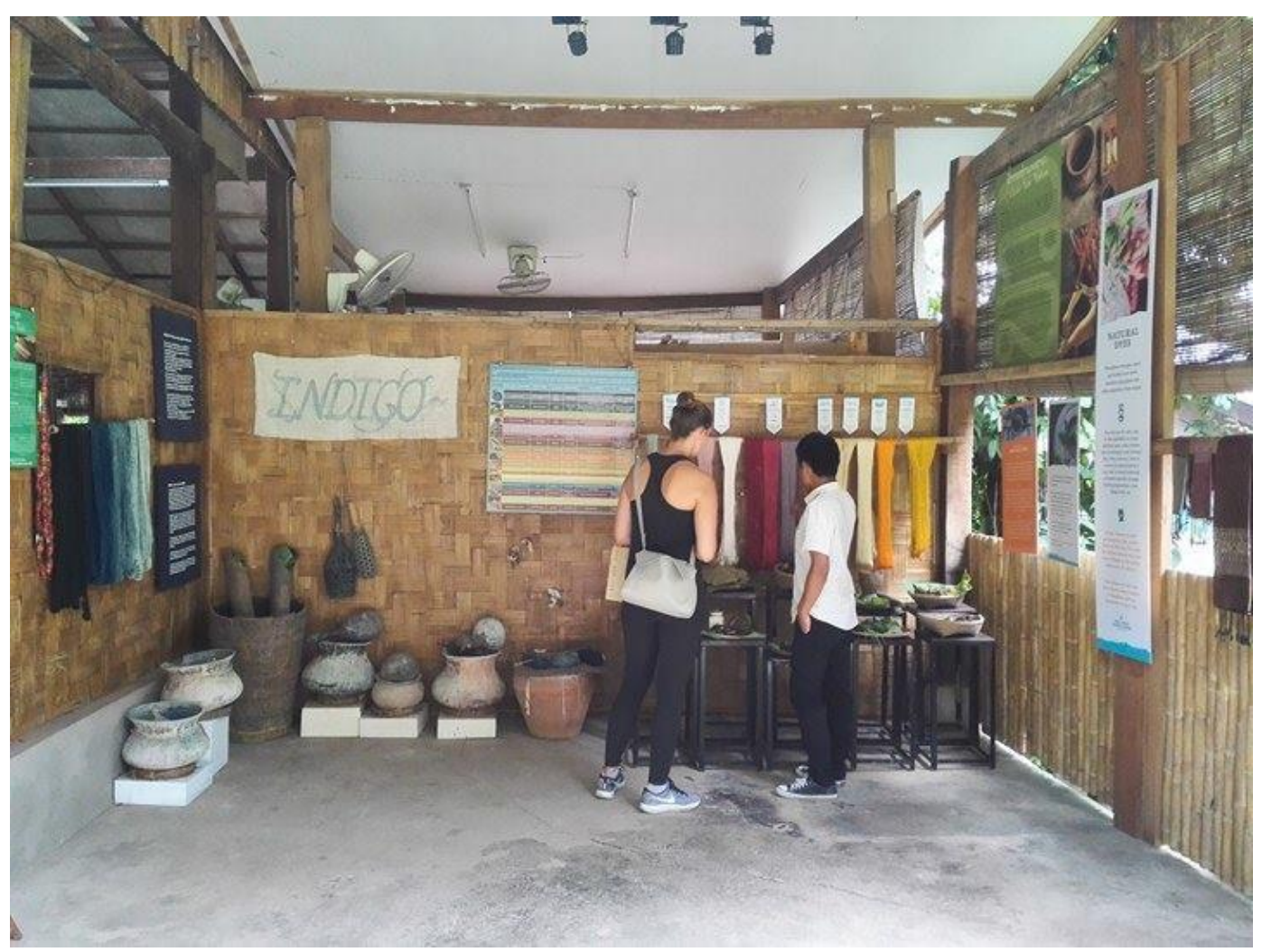

Figure 3.10: Free one-on-one or group tour at the Ock Pop Tok Living Crafts

(Source: author, 2018)

These research sites were selected because they are some of the most popular tourist attractions, where the souvenir shops/stalls are located as well as having a variety of souvenir product exchanges. These locations are also suggested by LPB Handicraft Association as well as other suppliers in LPB that products placed in these areas are well-known and represent the significance and authenticity of LPB and Laos. It is interesting to note that the participant observation was conducted in the five research areas highlighted above, of which three locations had the interview section conducted in them also, namely: LPB night market, Phanom Handricraft Centre and Ock Ock Pop Tok Living Crafts, and this includes the areas within LPB district or LPB city centre.

\subsubsection{Data Analysis}

The general aim of qualitative data analysis is to identify the phenomenon of souvenir suppliers' perspectives in LPB. It aims to investigate the overall ideas of suppliers in the souvenir businesses. Thus, the primary data was analysed manually through thematic analysis and supported by field notes. Thematic analysis refers to a systematic technique that identifies, analyses and construes patterns of data and classifies them into 'themes' (Clarke and Braun, 2017). It comprises six 
stages (Please see Figure 3.11), namely data familiarising, data generating, initial codes, searching for themes, reviewing themes, defining and naming themes, and interpreting the meaning of them (Creswell, 2014). First, raw data was transcribed; this included translation of both field notes and interviews from Laos into English. Next, the researcher revisited and reviewed data several times to familiarise data. After that, the key features of data are coded and recoded. The researcher then looks for themes that are repeated. The last step is to write up the themes which were organised and allocated to fit with the objectives of this research.

The data was analysed through delimiting the information and data that had been collected from the secondary data which can be from inside reports (nonpublication reports, used within or intra organisation). Finally, interview information was integrated with the information obtained from participant observation and assessed, compared to the thematic analysis results. Attempts also try to compare and integrate with secondary data to ensure the validity of data and discussion in this study.

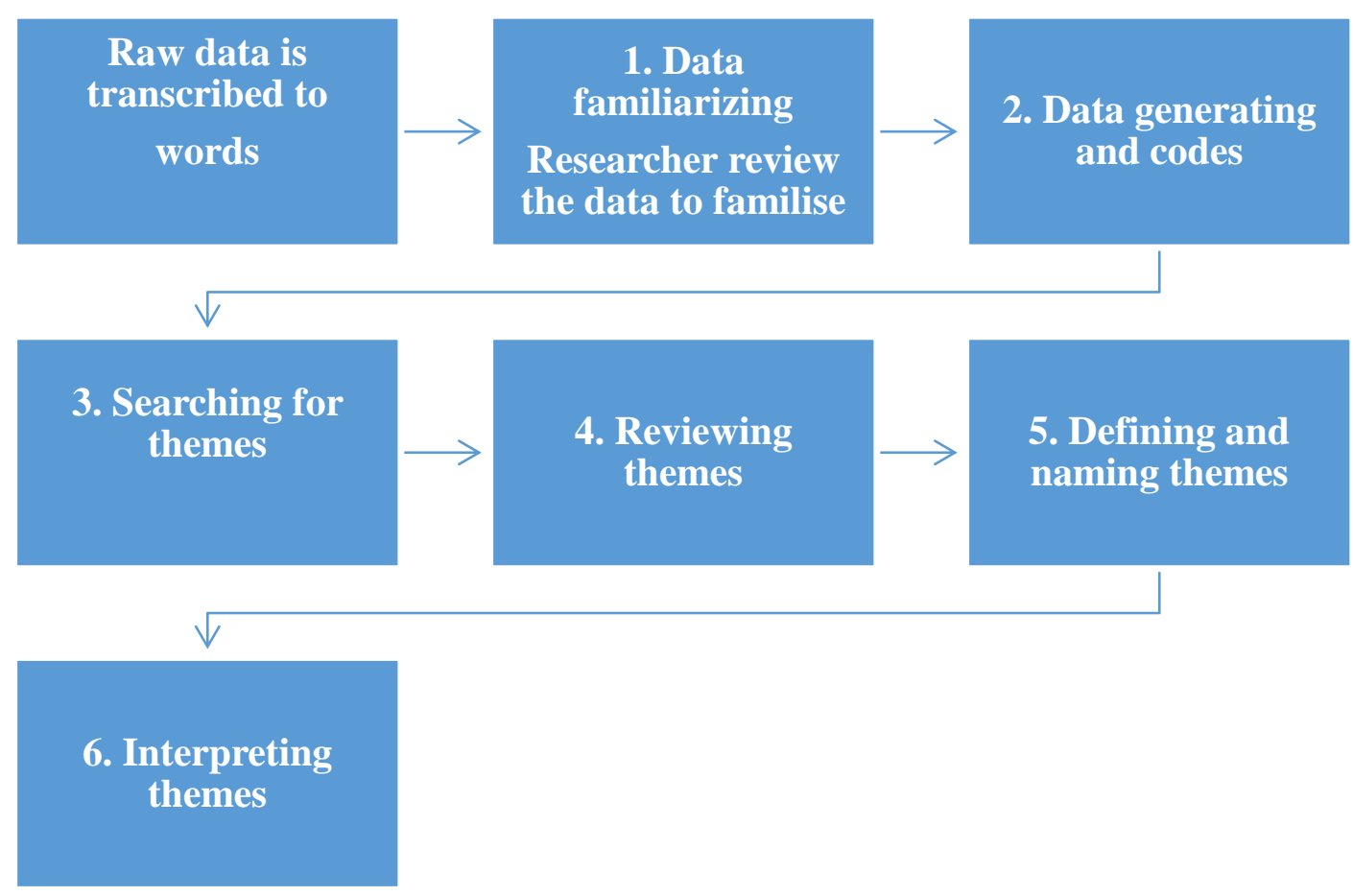

Figure 3.11: Data analysis process

(Source: adapted from Clarke \& Braun, 2017; Creswell, 2014) 


\subsection{Pilot study}

According to Dann, Nash and Pearce (1988), a pilot study is the process of ensure validity and reliability of questions. The pilot study can assist the research to adjust the research questions as well as minimise the errors (Ary, Jacob, Sorensen \& Walker, 2018). Thus, it was important for the researcher to conduct a pilot study to gauge the overall questions by gaining the feedback from the peers before the official interview was taken.

This pilot study was undertaken with three souvenir suppliers, one from the group of SPs and middlemen, and the other two from SRs and SVs, who sell the souvenirs in the LPB night market. These participants were excluded in the study. Meanwhile, the researcher had the chance to observe the logical flow of questions and interview time taken. Thus, there are some minor adjustments to better improve the interview questions. The change has been made by deleting some of the repetitive questions. This includes using plain or simple language (Lao language) and controlling interview time.

\subsection{Human Ethics}

Ethical considerations are an essential responsibility of the researcher (O'Leary, 2013). Ethics is "the process of investigation, criticism, and decision making" (Weathington, Cunningham, \& Pittenger, 2012.p.26). It assists a researcher to act with participants that ensure their well-being (O'Leary, 2013). This research was conducted following the requirement of Human Ethics Committees of Victoria University of Wellington (VUW-HECs). It has obtained VUW-HECs approval number: 0000024730. It also received the approval letter from the LPB Department of Information Culture number 019/ICT. (Please see Appendix E1). All participants are required to sign consent before commencing the interview.

Some conditions have been met regarding VUW-HECs. This includes the rights of participants in this study. Participants are volunteering without any pay or coercion. This includes the right of the participants to withdraw from this study at any time. In the case that the participants cancelled, the information provided will be excluded or destroyed, and they can cancel within four weeks after the interview or during the interview period. Additionally, this study considered participants aged 18 or over to ensure they were mature. The participants' information will be kept 
completely confidential. Their name will not be mentioned in any reports. They are only referred to as a group type and the information would never affect their personal life. The data will be destroyed within a certain time (three years) after the research ends. The ethic consideration also seeks for permission in order to use this research information to be interpreted, analysed, and published in student reports and in a thesis. This includes to be presented at conferences and to be available in other forms of publication such as journal articles and magazine or newspaper articles if there is.

\subsection{Methodological limitation}

The qualitative research used in this project allowed the researcher to gain a greater meaning by using data collection tools, interviews and participant observations. Due to the time limitation on the research timeline, small sampling is involved in this study. Thus, it may not generalise all souvenir suppliers in LPB. In addition, participant observation is technique which its nature of analysis is required researcher's involvement. Thus, the result will be based on her interpretation in the context of developing countries and this may be different from developed countries on some points.

\subsection{Chapter conclusion}

This chapter presents the researcher's justification for the researcher's standpoint and means to achieve the aim and objectives of this study. With the aim of exploring the suppliers' perspectives of authentic product, the researcher takes the view of interpretivism and this can directly guide research design and research method. The researcher has employed qualitative research and thus interview and participant observation is used as way to collect data. This research is conducted in Laos in which LPB is selected as the case study due to its significance as a World Heritage site and popular tourist hotspot. It is also a province known among domestic and international visitors for having plenty of authentic souvenirs. This chapter presents the discussion of methodology and the research method used in this research. In addition, a pilot study was undertaken to cross-check the validity and reliability of interview questions. Data analysis used the six steps of thematic analysis manually. This chapter also considers the Human Ethics of Victoria University of Wellington and finally it justifies the methodology limitation of this study. 


\section{CHAPTER 4: FINDINGS}

\subsection{Introduction}

This chapter summarises and presents immediate discussion on the findings. First, it presents the overall situation of souvenir businesses in LPB. This includes the souvenir business types, souvenir classification, suppliers' revenues, and suppliers' motivation. It also highlights the souvenir product quality and quantities as well as the suppliers' ability to offer local products instead of imported items. Second, it presents five main attributes of authentic souvenirs perceived by LPB suppliers, namely: handicraft and handmade work, historical and cultural integrity, product location, skilled craftsmanship, pattern and aesthetic presentation. Third, it elaborates on the sources with whom souvenir suppliers have traded across three different geographical areas, namely: local (within LPB province), domestic (throughout or within the country), and international suppliers. Finally, it ends by exploring and examining the key values and challenges of authentic souvenirs from the souvenir suppliers' perspective.

\subsection{LPB's souvenir business}

The snapshot of LPB's souvenir business reveals that LPB's souvenir suppliers have worked between two and twenty years in the business. LPB suppliers have produced and sold products that are related to the artwork, textiles, wooden items, food and drink, T-shirts, and painting and drawing. According to Table 4.1, the majority of souvenir suppliers are female, accounting for over $70 \%$ of total respondents. Major souvenir stalls sell a mix of different types of souvenirs, but most of them have attempted to sell local souvenirs such as local food, pictorial souvenirs (natural painting and drawing), and handicraft work. Textiles are the main products displayed and sold. Major suppliers set their stalls up at their house, but many of them prefer to sell at the LPB night market, which is the place that the author met at for the interviews and observations. 
Table 4.1: Snapshot of LPB suppliers profiles

\begin{tabular}{|c|c|c|c|c|}
\hline Respondent & Gender & Souvenir Products & Business location & $\begin{array}{c}\text { Years } \\
\text { involved in } \\
\text { business }\end{array}$ \\
\hline $\mathbf{R} 1$ & Female & $\begin{array}{l}\text { Drawings } \\
\text { paintings }\end{array}$ & $\begin{array}{c}\text { LPB city \& Night } \\
\text { market }\end{array}$ & 5 \\
\hline $\mathbf{R 2}$ & Male & Textiles & LPB city & 3 \\
\hline $\mathbf{R 3}$ & Female & Textiles & $\begin{array}{c}\text { LPB city \& Night } \\
\text { market }\end{array}$ & 18 \\
\hline R4 & Female & Textiles & $\begin{array}{l}\text { LPB city \& Night } \\
\text { market }\end{array}$ & 10 \\
\hline R5 & Male & $\begin{array}{l}\text { LPB baskets } \\
\text { (Cha num keng) }\end{array}$ & LPB city & 5 \\
\hline R6 & Female & Clothes (T-shirts) & Night market & 2 \\
\hline $\mathbf{R 7}$ & Female & LPB local food & $\begin{array}{c}\text { LPB city \& Night } \\
\text { market }\end{array}$ & 5 \\
\hline $\mathbf{R 8}$ & Female & Wooden products & Night market & 5 \\
\hline R9 & Male & Paintings & Night market & 5 \\
\hline R10 & Female & Textiles & Phanom Village & 16 \\
\hline R11 & Female & Textiles & Phanom Village & 10 \\
\hline R12 & Female & Textiles & Night market & 5 \\
\hline R13 & Female & LPB local food & $\begin{array}{l}\text { LPB city \& Night } \\
\text { market }\end{array}$ & Over 15 \\
\hline R14 & Male & LPB local food & $\begin{array}{c}\text { LPB city \& Night } \\
\text { market }\end{array}$ & 18 \\
\hline R15 & Male & $\begin{array}{l}\text { LPB traditional } \\
\text { handicrafts and } \\
\text { house amenities }\end{array}$ & $\begin{array}{c}\text { LPB city \& Night } \\
\text { market }\end{array}$ & 12 \\
\hline R16 & Female & $\begin{array}{l}\text { Textiles, clothes } \\
\text { and T-shirts }\end{array}$ & Night market & 8 \\
\hline R17 & Male & $\begin{array}{l}\text { Drawings, } \\
\text { paintings }\end{array}$ & Night market & 10 \\
\hline R18 & Female & $\begin{array}{c}\text { Imported ladies' } \\
\text { bags } \\
\text { T-shirts }\end{array}$ & Night market & 3 \\
\hline R19 & Male & Coffee, drawings & Night market & 5 \\
\hline R20 & Female & Textiles & $\begin{array}{l}\text { Phanom } \\
\text { Village }\end{array}$ & 5 \\
\hline R21 & Female & Ladies' clothes & Night market areas & 3 \\
\hline $\mathbf{R 2 2}$ & Female & $\begin{array}{c}\text { Textiles, postcards, } \\
\text { drawings }\end{array}$ & Night market & 22 \\
\hline R23 & Female & Textiles & Ock Pop Tok & 11 \\
\hline R24 & Female & Paintings & Night market & 15 \\
\hline
\end{tabular}

\subsubsection{Sample profiles}

24 participants in this study can be categorised into four souvenir suppliers, namely: souvenir producers (SPs), souvenir retailers (SRs), souvenir vendors 
(SVs), and middlemen (MM). Souvenir producers tend to carry out more than one role to sustain their businesses.

Table 4.2 LPB souvenir suppliers' role profiles

\begin{tabular}{|c|c|c|c|c|}
\hline $\begin{array}{c}\text { LPB Suppliers } \\
\text { categories }\end{array}$ & $\begin{array}{l}\text { Single role } \\
\text { taker }\end{array}$ & \multicolumn{3}{|c|}{ Multiple roles taker } \\
\hline $\begin{array}{c}\text { Souvenir retailers } \\
\text { (SRs) }\end{array}$ & R2, R23 & \multirow[t]{2}{*}{$\begin{array}{l}\text { R3, R4, R5, R7, } \\
\text { R10, R12, R13, R16 }\end{array}$} & & \\
\hline $\begin{array}{c}\text { Souvenir } \\
\text { producers (SPs) }\end{array}$ & N/A & & \multirow[t]{2}{*}{$\begin{array}{l}\text { R9, R11, R19, } \\
\text { R20, R21, R22 }\end{array}$} & $\mathrm{R} 1$ \\
\hline $\begin{array}{l}\text { Souvenir vendors } \\
\text { (SVs) }\end{array}$ & $\begin{array}{l}\text { R6, R8, R15, } \\
\text { R17, R18, R24 }\end{array}$ & & & \\
\hline $\begin{array}{l}\text { Middlemen } \\
(\mathrm{MM})\end{array}$ & R14 & & & $\mathrm{R} 1$ \\
\hline
\end{tabular}

According to Table 4.2, 15 out of 24 interviewees hold dual duties, accounting for over $60 \%$ of total respondents. Of those, eight suppliers belong to the SPs and SRs groups, which account for approximately over 33\% of total samples. Six souvenir suppliers belong to the SPs and SVs groups, accounting for one fourth, or around $25 \%$, of souvenir suppliers in this study. Interestingly, middlemen seem to be a minority souvenir supplier group. Surprisingly, there is no record in this study of suppliers who perform a single role as a producer.

The performance of multiple roles seems to be a trend for souvenir suppliers in LPB with the need for substantial incomes, market share, and an increase of the product profits and ability to secure consistent incomes in off-peak season. These views are supported by the SPs and SVs group and the SPs and SRs group. Respondents 9 and 12 describe and explain their view as follows:

“...I have produced local souvenirs....; and rely on the MM to get my products .... Sometimes it is hard to predict the incomes and not easy to sell all souvenir products to MM but it is much easier to sell to tourists... (R9)

“...I used to only sell the souvenir products but there are not many products for me in high seasons...thus I start to learn, and mimic other people souvenir products that I sell... practice make perfect..." (R12)

In addition, there has been an upward trend of shifting the roles among suppliers', which also implies authenticity issues. The SPs have been shifting towards the SVs and SPs group in which some SPs have discontinued their role as 
SPs and taken on the role of SVs. The reason behind their quitting is because the production process for handmade and handicraft work is time consuming and there is a shortage of raw materials. Whereas SVs who become SPs discover that their profits increase because they can set the price themselves and understand consumers' needs as they have direct interaction with tourists. Additionally, this study also highlights that the SVs have learned to imitate and produce local souvenir items when SPs cannot provide them with souvenir items in larger quantities in peak season. In short, the groups of SPs and SVs state similar reasons for their adaption which is primarily for market access, and raw materials shortage. Respondent 16 states this view:

“...Previously, I had produced local food souvenir only...it took time to clear all items.... (The shop is in the main tourist street, city). I find it much easier to reach the customers and sell our products in my outlet" (R16)

LPB souvenir suppliers have perceived that holding dual roles seems to gain them an advantage. They have learned from previous experience to secure the ratio of market share. The shifting roles of LPB souvenir suppliers are continuing, with an upward trend. The impact of the SPs becoming SVs is inevitable and consequently, SPs have indirectly reduced their souvenir production while some have attempted to gradually stop production. In fact, SPs and SVs have embraced the selling of other SPs' products instead. Consequently, the number of SPs will be reduced, and this impacts on the overall souvenir production in which many scholars claim that SPs take a crucial role of suppliers for constructing the authentic souvenirs.

\subsubsection{Business classification}

Souvenir businesses in LPB are classified as small and medium-sized enterprises (SMEs). The majority of souvenir suppliers are classified as family businesses, with less than $20 \%$ being SMEs. According to Laos National Chamber of Commerce and Industry (LNCCI, 2010), a small business/enterprise can be defined as the firm operating with an average number of employees hired yearly not exceeding 19 persons, or total assets do not exceed two hundred and fifty million Kip (equivalent to USD 30,000). A medium business refers to the business employing not more than 99 staff yearly, or total assets do not exceed one billion two hundred Kip (equivalent 
to USD 144,266) or its annual turnover does not exceed one billion Kip (equivalent to USD120,221 (LNCCI, 2010). A family business is even smaller than a SME in terms of labour and assets, in the context of souvenir business in Laos, particularly in LPB. In saying this, the majority of people who are in family business usually start the journey as hobby activities or do it as an alternative job for additional income. It is also done as a passion and later more funds are invested to produce more souvenir products for sales.

This research findings claim that LPB souvenir business under family type covered approximately $80 \%$ of overall respondents. Family business in the context of LPB souvenir businesses refers to the process of producing, selling, and delivering souvenirs, mainly relying on family members. In other words, family members are the main contributors of labour in the souvenir supply chain to supply the souvenir products. Taking the advantage of family business style, especially found in the SPs group, SPs can use their own knowledge and passion, derived from their local unique culture or lifestyle and apply these authentic concepts through the objects or authentic souvenirs. This type of business can also start with lower assets due to the fact that key labour is based on the family member. It usually starts with a lower investment as the majority of souvenir suppliers will promote local products that are natural based and made by indigenous artisans. Thus, souvenirs made locally are more environmentally friendly and offer authenticity, which is one of the criteria that tourists look for.

\subsubsection{Suppliers' revenue}

There is a huge disparity between the four supplier groups' revenue. Souvenir revenues depend on the product types that the suppliers sell or produce. SRs make the most income among the four suppliers, approximately between LAK 20, 000,000 and LAK 40, 000,000 (equivalent to USD 4,797) per month in high season. The groups of SPs and SVs earn from LAK 3,000,000 to LAK 6,000,000 (equivalent to USD 360-720) a month, with no sales at all some days in the low season. Middlemen seem to earn incomes between LAK 2,000,000 and LAK 4,000,000 (equivalent USD240 and USD 480).

Figure 4.1 shows the pictorial souvenirs as a traditional painting, each piece of work cost minimum LAK 30,000 (equivalent to USD 3.62) Dual-role takers are considered to be the groups that have higher and better incomes than one-role 
takers, especially the groups of SPs and SRs who produce their products and sell in their own stalls.

The souvenir supplier revenues have also been influenced by seasonality and tourist nationality purchase. In fact, $80 \%$ of respondents assert that peak season can be seen as the highest money-making period for souvenir suppliers. The peak period is between October and April each year. The peak season includes the local festival and important events such as Laos New Year (generally in the middle of April), international New Year, Chinese New Year, and Valentine's. Many SVs and SRs agree that, during these periods, LPB has welcomed international visitors as well as domestic travellers. In 2015, total visitors' count was 643,319 in which international tourists totalled 469,586 and domestic tourists totalled 173,733 . This number has increased from 2016 by approximately $7.43 \%$, domestic visitors, and $5.32 \%$, international visitors (TDD, 2016).

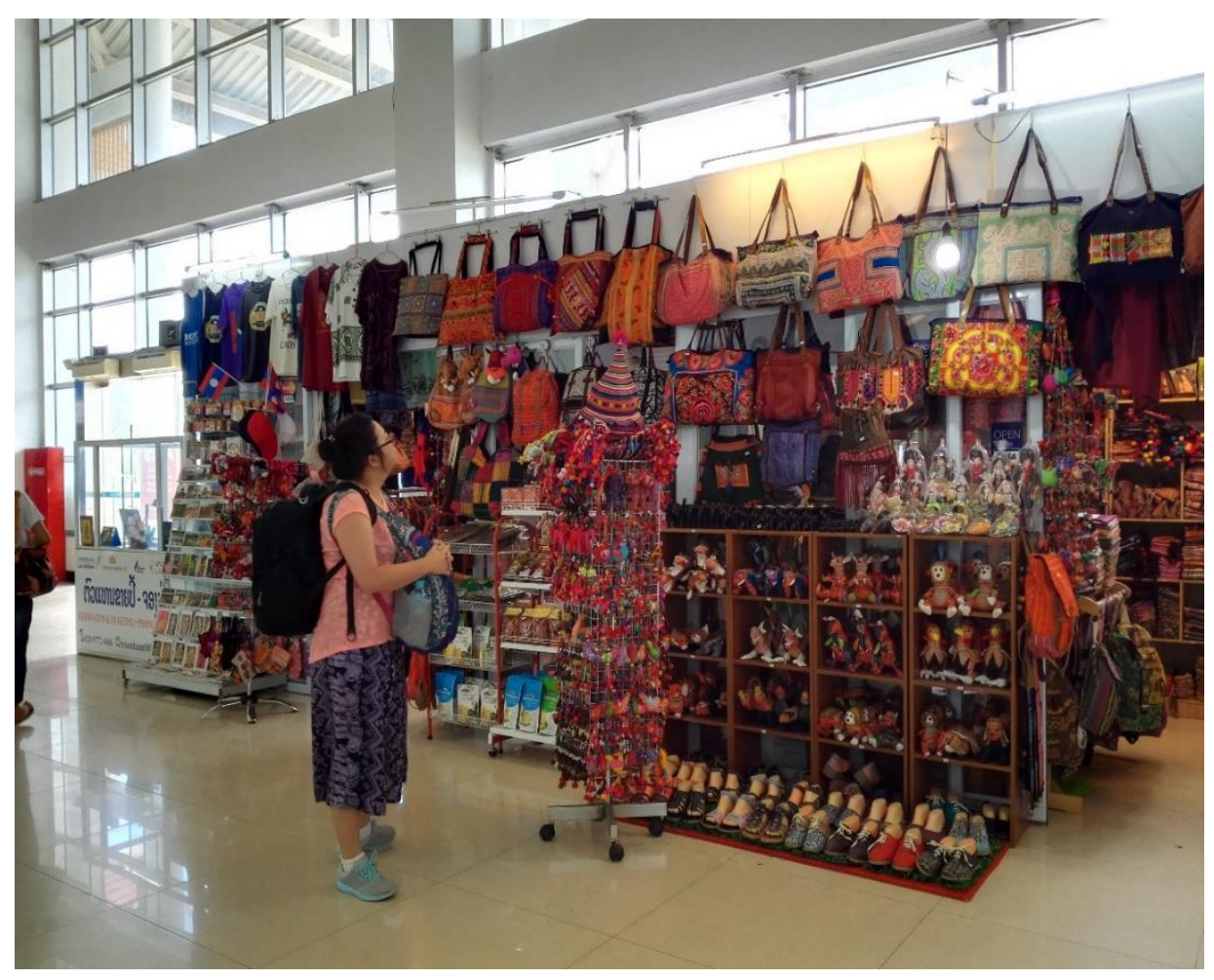

Figure 4.1: Authentic souvenir stall in LPB international airport

(Source: author, 2018) 

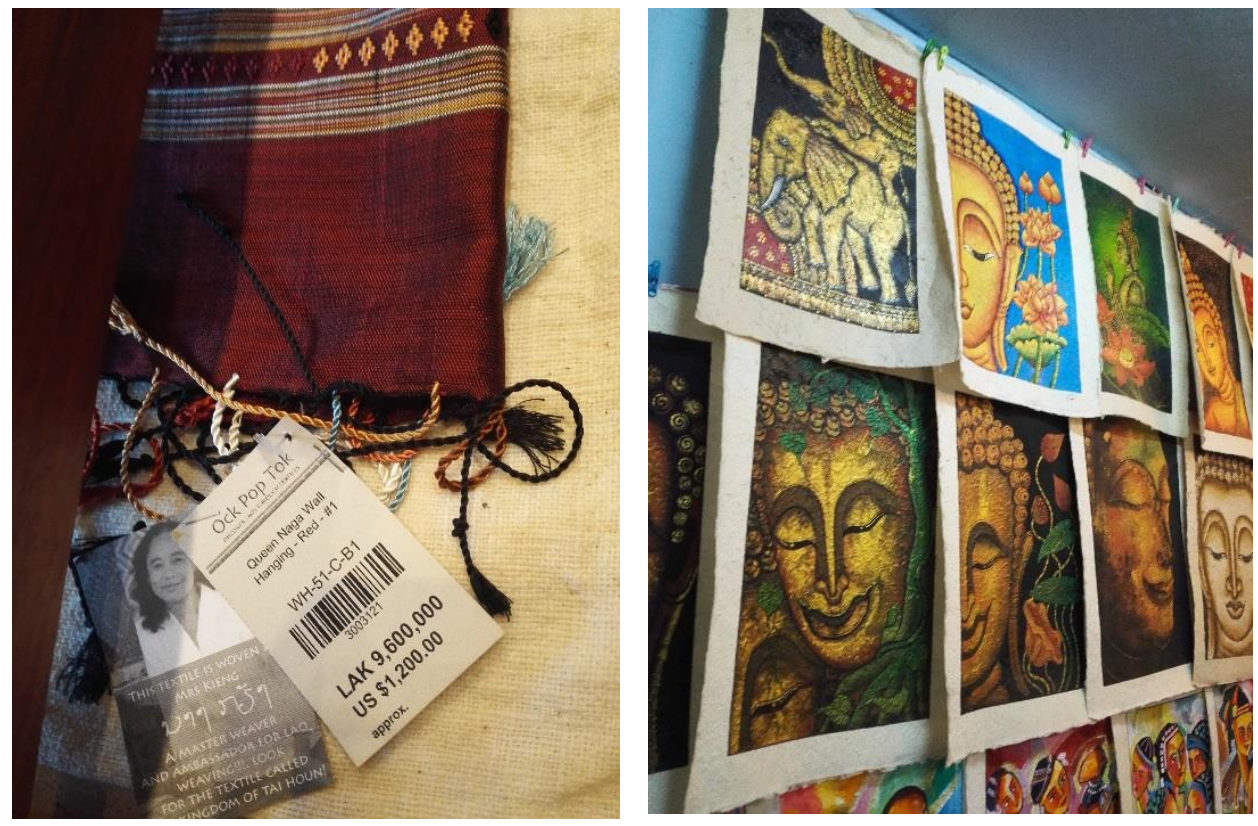

Figure 4.2: Authentic textile souvenirs (left), and Buddha painting (right)

(Source: author, 2018)

LPB souvenir suppliers perceived that international tourists and domestic travellers can generate more revenue. In fact, the perception is that these tourist types' souvenir purchasing amounts are higher compared with local buyers. LPB souvenir suppliers advise that the majority of international tourists are those from China and Europe, where Chinese tourists purchase the most in terms of quantity, whereas European visitors tend to go for premium products. The domestic market, as advised by the LPB souvenir suppliers, mainly comes from provinces nearby and Vientiane capital. Thus, many souvenir shops are arranged at the LBP airport see for the (see figure 4.1)

Souvenir suppliers' revenue also depends on the types of souvenir products sold. The products that are related to the handicraft work and handmade (e.g. textiles, lady costumes, woodcrafts, and drawings) have made greater incomes for them (see Figure 4.1). In their perspectives, those items need a skilled artisan and time consumption for production process, for example some lady costumes take almost a month to complete as one finished product.

According to field observation, the majority of SPs' and SVs' souvenir outlets rarely use price tags on products. There are only a few shops that present the price and attach information about the products. The majority of suppliers assert that they do not see the necessity in doing so, while attempting to avoid redundant cost. In fact, there is no best practice in this regard to pursue for souvenir suppliers 
in LPB. With no strict rules and regulations governing this area, many suppliers do not see its importance. Nevertheless, LPBHA attempts to urge all SRs and SVs to put the price tags on the souvenir products, with the aim of giving buyers a chance to look around and make price comparisons, hopefully leading to sales. Yet, there is no clear guidelines or instructions on how to do so, given to the SRs and SVs.

According to the interview, the majority of respondents admitted that the food souvenirs and textiles are more preferred by domestic travellers and other countries in the region, respectively. It is quite hard, though, to predict the income from selling souvenirs, where suppliers have been encouraged to find better solutions to distribute their souvenir products, with no or little support from relevant authorities. Respondent 11 exemplifies this view:

“...I have been involved in this business for roughly 10 years, yet I have no support from authority here, especially on financial term.... The authority used to provide training though, but I did not attend. There is no more now (R11)

It is interesting to highlight that sales volume in LPB has decreased compared to the last decade. Many participants in this study agreed and indicated that there is more market share to split among the players who are active in the market. Moreover, there is an increase in international investors such as retailers and middlemen in the main market in LPB as well as in the tourist hotspots.

There is a trend of small SPs and SVs in LPB. SPs strive to sell on their own to get a better price. At the same time, vendors also learn to be SPs because high demand from tourists makes suppliers look for the same products. Small vendors cannot secure large quantities of souvenirs due to financial limitation, while the majority of SPs also want to deal with big SVs rather than small ones. Sometimes, great and appealing souvenir products are sold to larger vendors, leaving lower quality/sub-quality souvenir items for small vendors. Suppliers (sellers) also agree that higher-price souvenir products are hard to sell and block their cash flow. It is also good to highlight that SVs try to have a variety of products in the same shop to offer to buyers. By observing at the night market, major vendors tend to sell similar souvenir items. The unique and appealing products that can represent LPB or Laos are the most sellable, and the most demanded from tourists. 
To sum up, the sales revenue of LPB suppliers is influenced by product sales, role-taker functions, seasonality, and types of tourist markets. The decrease of sales could be as a result of more overseas suppliers' interference and imported products. This is because the majority of interview participants rarely do proper financial recording. Thus, it is not surprising to observe that there are less than $20 \%$ who kept financial business records.

\subsubsection{Suppliers' motivation}

This study reveals that the majority of respondents perceived an economic gain as the main motive for them to join the souvenirs industry. According to Table 4.3, economic gain or healthy economy accounts for over $70 \%$. Almost $13 \%$ of respondents in this study have continued being involved in the souvenir industry as part of their family business inherent. Some suppliers have joined souvenir business because they love to do it. This is accounted at the same percentage as suppliers who have selected this because it offers them flexible time or an alternative job. More detail and explanation of these motive themes will be clarified in the following section.

Table 4.3. Suppliers' motives for working in souvenir business in LPB

\begin{tabular}{|l|c|}
\multicolumn{1}{|c|}{$\begin{array}{c}\text { Motives on souvenir business } \\
\text { involvement }\end{array}$} & Percentage (\%) \\
\hline Healthy economy (Economic gain) & 70.84 \\
\hline Family inherent & 12.5 \\
\hline Passion & 8.33 \\
\hline Alternative jobs (due to flexible time) & 8.33 \\
\hline \multicolumn{2}{|c|}{ Total } \\
\hline
\end{tabular}

\subsubsection{Economic gain}

The LPB suppliers' main motivation for working in the souvenir business is primarily to contribute to their healthy economy. This includes an increase of family income and living conditions improvement. Many souvenir suppliers accept that their incomes are better now when compared with the period before joining the souvenir business. Respondents 3 and 7 stated these opinions: 
"I used to be a government official staff and produce local souvenirs in free time. ...Later, I become full-time souvenir producer and my wife sell them...the incomes are pretty good. My kids have better chance to be educated, we have our own house and a second-hand car... (R3)

"Food souvenir business allows me to support my family, offer better education for kids, buy the house and take care of family expenses. Today I even have my accommodations (Bread and breakfast) and bicycles to rent out for tourists...”(R7)

The healthy economy that souvenir suppliers refer to is the method to improve suppliers' living conditions. According to various respondents' statements mentioned above, it is noted that, during the interview section, many suppliers showed their happiness and proudly presented their living conditions, which have been changed by pursuing this career. This includes the capability to take care of the family and fulfil other family commitments. Ladies can stay at home to take care of children and sell or produce souvenirs. Meanwhile, they agree that sometimes they do not need to travel to the city quite as often or to another place to work for wages.

"I am proud of what I have now... (Smile)... Producing and selling the food souvenirs are the only job that make money from the beginning... and I only work in my place..." (R5)

Thanks to local people in LPB who have preserved their cultural and historical authenticity, ways of living and stunning physical buildings in the city, LPB was granted the UNESCO World Heritage site award. This has turned LPB into a popular tourist hotpot and has become one of the most desirable tourist destinations in the world. According to the media, LPB was claimed the best destination for tourists that should be visited in the year 2018 (Guardian, 2018). In fact, LPB can accommodate and welcomes travellers from different parts of the world and this includes regional and international travellers. The tourism in LPB indeed improves social-economic development and improves the living conditions of the local community. Souvenir suppliers can be seen as one of the careers that 
could help the local people gain incomes, especially residents who live in rural areas. They have an opportunity to create the souvenir products incorporating the culture and uniqueness of each area in each village or place. Joining this industry allows the suppliers to achieve the economic gain, while the souvenir business can also assist them to alleviate the poverty in the society.

\subsubsection{Family inheritance/family business}

Family inherence is one of the main reasons for LPB souvenir suppliers. This is especially the case in LPB where the majority of people living in big families, producing and selling specific traditional items inherited from their ancestors, this is the main source of income to support the families. As in other Asian countries, people in Laos still live together as a big family and continue the family business operation from one generation to the next, especially in rural areas. This is also the case for souvenir business as highlighted by Respondent 22 below:

“...People here are born to do the textiles and deliver from one ancestor to another...I just continue from what I saw my mother did...I have tried to do another job but it does not suit me" (R22)

The group of SPs asserts that their reason for joining the souvenir business is about familiarity since they were born and inherited from their families. They expressed that, partly, they see their family members doing it and subsequently absorb it. By following this, they can make money. Respondent 10 describes her view on the takeover process:

“...I have received this business from my family, I have continued this and adapted the quality to suit consumers nowadays ......" (R10).

\subsubsection{Passion}

Passion is another factor driving suppliers to enter the souvenir business, especially when combined with the fact that LPB has a long history and culture. Respondents 5 and 12 exemplify this view:

“...I have first started from my passion in art design and I studied at the local poly technique school during my study, I worked with my neighbour..." (R5) 
"...While it is fun, I also make good money from producing souvenir products. Today, I own my souvenir stall at home...I have never tried new job since then..." (R12)

This study indicates that suppliers' personal passion for joining the souvenir business is not only the way to preserve local culture and heritage through authentic souvenirs, but also the mechanism to assist the souvenir suppliers to gain their incomes. Some authentic souvenirs have been selected to be produced based on the producers' preference and their indigenous pattern, and the producers' location/signature. For example, Phanom Village is the best place for textile makers. Based on the observation during the visit and personal interview notification, the majority of females who have worked here have more passion for continuing their textile style daily at the centre, compared to other villages.

\subsubsection{Alternative jobs}

Souvenir suppliers have joined this business as an alternative job since this job provides them with time flexibility. The SPs can work on the souvenir production in their free time whereas the SVs can commit to their main duty as well as selling souvenirs. This is especially the case for women who are housewives and youths who are students. This can help them to earn extra income. Respondents R6 and R11 exemplify these views:

“... I am a student who sells souvenirs as a part-time job...imported products give me more profits due to lower investment cost..." (R6)

“...day time I work in the office... and night time I decide to become SVs. I need to earn more money." (R11)

Surprisingly, this study implies some crucial points about suppliers. Some of them decided to change from part-time to full-time later once they fully engaged with the business. Respondent 21 illustrates this view:

“...I have to sell souvenirs at night market after my normal working hour. It is the most making money and after three to six months, I become fully involved in the souvenir industry..." (R21) 
LPB souvenir suppliers become involved in this job as a way to supplement the agriculture incomes in dry season. Many suppliers work in this area primarily as an alternative job, which implies that involvement in this career seems to offer some financial increase. This means the souvenir business provides jobs with opportunities to earn good incomes with time flexibility. Laos has also opened the door to welcome regional and international tourists regularly. It is expected that the number of visitors will surge, as will their expenditure. Consequently, it also increases the tourism products and services, and this includes the local souvenir products.

\subsubsection{LPB's quality souvenir and price offer}

When asking about the quality of authentic products and price offer, there are different views among four souvenir suppliers. For example, majority of suppliers who produce the souvenir products (family business) assert that they can provide good quality of authentic souvenirs with rational prices. However, the groups of SPs and SRs (in small business) claim that they can offer numerous souvenir products. In addition, the SVs and SRs assert that the price traded among local suppliers on local souvenirs products (which are made from local craftsmen) seems to be higher compared with domestic and international suppliers.

Many suppliers are facing scarcity of local raw materials and, subsequently, local souvenir products. They, in fact, sometimes need to deal with international souvenir suppliers to keep the low cost investment. The group of SVs, who used to be SPs, suggested that raw materials in local areas are not only expensive but sometimes not enough to supply their needs. Many suppliers, especially the SVs who have a low cost of investment, have been advised by international suppliers (international middlemen, mostly from Vietnam and China) to sell imported souvenir products. International souvenir suppliers are willing to place the souvenir products with the SVs first and come back to collect the money later. This condition allows many suppliers to deal with international middlemen better.

There are various views on LPB souvenir suppliers' abilities regarding product offer and prices. On one hand, the SPs and SRs agree that they can offer the authentic souvenir products matched to overall demand. This is because they are confident that they can offer the local products to the consumers and tourists with the appropriate price setting. This seems to contradict with some perspectives of SPs and SVs. In fact, through the field observation, craft souvenir products can 
be offered to buyers, but the SVs and SRs also assert that in the high season, they may be unable to offer in larger quantities. The reason is that some local souvenir products, which are relevant to handicraft work and are handmade, such as textiles, take time to complete.

In conclusion, LPB's souvenir business comprises four main types of suppliers namely SPs, SVs, SRs, and MM. The SPs and SRs group, and the SPs and SVs group are dual-role takers accounting for the majority of respondents in this study. This study reveals that in LPB's souvenir business the family business, accounts for over $80 \%$, whereas SMEs accounted less than $20 \%$. The souvenir suppliers' four main motivations for joining the souvenir business are namely: economic gain, family inheritance, passion and alternative jobs. However, among the motivations stated by the souvenir suppliers, the underpinning motive is to gain a healthy economy. Souvenir suppliers believe that joining the souvenir business can reduce the poverty and improve the living conditions. This study reveals that scarcity and, subsequently expensiveness, of raw materials, can impact on the quality and price offer of the final authentic souvenir in this area.

\subsection{Identification authentic souvenirs}

Figure 4.3, illustrates that authentic souvenirs can be classified into five attributes based on the perceptions of LPB suppliers: 1) whether the souvenir products are associated with handicraft work or handmade; 2) whether the souvenir products integrate culture and history; 3) whether the souvenir products are created within LPB or some particular villages in LPB or place identification; 4) whether the souvenir products are produced by recognised persons/villages or specific art skills, and 5) whether the souvenir products look attractive or have a stunning presentation in the suppliers' views.

The findings of this study elaborate on the interconnection of authentic souvenirs from LPB perspectives in which skilled craftsmen, handicraft and handmade work have influenced the authentic appeal and good presentation. More detail about the authentic souvenir attributes follows in the next sections. 


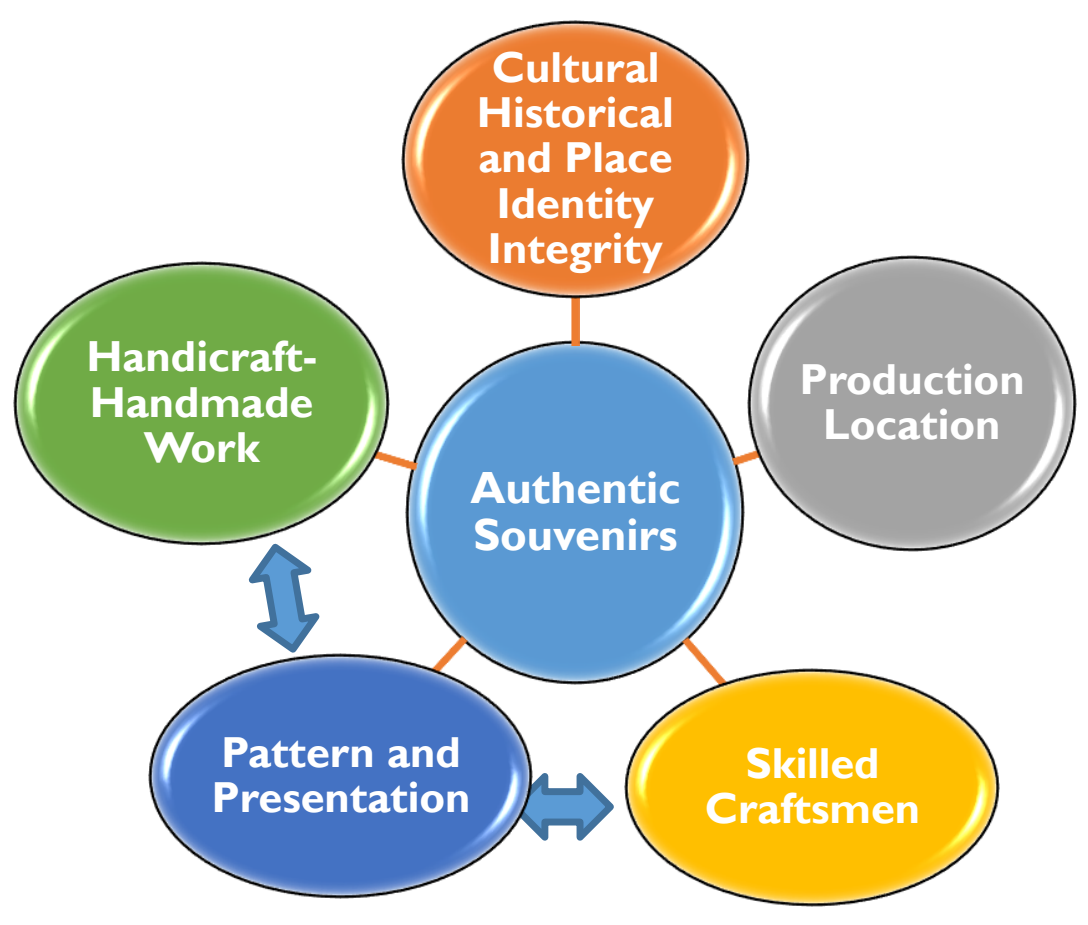

Figure 4.3: LPB suppliers' perception toward authentic

\subsubsection{Handicraft and handmade work}

The majority of souvenir suppliers in LPB agree that authentic souvenir products should be related to the handicraft work and produced by local craftsmen. Retailers, vendors and middlemen expressed that the quality of skilled craftsmanship and labour skills make the souvenir products more appealing to them as authentic souvenirs. From suppliers' perspectives, souvenir items that are related to handicraft work can be seen as one of the most authentic souvenir items in which suppliers agree that tourists perceived as high in value. Meanwhile, those items have received premium price. Respondent R6 shared her story:

“ This 'Sinh' (Laos skirt) have brought back from local textiles from Phanom Village...I showed and explained how this item had been made, customer asked for the price and bought it, I am kind of lucky as she did not do any bargain ... when I refer to this village, the buyer appreciate the quality..." (R6)

It can be reasonably stated that skilled craftsmanship is one of the criteria that SVs and SRs have used as the key consideration for buying local authentic 
souvenir products to sell. In fact, handicraft products are ranked as one of the top ten sectors that can generate revenue for Laos' economy as well as LPB province.

Handicraft products are reported as the items that can provide the most direct income for local suppliers as well as the indigenous people who live in rural areas. The SRs and SVs also look for other souvenir products, apart from handicraft products, that can be seen as significant and appeal to tourists. According to site observation, the majority of souvenir products that have been displayed in tourist hotspots in LPB city, such as at the night market and other attractions, are handicraft items made by local craftsmen. Suppliers value authentic items if they are handmade and related to tourists' demand. Suppliers are mostly interested in buying authentic souvenir items that are really appreciated by the tourists. Respondent 18 shows the stand point:

“...While selling souvenirs in night market, I also do my photo painting...tourists are interested in and stop by, ask and take my photos. Some of them buy it. I am really happy to interact with them" (R18)

Handicrafts in LPB have also been viewed by tourists as authentic and have received attention from various groups of tourists. According to Ashley (2006), out of the three different types of travellers (e.g. budget, middle-class, and upper-class), LPB handicraft products are more appreciated by upper-class travellers. On average, around USD 61 per trip for upper-class tourists, triple the amount of budget travellers, which is around USD21 per trip, and the middle-class tourists, is approximately USD23 per trip. This could be the point for Laos and LPB souvenir suppliers to consider which market they need to focus on and what products should be made. LPB souvenir suppliers need to find the pitching points in the souvenir business in order to be competitive and increase the tourists' spending in authentic souvenirs to take home.

The majority of respondents give value to, and appreciate, handmade and handicraft souvenir items. Most SRs and SVs have their criteria in their mind when they select souvenirs to sell. Meanwhile, SPs disclose that handicraft sales can be seen as one of the main incomes for producers and additional income for vendors. In addition, handicraft items are seen as popular tourist souvenirs. According to UNWTO (2012), handicraft souvenir items deserve to be paid well for, and is a means to improve the level of artisans' skills in local traditions and involve high- 
quality craftsmen/producers. In fact, the selection process for the authentic souvenir sales in LPB by souvenir suppliers is based on handicraft as well as handmade by indigenous people. Respondent R2 illustrates this view:

“...My shop usually sells handicraft souvenir items...my shop selects only items that are handmade and produced by local producer." (R2)

The handmade souvenirs are usually priced higher because of good quality materials and good presentation, usually involving natural dye colour. It is believed that these souvenirs are durable no matter how long the time has passed. However, the machine-made products seem not so appealing on the presentation and materials used. They are cheaper and they do not last for long. Respondent R11 addresses this below, based on the view of retailers.

"I have a guest who comes here almost every year. She does not mind for price. She is willing to pay for a good quality..., I care a lot about the reputation...This makes my business last for long." (R11)

\subsubsection{Souvenir patterns and presentation}

Souvenir pattern and presentation are key attributes in the authentic souvenir, as perceived by the souvenir suppliers in LPB. The majority of souvenir suppliers in LPB agree that LPB authentic souvenirs are more appealing compared with products from other provinces. The pattern and the handmade souvenirs seem to be authentic in quality in the view of suppliers. It is likely that imported souvenirs will be appreciated among certain groups of suppliers, mainly SVs. This is because SVs believe that selling imported products gives them more profit. Authentic souvenirs in this study means souvenir products that can represent Lao culture or LPB uniqueness.

“...I want to find some more souvenir products that I can sell and tourists are willing to buy. I looked at the products displayed by the vendors next to me. There are many tourists buying her products. In fact, her items are like mine but just the price is cheaper. My product is made by a local artisan and I think her products may not (with clear and strong voice, shows the confidence), as they seem not a real wood, but she can sell..." (R17) 
Recently, souvenir suppliers have tended to produce sellable souvenir products rather than authentic pattern or vintage souvenirs, compared with the last decades. Moreover, SPs also look for alternative materials such as those from other provinces and/or imported materials if local materials cost too much or are undersupplied. Some respondents have shared the same sources of raw materials for souvenir production and explain their difference in LPB compared with other places. Some respondents claim that the original pattern seems to gain attention from tourists as those souvenir style/pattern are viewed as authentic. According to field investigation, tourists admit that they buy the products because they feel those souvenir items are interesting and appealing to them.

\subsubsection{Skilled craftsmanship}

The retailer, vendor and middlemen groups expressed that the quality of skilled craftsmanship and labour skills make the souvenir products more appealing to them and it is required by customers. The SVs and SRs agree that authentic products made by indigenous people and local craftsmen who are highly skilled artisans, receive attention from the customers. Respondent 21 emphasised the uniqueness and the handmade quality delivered by the local SPs.

“...People here are born to do the textile and passing down from one ancestor to another." (R 21)

LPB souvenir suppliers, especially SPs and SVs, have look for ethnic features and limited editions. The suppliers can also get this in order to demand better prices, as the tourists are willing to pay for uniqueness. Some suppliers opine that tourists are happier and engage with the purchase when they are told the story behind the authentic souvenirs. This also communicates back to SPs to attempt to interlink the products with the story in their culture, prior to the production, to ensure that a well-grounded story is paved for later use. The authentic products, especially the items made from people in the higher land (Hmong) and some villagers living at far distances or rural areas, seem to have novelty due to the limited editions of patterns or uniqueness that cannot be found in the normal market. 
"...LPB souvenir textile is different ... due to the quality of handmade and skilled craftsmen..." (R2)

Souvenir suppliers perceived that high-skilled labourers produce quality and good presentation. SRs perceived that the authentic souvenir products require highly skilled artisans and are handmade.

\subsubsection{Historical and cultural integrity}

For souvenir suppliers, authentic souvenirs from LPB should represent the uniqueness of Lao culture, tradition, and place identity or LPB identity. For SPs, the authentic souvenirs related to culture integration and place identity are significant to suppliers in the production process, reflecting the way that souvenirs present the local culture and history, especially regarding the fact that LPB is titled as a World Heritage site. Respondent 2 supports this view:

"I have considered when they produce souvenir textiles, especially the lady clothes like 'Sinh', which are really more unique and different from other provinces in Laos." (R2)

LPB souvenir textiles, especially the 'Sinh', have been derived from the long history and culture of LPB, especially with the influence during the period ruled by the kings. From the suppliers' view, even though LPB Sinh's price is higher compared with products from other provinces, it is still needed among domestic and local travellers, especially Lao people who live overseas and are willing to pay for good products. This is a result of high-quality work produced by skilled craftsmen who are knowledgeable of the culture and tradition in a certain location, neatly portraying its identity through a particular pattern on textiles. Respondents 2 and 19 support this view:

"LPB souvenir textile is different from other provinces and other places due to the quality of handmade and craftsmen. People here are born to do the textiles and deliver from one ancestor to another." (R2)

"My saleable painting is the pattern representing Lao culture and tradition.... Recently the pattern of a novice is the most needed painting style ...." (R19) 
As a World Heritage site, LPB contains culture and a historical and unique identity. LPB is the place that can preserve the traditional building. Considering the view of R2 and R19, souvenir suppliers view the authentic souvenir linking to the place and unique culture of destinations and thus the suppliers also value these key attributes.

Souvenir items representing culture and place identity are not only viewed as the most appealing and sellable products, but also receive premium price. The authentic souvenir items include images of monks, Buddha, the traditional national flower, 'Champa', and the Laos-style traditional clothes such as the Laos skirt or 'Sinh'. Among the four groups, SPs expressed that they are confident to make souvenir products by themselves with the authentic pattern on heritage culture of LPB or LPB symbols. They differentiate their souvenir products by adding their producer's imagination. Souvenir suppliers believe that a good authentic souvenir can establish a great image for the tourism industry in LPB, Laos, and make people come back to the destination. Respondent 24 explained:

"...to me, the most impressive experience is when tourists look for my products and want to buy the wall magnet which she bought as gifts for her friends four years ago, and now she wants to have ones for herself" (R24)

Suppliers perceived that quality souvenirs interpreting Lao culture and customs are seen as the greatest items for tourists. Importantly, respondents expressed that these quality items can enhance the tourism souvenir market and raise profit generated by the local tourism products in LPB. In summary, souvenir items have been derived from history, culture and destination uniqueness. Tourists and local people have a role to play in cultural interactions; consequently, indigenous skills can be transferred through imagination and ideas about the place to tangible products that are viewed as authentic souvenirs.

\subsubsection{Production location}

Based on observation at LPB's night market, it is found that tourists keep asking where the products come from and how they have been made. A few vendors would like to impress the tourists by not telling the whole story on souvenir production while other vendors explained the differences of items by presenting the 
two samples, handmade and machine-made textiles. The difference between the two types is obvious from the suppliers' perspectives.

“...My souvenir products are 100\% handmade.” (R1)

The retailers acknowledge that authentic souvenirs are made in LPB and they obviously know that a product made in LPB is valued by customers. They are willing to impress customers by not telling the truth if the item is not made in LPB. Respondent 12 addressed below.

"...I know it is kind of cheating, when tourist ask where this textile is made but customers seem to be happy with my answer and they are not reluctant to purchase..." (R12)

Some producers have considered using raw materials within LPB or in Laos. The materials from outside LPB and overseas countries are also acceptable to replace local materials. Despite the fact that some materials are not enough to supply domestically, most suppliers believe that some raw ingredients in LPB cost higher than those in other provinces in Laos and even imported materials. As a result, many souvenir suppliers look for alternative materials from nearby countries, such as Thailand and Vietnam. To sum up, the authentic souvenir products depend on culture and custom; and, in fact, LPB souvenir suppliers have focused more on the products that have been produced here by local producers. However, this study also indicates that SVs are willing to trade and sell imported souvenirs items if those items can generate more income for them.

LPB souvenir suppliers identified various ideas about attributes to gauge the authentic souvenir products. Five main themes are derived from this study, namely: handicrafts and handmade, historical and cultural integrity, place location, skilled craftsmanship and appealing pattern and presentation. The authentic souvenirs from suppliers' perspectives should present uniqueness of Lao culture, tradition, and place identity. They value handmade souvenir products and the involvement of high quality craftsmen/producers, which can be seen through particular patterns in textiles such as 'Sinh'. There are some considerations regarding the scarcity of raw materials to supply to SPs for producing textiles. The insufficiency of raw materials 
could posit and affect the overall authentic souvenirs, especially the products that require good quality raw and local materials needed for production. Importantly, most suppliers, especially the SPs, are confident in their skilled craftsmanship to present and offer the authentic souvenirs to the consumers. Meanwhile, in souvenir producers' view, authentic souvenirs are rather judged from the outputs, as final products, rather than the inputs, as raw materials.

\subsection{Souvenir production sources}

The souvenir production also links to the issue of authentic souvenirs that suppliers deliver to their clients. Where LPB suppliers deal with various sources of souvenir production, including trading with local suppliers or within LPB, domestic suppliers and overseas suppliers. LPB suppliers have traded with approximately $70 \%$ local/domestic suppliers; $20 \%$ from nearby provinces; and $10 \%$ international suppliers. More details are elaborated on in the following sections.

\subsubsection{Trade among LPB suppliers}

The majority of respondents assert that local suppliers are the main suppliers for souvenir industry in LPB. This includes the souvenir items that are ready to sell as well as the raw materials. It asserts that approximately $70 \%$ of authentic souvenirs are handmade, and supplied by local suppliers, villagers and producers from rural areas. For example, Ban Xangkong or Xangkong village is well known for handmade and handicraft products such as silk weaving and Saa paper or Mulberry paper. The raw materials, especially cottons, have been supplied locally and there is adequate amount to meet the SPs' demand.

"I think there is enough quantity of raw material like cotton in LPB to supply for textile producers but it is not enough in Laos silk. I believed people who work in local food have faced with high cost of raw ingredients in local market" (R11)

This research findings also reasons that souvenir suppliers in LPB have traded with not only local souvenir suppliers, but also domestic and overseas suppliers. This is because there is inconsistent souvenir supply among suppliers in LPB, such as being unable to provide larger quantities. Alternatively, SVs are 
willing to take domestic and imported products such as items from domestic suppliers in Laos and international souvenir suppliers. Respondent 6 explained the situation from a different position.

"I have not much money to invest, you know I am a student who sells souvenirs as a part-time job...I found that selling imported products gives me more profits due to lower investment cost." (R6)

Although there are many souvenir stalls, SVs have sold almost similar souvenir products. Some of the vendors have questioned, though, the uniqueness and effectiveness of the souvenir products selling in these areas, especially when thinking about the way to improve the profits. Respondent 9 asserts this view:

“...We are facing with the constraint of price of raw materials that have increased in demand and this makes the price are higher..." (R9)

\subsubsection{Trade with domestic suppliers}

LPB suppliers assert that they are happy to trade with the domestic market as the domestic suppliers can provide several raw materials that they can order in the larger quantities each time. Respondent 12 states this view:

"I have to accept that domestic suppliers can deliver those materials to me no matter which seasonality and I usually order in large amount to save transportation cost” (R11)

Vientiane is the capital of Laos and it is refered to, by LPB souvenir producers, as the main source of domestic market. Many of them assert that there is a larger market where various products and materials are traded. Although many respondents are willing to share their sources of souvenir products or raw materials, it is notified that they try to mention generally rather than telling the specific places. Respondent 12 tries to explain: 
"My cousin in Vientiane capital deliver those raw materials to me when I called. I am not quite sure where she gets the products from" (R12)

As mentioned above, Vientiane capital and nearby provinces have been referred to as the alternative markets for LPB souvenir suppliers to trade with. This is believed to account for $20 \%$ of total $100 \%$ of respondent in this study according to the field interview. Meanwhile, many suppliers argue that they are willing and happier to trade locally or within LPB as they can save transportation costs and can support local business, if raw materials and souvenir items can be offered in various options, appropriate price, and larger quantities.

\subsubsection{Trade with overseas suppliers}

An alternative way to acquire raw materials, to ensure souvenir products are available in the market, is for LPB souvenir suppliers to engage and seek trading with overseas suppliers. Even though this practice accounts for only 10\%, it is predicted that the figure will gradually increase in the future, due to more international suppliers emerging on the scene. Souvenir suppliers understand that imported souvenir products differ from locally made, in colour, pattern, quality and cost. However, some suppliers need to consider their convenience and the return on the investment. Respondent 10 exemplifies this view:

"I have to use the raw materials from domestic markets and imported from nearby countries when the LPB market cannot offer me... and I have realised that raw material prices are slightly cheaper and they do deliver materials to my place too" (R10)

In the view of many suppliers in LPB, although the price of imported products is cheaper, some SPs and SRs have concerns that items may not represent authentic souvenir products of LPB. SPs believe that the imported souvenir products' quality is not resilient when compared to local ones. Many SPs attempt to explain that imported raw materials are not complicated in terms of the process and they use machine to make it. Respondent 19 has emotional feeling while explains this view: 
"Sometimes SRs try to bargain for lower price and tell me that my souvenir items are quite expensive; but do they know that those items are made by hand and take time to complete one" (R19)

SVs claim that the price of local handmade souvenir products is much higher than the imported products. As a result, many souvenir suppliers have attempted to embrace imported products. Respondent 6 indicates this perception:

“... I am a student who sells imported souvenirs. Selling imported products gives me more profits due to lower investment cost" (R6)

In addition, many souvenir producers agree that they are willing to embrace and welcome imported raw materials for souvenir products and they are very happy to state the names of the countries where they get the raw materials from. Some raw materials can be bought in the local market. Respondent 9 expresses this view:

“...I used the raw materials (colour for painting) from nearby countries such as Thailand and China ... and the paper is from Xang khong village in $L P B ”(R 9)$

With regard to the souvenir production sources, SRs who sell in the main tourist attractions seem to worry about the increase of foreign investment in souvenir products in LPB. Local SRs have seen interference from overseas investors (e.g. Chinese and Vietnamese investors) who have gained the market share and have stronger bargaining power due to a larger investment fund. Respondent 18 expresses this view:

"I totally disagree with my next-door mate to get their own house to overseas investors to rent. It impacts me a lot in terms of product diversification display. I believe that those items come from nearby countries. The pattern is totally similar to our products" (R18)

Respondent 18 keeps continuing to express her view as she worries that overseas investors can impact souvenir business in general due to the fund capacity 
and stronger bargaining power. SRs and SVs may be forced out of the business because of less product diversification and quality and quantity offered. In addition, local SPs may feel an impact on souvenir production as the imported products start to flow into LPB. More importantly, some SVs described the generosity of overseas souvenir suppliers. Respondent 6 specifies this view:

“...Overseas traders, who ask me at the night market whether I am interested to sell the lady clothes and textiles, will give me the products first to sell and I can return money later" (R6)

Although LPB souvenir suppliers trade with overseas suppliers, in this study this accounts for only $10 \%$, but this is predicted to be an upward trend in the future. If this is the case, LPB will be affected negatively in terms of its uniqueness and reputation, especially in relation to the world heritage title. In the long term, some SPs who produce great local quality souvenirs will be forced out and handmade authentic souvenir will vanish in time.

\subsection{Suppliers' values and challenges 4.5.1 Suppliers perceived values 4.5.1.1 Economic values}

Several respondents were proud of sharing their perceived benefits and values of souvenirs in terms of economic value. They appreciate that souvenir businesses generate enough profit for themselves and their families. This study reveals that SVs seem to concentrate on the value of the economy more than other groups. Many of them assert that joining this industry can alleviate their poverty and improve their living conditions. This study reveals that the LPB suppliers' perceived economic values and their motives for joining the souvenir industry are interlinked. Respondent 6 is proud of presenting the view toward economic value:

"I can pay off my school fee and support myself to study by selling souvenirs ...my younger brother who is from my original village (intentionally not to be named) is with me now to pursue his study through my support" (R6) 
It is noted that the SPs and SRs seem not to heavily focus on the economic values, but they do gain economic value through offering the authentic experience by accommodation and food. Meanwhile, some souvenir suppliers' premises/locations offer a free souvenir tour experience of the souvenir production process, and gain an economic value from other tourism products. Respondent 24 explains her view through her work place situation:

"The centre where I have worked offers the tour with guide with no charge. We do offer bed and breakfast, and selling the handmade souvenirs on site" $(R 24)$

The value section should link the authenticity and commodification elements. Analysis should be added and supplemented by field observation, while souvenirs are the commercial objectives. Respondent 20 points this out:

"Our village is well-known as the best centre in LPB for the textile products, which has a long story and great reputation among tourists from different parts of the world. I can see that I can make more money" (R20)

To sum up, economic values are perceived as the main value among LPB suppliers, especially the SVs. However, SPs and SRs tend to focus on giving the symbolic values to consumers or attempt to show the artisan values that they can give to the visitors as an experience and thus the economic values will come along later.

\subsubsection{Symbolic values}

Several respondents were proud of sharing the benefits and values of souvenirs that they perceived in terms of cultural conservation as well as symbolic values. Symbolic values, from the perspectives of LPB souvenir suppliers, represent the place, culture and significance of Laos and LPB. SPs tend to give this value to the products or items that they produce by adding a symbolic Lao or LPB icon. 


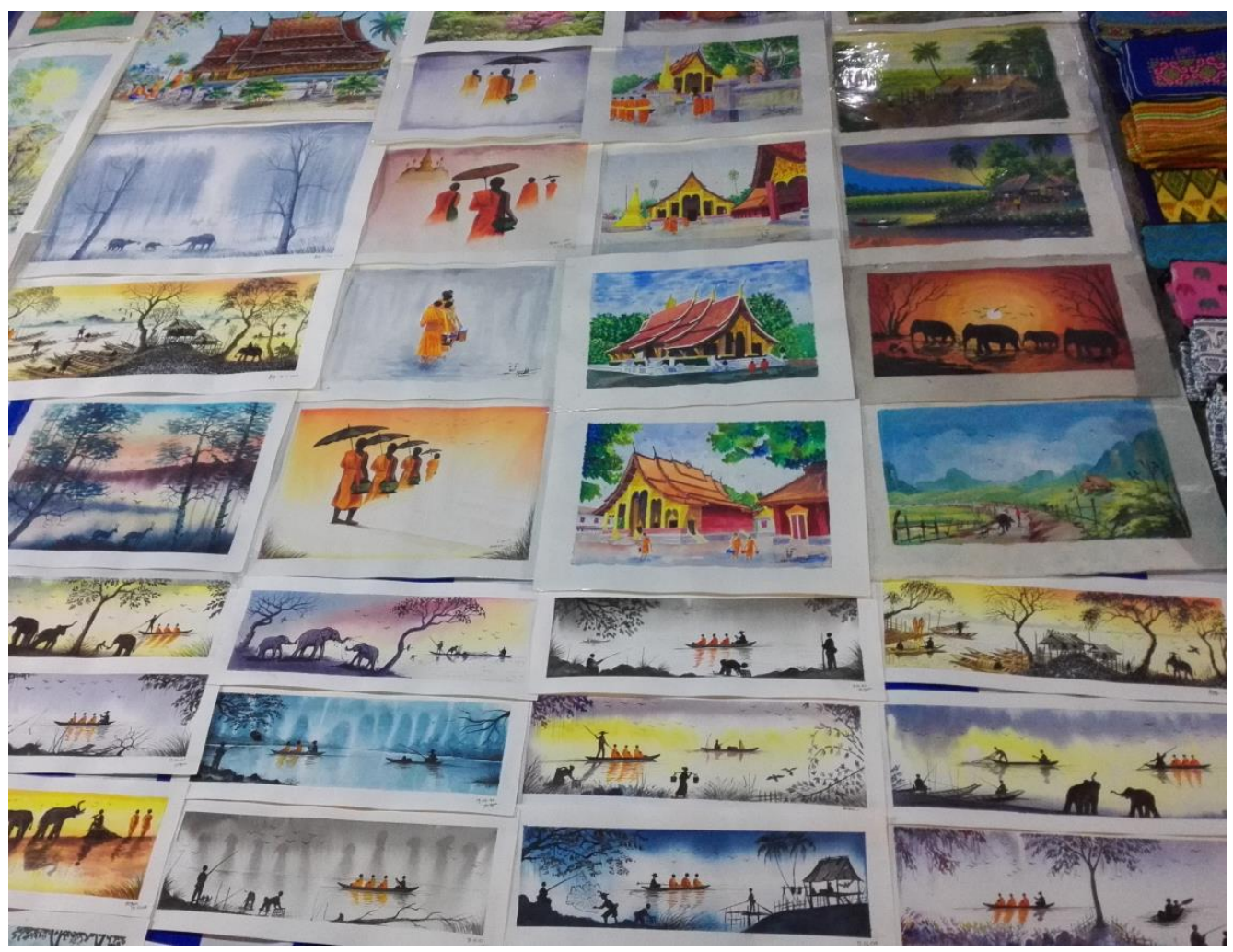

Figure 4.4: LPB pictorial souvenirs of Luang Prabang

(Source: author, 2018)

Figure 4.4 depicts the pictorial souvenirs. The image on souvenir items represents Lao, which SPs have produced with their imagination using the destination's history and cultural integrity. The symbolic souvenir items in LPB include painting about novices/monks, elephant, natural scenes, and temples (e.g Xiengdong Xiengthong temple, which is the most popular temple in LPB). The symbolic value is perceived to be very important for authentic souvenirs particularly in the pictorial painting. Respondent 16 described this view:

"Producing souvenirs on my own allows me to think and reflect to my Lao culture and LPB symbolic places, and tradition" (R16)

In terms of cultural benefits, the suppliers believe that the souvenir items made in LPB by indigenous producers represent the culture and uniqueness of LPB and Laos. Although it is viewed that the small souvenir items hold or carry the meaning of the uniqueness and represent destinations, there are people behind those items who search, collect, and assemble the uniqueness and package it to make a sellable product. They are suppliers. Thus, through this process, they select the quality of culture, tradition, and place identity and serve them to the souvenir 
buyers. Thus, suppliers take a main role in constructing the local value, make and deliver the story behind the souvenir, help consumers to know what makes the souvenirs so special, and present novelty.

\subsubsection{Artisan values}

Suppliers in LPB assert that involvement in this industry allows them to practice and preserve their indigenous tradition and culture. Respondent 11 states this view:

"There is a chance for me to deliver my skill into the product that I made" $(R 11)$

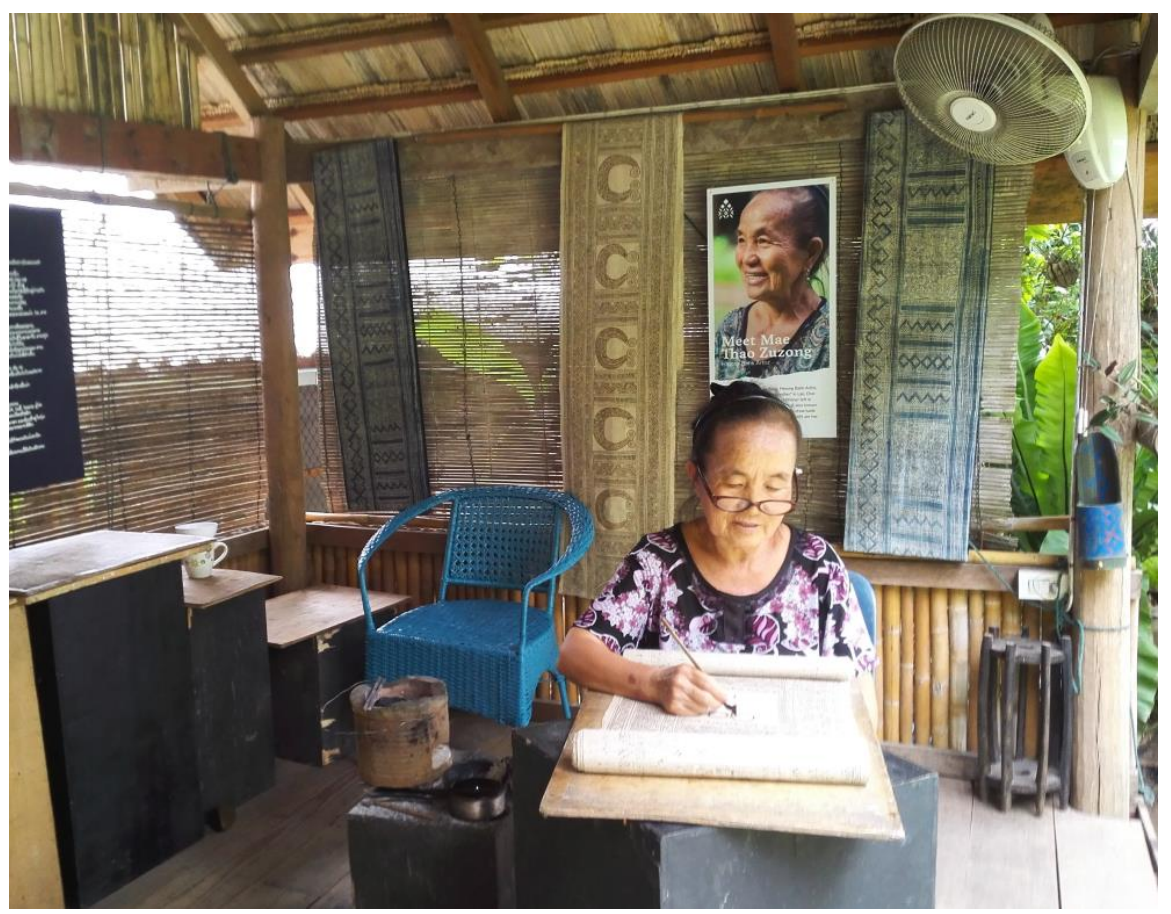

Figure 4.5: artisan value perceived by LPB suppliers

(Source: author, 2018)

Figure 4.5, shows the local producer performing or called 'stage authenticity' performance. She delivers Hmong ladies' clothes patterns at OCK POP TOK living craft centre in LPB. The artisan values are one of the main values perceived by suppliers to be interconnected with the economic value. SVs and SRs believe that selling an authentic souvenir, which is real, has appealing presentation and is representative of LPB identity or Laos, brings significant incomes to the destinations. Some of the well-known souvenir products sell in LPB are the wooden crafts such as elephants, and utensils in the kitchen such as plates (see Figure 4.6) 


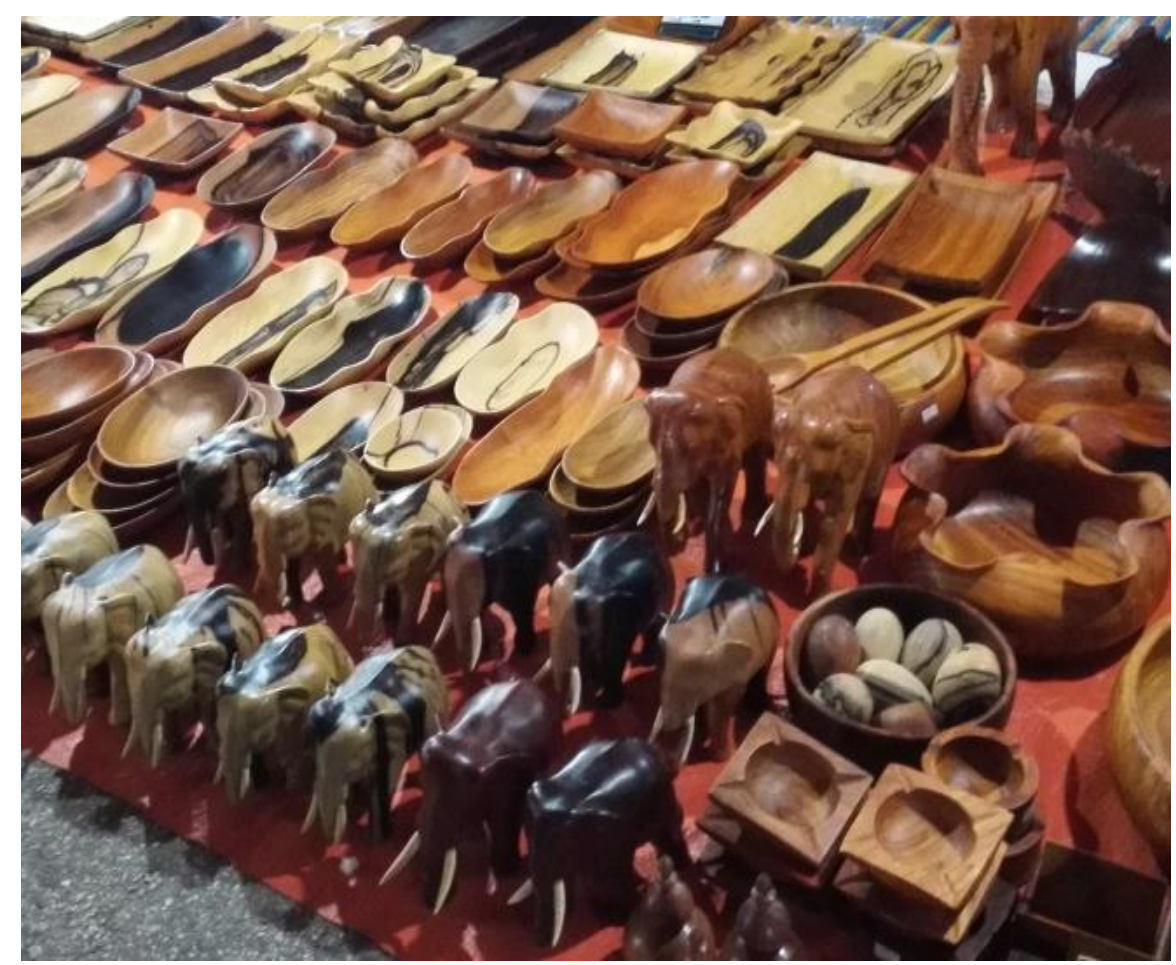

Figure 4.6: artisan value perceived by LPB suppliers

(Source: author, 2018)

\subsubsection{Souvenir suppliers' challenges}

This study raises some challenges from the perspectives of LPB souvenir suppliers and indicates four issues, namely: lack of raw materials, insufficient souvenir products, insufficient product control, and limited distribution channel. More details will be elaborated on shortly.

Despite the deep meaning of souvenirs that suppliers perceive, LPB's souvenir industry has been confronted with the lack of raw materials. Consequently, it impacts the production process and thus sometimes the souvenir products cannot be offered in LPB. The lack of raw materials impacts on local suppliers, forcing them to engage with domestic and international suppliers. This situation has led many suppliers to seek new items or substitute the raw materials with those from outside LPB. Respondent 5 states this view: 
"There are many times that our family cannot find the local ingredient. I need to look for alternative market and try to deal with various suppliers" $(R 5)$

The shortage of raw materials has an impact on four suppliers, in particular, the SPs. It takes time to finish each item and the shortage of raw materials affects the supply chain system. Respondent 11 posits this view:

“...I have a problem to find the raw materials to produce ladies' clothes. People who I buy the raw products from cannot supply me frequently" (R11)

Insufficient quantity of souvenir products can be seen as one of the themes that have been mentioned among souvenir suppliers, especially in the group of SVs, SRs and middlemen. Respondent 18 posits this view:

"I have faced with the scarcity of souvenirs items in peak season" (R18)

Many SPs expressed that the industry's quality control effort for souvenir products is ambiguous. There is a mixture of mass-machine souvenirs and handmade products, local and imported souvenir products. Respondent 1 asserts this view:

"In my opinion, one shop should not sell all souvenirs. I think it should arrange between local and imported products in night market" (R1)

In addition, many trademarks are created as part of the marketing promotion and quality certification. These trademarks attempt to promote authentic souvenirs to the tourists. However, there are many trademarks that can confuse traders in terms of functional use, effectiveness, and roles in promoting sales volume, for example, 'LPB Handicraft'. Respondent 11 illustrates this view.

"There is a need for us to reconsider about the local and trademark that we have used in the market that many suppliers still do not know how to use..." (R11) 
It is interesting to highlight that weak management and inconsistency of quality control in the souvenir production allow sellable products to be imitated easily, regardless of 'copyright' issues; thus, local souvenir products are mixed up with imported products. Respondent 1 exemplifies this perspective:

"To me, It is a bit confused as there are many products sold in the same shops and each souvenir shop sells almost the similar products combined of local souvenir and international products" (RI)

This study reveals that limited market distribution is one of the key challenges among the SPs. Respondent 23 attempts to explain this view:

"I have worked a wage-paid now. Previously, I used to produce souvenir by my own with family, but we faced with many issues, such as no market for distribution products" (R23)

Many souvenir producers expressed that the industry's quality control effort in souvenir products is ambiguous. For example, there are too many trademarks or quality assurance marks such as 'LPB Handicraft', creating confusion, even though these marks attempt to promote authentic souvenirs to the tourist. Such confusion can be seen in terms of functional use, effectiveness, and roles in promoting sales volume.

\subsection{Summary}

This chapter presents the findings of this research and generates new information in the context of a UNESCO World Heritage site like LPB. It summarises the overall LPB souvenir business that tends to classify as small and family business gauged by the number of labourers employed and the flow of assets. In addition, this study highlights that among its four groups there is an upward trend that it seems to be risky for suppliers to carry sole duties as it provides insecure incomes and less connection accordingly. Importantly, this research ask for their incomes in which the majority of the respondents are happy to share and talk about. However, the statistics are only available as estimated numbers due to the fact that the majority 
of suppliers do not keep proper financial records and a few respondents indicate that they do not maintain as it is a sensitive issue, especially among the medium size business.

LPB souvenir suppliers view authentic souvenir products as crucial in terms of historical and cultural representation and place identity. They believe that souvenir items sold in LPB can represent LPB's authenticity and Lao culture, especially handicraft items, which rely more on highly skilled indigenous craftsmen who are seen to represent the LPB identity. Products made in LPB look appealing and authentic from the suppliers' perspectives. There is the connection of souvenir suppliers with location uniqueness. Thus, LPB suppliers perceived that souvenirs tend to represent authenticity of the World Heritage site and extends its meaning and significance to the wider region as a significant historic, cultural destination. Interestingly, this research provides new authentic-souvenir attributes perceived by souvenir suppliers, in particular, the key three attributes, namely: handicraft or handmade products, skilled craftsmen and presentation are strongly associated with each other and linked to the concept of world heritage.

LPB suppliers categorised souvenir values into three groups, namely: economic, symbolic and artisan. Such values have motivated them to be continually involved in the souvenir industry. However, most of them also face the challenges of raw materials scarcity. This includes the lack of some souvenir items in peak season. It is interesting to highlight that weak management and inconsistency of quality control in the souvenir production allow sellable products to be imitated easily, regardless of 'copyright' issues; thus, local souvenir products are mixed up with imported products. 


\section{CHAPTER 5: DISCUSSION}

\subsection{Introduction}

The previous chapter presents the research findings according to four objectives. This chapter discusses the research findings together with existing research papers. First, it discusses the perspectives of four suppliers, namely: producers, vendors, retailers and middlemen with key concepts from three types of authenticity introduced by Wang (1999) which are: objective authenticity, constructive authenticity, and existential authenticity. Second, it compares authentic souvenir attributes from demand (tourists) and supply (suppliers) perspectives, and highlights the influence of souvenir suppliers on authentic delivery. Third, there is reflection regarding key values and challenges and the chapter finishes with the chapter conclusion.

\subsection{Discussion}

\subsubsection{Suppliers and authentic souvenirs}

First, this study indicates that authentic souvenirs from suppliers' perspectives should be: (1) related to handicraft work and handmade items; (2) appealing product presentation; (3) produced by skilled craftsmen; (4) produced in LPB areas; and (5) cultural, historical and place identity integrity. The literature identified three authentic typologies, namely: objective authenticity, constructive authenticity, and existential authenticity (Wang, 1999). This study finds that the suppliers' perspective in LPB is a combination of objective and constructive authenticity, in which constructive authenticity is strongly expressed by LPB suppliers.

The LPB suppliers' perspectives on authentic products is associated with the view of objective authenticity. Objective authenticity refers to authenticity based on the actual objects intensifying how authentic souvenirs are made, which objected appearance or object orientation is more important (Chhabra, 2005; MacCannel, 1976; Healy, 1994). According to MacCannel (1976), objective authenticity products are gauged by a professional or expert. In this case, the souvenir suppliers are expert in the selection of souvenirs. As discussed under the theme, appealing pattern and presentation, among suppliers, SVs, SRs, and MM have their main criteria when they have to select which authentic products to sell. 
They are also concerned with the pattern and appealing appearance of souvenir objects. Interestingly, this study reveals that SPs are more focused on the final products rather than input materials.

However, constructive authenticity is even more strongly expressed by LPB suppliers. They believe that authentic souvenir products are grounded from destination uniqueness and are constructed. Cohen (1988) states that constructive authenticity can be negotiable where Timothy (2005) claims that authentic souvenirs are a more subjective concept and influenced by communal construction. Torabian and Arai (2006) argue that souvenirs are constructive authenticity because the souvenirs carry many forms and are based on the eye of the possessors. As discussed under the themes, produced by skilled craftsmen, produced in LPB areas, cultural, historical and place identity integrity, LPB suppliers perceived that the value is related to the interconnection between local handicraft work and skilled craftsmen involvement. This also interlinks with the place where products are made. The SRs and SVs look for better souvenir presentation from skilled craftsmen and this can be one of the crucial attributes for authenticity. This indicates that their view on authentic souvenirs can be influenced by people from their society. SPs carry the view of constructivist authenticity.

Importantly, those souvenir items need to be integrated with LPB's significant cultural, historical and place identity. In this sense, suppliers are the group who perceive and give the value. Interestingly, the SVs and SRs justify and influence constructive authenticity even to the tourists because many tourists like to listen to the story behind those items. Under the themes stated in this study, LPB suppliers' view of authentic product comes under constructive authenticity. They are the people who give the meaning to how souvenir items are produced/delivered. The SPs take a constructivist authenticity view as they believe that the products they make carry some meanings from the destinations' society or community.

This study highlights the authentic souvenir in the suppliers' view, which should represent the culture and place identity. LPB souvenirs can represent their place and their identity and convey to visitors that the souvenir products are made in LPB. This similar concept can also be seen in various places (e.g. food souvenirs can represent the place identity or country origins). This study reveals similar attribute perceived by tourists and suppliers. This study is in line with the studies by Anur et al (2017) and Pentol (2013), which asserted that tourists view authentic souvenirs by originality and uniqueness (e.g. under the well-known food souvenirs, 
Sushi is part of Japanese cuisine and popular Kimchi originates from Korea). Thus, products representing place and showing the uniqueness and identity of locations offer attributes that both tourists and suppliers are looking for in authentic souvenirs.

\subsubsection{Perspectives of tourists and suppliers}

This research findings demonstrate that authentic souvenirs provide results and confirm the souvenir suppliers' view that authentic souvenirs should be made by local craftsmen and handmade. This research result supports the study done by Littrell et al (1993), Swanson and Horridege, (2004) and Xie et al (2012). This highlights the key attribute of authentic souvenirs from tourists' perspectives, who look for local craftsmanship and handmade. Thus, this research concludes that authentic souvenirs from suppliers' and tourists' perspectives are associated with 'local crafts labour/handmade', key to what they look for in authentic souvenirs. This study advances existing literature by adding the new contexts of the developing country and world heritage; that is to say, authentic souvenirs should be related to handicraft work. In addition, the themes that emerged from this study are in line with and support similar attributes in previous studies (Chhabra, 2005; Littrell et al., 1993; Torabian \& Arai, 2006).

Many scholars mention the benefit of having local craftsmen on sites demonstrating crafting skills on souvenir products is better attention from the tourists. This study reveals that many LPB souvenir suppliers attempt to offer this kind of stage authenticity to increase tourists' experiences. This study provides new understanding from souvenir suppliers on a number of facts. The findings of this research assert that, among four different types of LPB suppliers, the SPs perceived that authentic items are strongly interconnected to local production location and focus on the final products. This study acknowledges that authentic souvenirs from suppliers and tourists are often portrayed through local craftsmanship and skilled labour.

\subsubsection{Reflection of suppliers' values and challenges}

Third, this research confirms its findings highlighted in Laos media report regarding the challenges that local souvenir producers cannot provide larger 
quantities and consistent quality of souvenir products, with varied patterns. Yet, overseas souvenir providers can with lower. To preserve the values and strengthen the local souvenir products as well as gaining profit for host destinations, it is essential to understand how suppliers perceive the souvenir products they produce/deliver/serve. Embracing imported souvenir products have been taken when local souvenir makers were unable to provide large quantities, and thus, local souvenir suppliers are required to work with other suppliers as a way to sustain their businesses. Souvenirs products have been underlined by the concept of commodification, which means converting the destination uniqueness into objects to generate income for the host destinations. Among four different types of souvenir suppliers, SPs as a sole group, received small and inconsistent revenues in each period.

LPB souvenir businesses are classified as SMEs and family-run. In fact, the family-run and small business suggest there is little financial involvement and lower effective management. This can affect the minimum production outcomes of local suppliers. It is also difficult to predict the quantity of raw materials used in the production in each period due to inconsistent labour skilled involvement. This research reveals that the majority of respondents rarely get the financial support from key authorities (e.g. the government and LPBHA). In addition, many of them have faced constraints regarding raw ingredients in local areas, especially during the peak season. The first findings of this research are aligned with the report done by SNV (2006), presenting the concerns of local souvenir producers and suggesting ways to increase raw materials within LPB.

By considering the place identity a crucial element linking to the concept of authenticity, location of final production should be integrated into and use the name tag, to highlight the location and source where such authentic souvenirs are made. SPs may need to prioritise the main ingredients for their products to be sourced from the local community as a way to help support local business, while maintaining good connections. This is because authentic concepts can be used to preserve indigenous cultures and traditions and gain collective values.

The perspectives of suppliers (SVs, MMs, and SRs) need to be addressed as they are the influencers. This is because these groups are inclined to sell imported souvenir products in some difficult circumstances. Thus, this may influence negatively toward the LPB souvenir businesses. In particular, SVs, who do not have many investment funds, are willing to sell the imported souvenir products. 
Although SVs will receive an income, overall LPB souvenir business will be impacted on in the long term. Thirumaran et al., (2014) reported to the Vietnamese research institute on the tourists' souvenir consumption behaviour, stating that tourists tend to avoid fake and inauthentic souvenirs. Moreover, many scholars argue that visitors seek authentic souvenirs; thus, distributing a high volume of unknown souvenirs leads to the loss of the sense of authenticity (Charters, 2012; Nazariadli, Morais, Barbieri, \& Smith, 2017). Thus, if LPB suppliers keep selling those souvenirs in high volumes and low quality, LPB souvenir business will not be sustained and this may affect the tourism industry and souvenir business in the long term. In addition, Healy (1994) emphasises the key benefits for local artisans, such as regular work, employment and income opportunities. The imported souvenir products will not provide any values for the local artisan and will lessen local raw materials suppliers' revenues. In fact, many jobs and opportunities will be reduced and diminished in time.

Tourism brings significant changes to LPB tourism and authentic souvenir product sales. LPB souvenir suppliers agree that tourists create high traffic for souvenir distribution and souvenir production. This study presents key considerations on souvenir classifications, suppliers and revenues, and ability to provide local souvenir products. The changing trend of suppliers' role used by LPB suppliers as a way to sustain their incomes could posit negative impacts on the overall LPB souvenir business in the long term. As stated by Chhabra (2005), SPs and SVs are the key people influencing the authenticity, offering the authentic experience to tourists, in terms of product quality as well as the authentic patterns which link to the quality of their roles or their service offers. Interestingly, people who become SVs consequently tend to stop producing due to more profits gained and less financial investment. This may reduce the number of local producers gradually.

Conversely, shifting from SVs to become SPs seems to need competent SPs skills. In fact, SPs are the crucial authentic influencers (Chahhba, 2005). This is because not everyone is an artisan or high-skilled labourer. It needs practice and learning, especially the handicraft souvenir products, which involve high-skilled labour, and these kinds of products are also time consuming. From SVs to SPs, the concept of authenticity in souvenirs in LPB could be reduced because SVs might think more about the cost and time involved and consider return on investment over the other aspects. They might thus interrupt the souvenir producing processes and 
the quality of souvenir products, and this could reduce the authenticity of the souvenir items.

Commodification is part of the souvenir and this makes the souvenir generate profit. This study reveals results that are in line with the key element of souvenir consumption related to value. The acceptance of imported souvenir products into LPB souvenir production could be seen as a means to assist souvenir suppliers to meet the tourist demand. In fact, some textiles and raw materials have been replaced from domestic suppliers and this study reveals that souvenir suppliers seem to accept imported raw materials. According to Thirumaran et al. (2014), imported souvenirs, although they can be seen as a source of good profits, especially for those who sell them (e.g. retailers and vendors), they do not generate benefits for the overall industry. A new strategy or way to improve the souvenir products is needed to provide better experience and meet with tourist demand. According to Poon (1989), tourists nowadays have more experience, thus they are more quality sensitivity. Souvenirs are also changed in values.

The decrease of souvenir sales in LPB can be improved through an increase of domestic tourists. This is because LPB souvenirs are well-known in the domestic market. For instance, according to Milne (1987), reducing local leakage on souvenir products can be done by increasing the souvenir local ownership through offering new rules and regulations. This should be implemented in conjunction with the tourism industry and government agency. This is especially the case for LPB, which is one of the major tourism destinations generating revenue for the country. Thus, the government needs to assist and protect local businesses so that they can work independently. Seckelmann (2002) has suggested increasing the number of domestic tourists to reinforce tourism industry. Domestic tourists can maintain the seasonality, spread incomes regionally, and reinforce domestic purchase (TIA, 2014).

Despite the fact that LPB souvenir businesses are classified as small and family businesses, this presents some limitations on LPB's business development. First, the SPs have limited financial support. It can be seen that the majority of them have worked using their own investment. Thus, they cannot offer increased production with the majority of raw materials to be acquired and delivered from nearby provinces or international suppliers, in which some additional transportation costs are normally involved. Second, the majority of LPB souvenir suppliers tend to work individually and independently. The majority of SPs produce their souvenir 
products based on their experiences with minimal technology involved. This can be shown by the limited patterns and sellable products are imitated. Because of this, several souvenir shops sell almost similar products and limited patterns.

Producers can be seen as the people who could have an impact on the souvenir production. According to the supplier groups, between SPs and SVs, the handicraft souvenir products are labour intensive, which in turn generates more job opportunities for both skilled and unskilled people (International Trade Centre, 2012). However, the shifting of these two roles might not only affect the pattern of employment creation, but also reduce the migration to the cities. This research finding asserts that there is an upward trend of shifting roles between SPs and SVs. In this regard, the shift from SVs to SPs needs attention from destination managers, as it is believed that this may affect the quality of souvenirs.

This study can also inform the government to find better solutions to support the LPB suppliers as it can be a means to alleviate the poverty, especially if it generates/disperses incomes to far distance areas (GMS, 2015). Most of the support is limited and inconsistent for souvenir suppliers in general. Government may need to give priority to whoever wants to work in this industry to get lower interest rates or offer incentives if possible. The motivation needs to increase local raw material suppliers, particularly the local raw materials to seek the greater productions in SPs. In fact, the key support for this industry is from entrepreneurs, small business and foreign aid, but these groups work independently. Because of the paucity of research with reference to the local context, the souvenir sector in Laos rarely accesses references and industry frameworks for its businesses.

\subsection{Chapter conclusion}

Souvenir production has been stated by several researchers as the way to sustain economic development for host and community destination. This chapter discuss the findings with the concept of authenticity, commodification, and values. First, this study becomes earlier paper to investigate souvenir suppliers' perspectives in the context of World Heritage sites in Laos. The authentic souvenirs have a production and distribution process through SPs, SVs, SRs and MM. This study indicates LPB souvenir suppliers perceive an interconnection between authentic souvenirs and objective authenticity because they give their attention the appeal and product presentation, but they strongly perceived on constructive authenticity. This 
discussion has expanded the framework that depicts the difficulties of interlinked the concept of authentic souvenir in the context of world heritage. Authentic souvenirs in this area need to connect with the key culture and local identities. In addition, commodification is also crucial. When suppliers commodify their culture and place uniqueness in a tourists' product, this generates the concept of authentic product.

It also argues that increasing the raw ingredients for producers should be a means to increase souvenir production in larger quantities and allow SPs to deliver to their artisans who create the authentic souvenir items linked to the place identity. It is also indicates that souvenir development faces similar issues. The purpose of this research is to answer the main objectives in relation to exploring the suppliers' perspective on authentic souvenir products. This research presents the current situation on authentic souvenir products to souvenir suppliers, tourism marketers, and destination managers as well as government agencies like LPB departments, to be informed and use this information. Importantly, this research findings present the concerns that souvenir suppliers need to address as well as the key stakeholders. 


\section{CHAPTER 6: CONCLUSION}

\subsection{Research findings and contributions}

This empirical study advances our understanding of the souvenir sector in tourism by exploring the perspectives of diverse groups of souvenir suppliers, namely: producers, retailers, vendors and middlemen. This research has satisfied the number of researchers who call for more research in this area (e.g. Cave et al., 2013; Chhabra, 2005; Thirumaran et al., 2014; Trinh et al, 2014). The results and implication of this research have contributed to both industry and academia.

This study has added to the tourism literature, especially in relation to the five themes that emerged from the data. Most of the tourism research on souvenirs has focused on the tourists' view. This study adds more context to the supplier side, which will provide an entire picture of the souvenir business overall. In the souvenirs research, most of the methodology used is more toward conceptual research and uses quantitative data collection. This study employed a qualitative approach and a combination of data collection through in-depth interview and participant observation, integrated with secondary data. Such methodology can respond to the key questions of this research.

LPB souvenir suppliers view authentic souvenir products as crucial in terms of historical and cultural representation and place identity. They believe that souvenir items sold in LPB can represent LPB authenticity and Lao culture. This is especially the case for handicraft items, which rely greatly on skilled indigenous craftsmen who are seen as representing the LPB identity. Products made in LPB look appealing and authentic from the suppliers' perspectives. This study is in line with the study done by Trinh et al. (2014), which focuses on the World Heritage site and asserts similar outcomes. It is from the World Heritage site that souvenirs exemplifying place identity were derived and those souvenir items are authentic and represent their country images. This study indicates that souvenir suppliers in LPB perceive that souvenirs can authentically represent the World Heritage site and extend its meaning and significance to the wider region as a significant historical and cultural destination. 
This research newly finds that attitudes toward, and willingness to sell, imported and mass-produced souvenirs are more typical among souvenir vendors, especially those who have fewer resources and less financial capacity, despite the awareness of the value of locally produced souvenirs. However, souvenir producers and retailers have a strong tendency to insist on locally produced, handmade souvenirs to sell as they believe that such products are authentic souvenirs representing LPB. Despite this strong willingness to manage the authentic features of souvenirs, while attempting to cope with the shortage of raw materials to feed to the production, souvenir producers have opted to secure imported materials from domestic and/or overseas sources instead. After all, souvenir suppliers believe that authenticity could be achieved and presented through the final souvenir products.

The findings of this research provide souvenir suppliers in LPB with a view on the souvenir supply sector from a holistic perspective and present crucial information on key souvenir players in the supply chain system. Players in the souvenir sector in destinations, including marketers and government agencies, should have more frequent discussions on the issues addressed by various suppliers in order to assist each other and find solutions to improve the quality of souvenirs and the overall souvenir sector in the tourism industry. This is because souvenirs generate substantial incomes for local people, especially those who live in remote areas in developing countries. LPB may face a downward trend and interference from overseas products in the long term if the issues found in this research are not properly addressed and managed. A collective effort among souvenir suppliers and the key tourism agencies at a local level is required to understand the existing issues on authentic souvenirs and the areas of authentic features to keep or maintain. Thus, the appropriate management strategies can be developed to strengthen the souvenir business in LPB.

In this competitive era, where Laos is also one of the AEC countries, there is high level of competition surrounding tourism products within this region. Precisely, to compete with souvenir business in this region, it requires some consideration about key issues and the means for improvement, in particular, it needs strong and supportive assistance from key authorities/stakeholders. 


\subsection{Implications}

The implications of this study are various, and they should be addressed carefully by the key stakeholders and authorities to keep industry competitive, maintain local entrepreneurs, and ensure constant development of LPB souvenir products. The more details are highlighted below:

- The souvenir sector in destinations, including marketers and government agencies, should not only have more frequent discussions on the issues addressed by various suppliers, but also find solutions to tackle suppliers' challenges.

- LPB SPs have been confronted with shortages of raw materials (e.g. Lao silk) and limited funding. The government should collaborate and discuss with financial institute (e.g. Agricultural Promotion Bank) how to implement supportive policies to offer loans with low(er) interests to agricultural workers. This should be done in conjunction with the feasibility assessment from relevant parties (e.g. agricultural experts and strategists) to ensure fruitful outcomes for all parties involved, such as the availability of raw materials and acceptable return on investment. The loan policies should provide benefits to SPs who want to borrow and those who have small funds but want to borrow, as well as people who work as producers.

- Authorities need to get the support for the SPs in terms of market distribution. This is because souvenirs generate substantial incomes for local people, especially those who live in remote areas. The discussion about key improvements should be made part of regular meetings (e.g. fortnightly meeting, monthly meeting).

- Souvenir suppliers should strongly consider producing souvenir products in a way that they can represent the destination's culture and appeal to consumers. Research indicates that destinations should consist of its tourism products and services. Souvenir suppliers who need to take advantage of authentic souvenirs need to develop souvenirs that look appealing and have a story to tell. In fact, suppliers should have an inclusive strategy that appreciates the local culture and history, two criteria required by tourists. This can be done by key authorities conducting a survey and collecting data on the overall souvenir products produced by local souvenir producers. 
- Authorities, related local government agencies and local non-profit organisations such as LPB Handicraft Association, should consistently support souvenir suppliers in order to seek better development tools. The assistance should focus on product quality control, distribution channels, and the method to reduce the scarcity of raw materials. In addition, the key authorities should implement the rules and regulations regarding copyright. In fact, this kind of souvenir business should be restricted to Lao residents only as a way to preserve the World Heritage site, while developing the local economy. It is perceived that other nationalities will rarely understand the authenticity of local authentic souvenir products as opposed to those who are immersed in it since birth. Furthermore, there is a need to reconsider and justify the trademarks and offer strictly to only those products that meet all criteria. This will assist both suppliers and tourists to clearly understand the values of trademark.

- The process of souvenir production in LPB is much too complex and the majority of suppliers rely more on their normal and simple products with less technological involvement. The business also runs in small production. Because of this, it can limit the diversification of authentic or contemporary souvenir patterns, which may be needed for tourist items. There is a need for relevant stakeholders to implement new knowledge or acquire lessons learned from developed countries and countries that have best practices. Such lessons learned would assist the suppliers to improve their souvenir businesses.

- Souvenir suppliers are confronted with higher prices for raw ingredients or raw materials and sometimes those materials are difficult to acquire at local markets. The scarcity of raw materials to produce souvenirs in this region seems to posit key issues to the SPs, which affect their production, quality and price setting. To tackle this challenge, they opt to order from nearby domestic markets and purchase imported materials from nearby countries. Some souvenir vendors have replaced the local products with imported products during high seasons. This research notes that participants have started to import souvenir products from nearby countries because they believe that those items are more accessible. In fact, the middlemen from the overseas market like to come and explore the souvenir market in LPB and have a chat with local SVs and SRs to advise on selling similar items in LPB. This issue should be considered and properly addressed with thoughtful strategies to overcome future negative impact. 
- Family business should explore the interconnection between three main concepts that are associated with souvenir products, namely: commodification, values and authenticity. In fact, family businesses do not have much investment capacity. They may need to ask for external financial support to acquire more raw materials to develop and/or sustain their souvenir business.

- This study has developed the conceptual framework in the context of souvenir industry, which combines key functions, namely: demand (tourists) and supply (supplier). Later scholars can refer to this information as well as field data for their future study.

\subsection{Summary}

This empirical study advances our understanding of the souvenir sector in tourism industry by exploring the perspectives of diverse groups of souvenir suppliers, namely: producers, retailers, vendors and middlemen, compared to previous literature where the scrutiny was more on retailers. Results of this research indicate that LPB souvenir suppliers view authentic souvenir products as crucial in terms of historical and cultural representation and place identity. They believe that souvenir items sold in LPB can represent LPB authenticity and Lao culture, especially handicraft items, which rely on highly skilled indigenous craftsmen who are seen as representing the LPB identity. Products made in LPB look appealing and authentic from the suppliers' perspectives. Similar to Trinh et al's finding (2014), souvenir suppliers in LPB perceive that souvenirs tend to represent the authenticity of the World Heritage site and extend its meaning and significance to the wider region as a significant historical, cultural destination.

This research found that, regardless of the awareness of the value of locally produced souvenirs, suppliers' perspectives on, and willingness to sell, imported souvenirs are acceptable among souvenir vendors as many of the suppliers have limited resources and finance. However, souvenir producers and retailers have a strong tendency to insist on locally produced, handmade souvenirs to sell as they believe that such products are authentic souvenirs representing LPB. Despite this strong willingness to manage the authentic features of souvenirs, welcoming domestic and imported materials is an alternative option and LPB suppliers seem to focus more on the final products. The findings of this research provide 
information on souvenir suppliers who have influenced authenticity. Thus, this allows them to understand the current issues and use this information to improve their business.

This study addresses more historic information and presents authentic souvenir attributes from suppliers' perspectives, an area not many scholars have investigated in tourism research. The souvenir suppliers' perspectives are crucial for comprehensive destination management. In LPB, research in the area of souvenirs and the issue of authentic souvenirs, particularly in cultural heritage destinations, where natural and cultural attributes have the competitive edge in tourism, has identified a requirement for a strong and effective management system to keep the business sustained. The findings of this study will be used to inform key stakeholders and encourage government authorities to focus more on souvenir development. 


\section{Reference List}

Adams, V. (1996). Tigers of the snow and other virtual Sherpas: An ethnography of Himalayan encounters. Princeton University Press.

Altintzoglou, T., Heide, M. \& Borch, T. (2016). Food souvenirs: Buying behaviour of tourists in Norway. British Food Journal, 118(1), 119-131.

Anderson, L. F., \& Littrell, M. A. (1995). Souvenir-purchase behavior of women tourists. Annals of Tourism Research, 22(2), 328-348.

Andriotis, K. (2011). Genres of heritage authenticity: Denotations from a Pilgrimage Landscape. Annals of Tourism Research, 38(4), 16131633.

Anuar F.I., Yulia A., Hamden H.N.B., Abdul Aziz K.F.B., Wan Hamid Edruce S.M.B (2017). Exploring the rationales of souvenir purchase behaviour and roles of behavioural belief and perceived authenticity among international tourists in Malaysia. In: Saufi A., Andilolo I., Othman N., Lew A. (eds) Balancing Development and Sustainability in Tourism Destinations (pp. 7987). Springer, Singapore.

Ary, D., Jacobs, L. C., Irvine, C. K. S., \& Walker, D. (2018). Introduction to research in education. Cengage Learning.

ASEAN (2015). ASEAN Tourism Strategic Plan 2016-2025. Retrieved from http://www.asean.org/storage/2012/05/ATSP-20162025.pdf

Ashley, C (2006). Participation by the poor in Luang Prabang economy: Current earnings and opportunities for expansion. Retrieved from https://www.files.ethz.ch/isn/44307/wp273.pdf

Asplet, M., \& Cooper, M. (2000). Cultural designs in New Zealand souvenir clothing: the question of authenticity. Tourism Management, 21(3), 307-312.

Benson, J. (2011). DK Eyewitness Travel Guide. London: DK Publishing.

Boorstin, D. (1964). The image: A guide to pseudo-events in America. New York: Harper \& Row.

Brennan, L., \& Savage, T. (2012). Cultural consumption and souvenirs: an ethical framework. Arts Marketing: An International Journal, 2(2), 144-160.

Brunt, P. (1997). Market research in travel and tourism. ButterworthHeinemann Ltd.

Bryman, A. (2015). Social research methods. Oxford university press.

Cavana, R., Delahaye, B., \& Sekaran, U. (2001). Applied business research: Qualitative and quantitative methods / Robert Y. Cavana, Brian L. Delahaye, Uma Sekaran. (Australian ed.). Milton, Qld: J. Wiley.

Cave, J., Baum, T., \& Jolliffe, L. (2013). Tourism and souvenirs: Glocal perspectives from the margins. Bristol: Channel view publications.

Charters, S. (2012). The Business of Champagne: A Delicate Balance. London: Routledge

Cheng Jack C.P, Law, Kincho H, Bjornsson, Hans Jones, Albert \& Sriram. Ram (2010). A service oriented framework for construction supply chain integration. Automation in Construction, 19(2), 245-260. 
Chhabra, D. (2005). Defining authenticity and its determinants: Toward an authenticity flow model. Journal of Travel Research, 44(1), 64-73.

Clarke, V. \& Braun, V. (2017). Thematic analysis. Journal of Positive Psychology, 12(3), 297-298.

Cohen, E. (1979). Rethinking the sociology of tourism. Annals of Tourism Research, 6(1), 18-35.

Cohen, E. (1988). Authenticity and commoditization in tourism. Annals of tourism research, 15(3), 371-386.

Cohen, E., \& Cohen, S. A. (2012). Authentication: Hot and cool. Annals of Tourism Research, 39(3), 1295-1314.

Collins-Kreiner, N., \& Zins, Y. (2013). With the Passing of Time: The Changing Meaning of Souvenirs. Tourism and Souvenirs: Glocal Perspectives from the Margins, 33, 29.

Creswell, J. W. (2014). A concise introduction to mixed methods research. Sage Publications.

Damrongpipat, N., \& Hirunraks, A. (2009). Determinants of souvenirs purchasing behavior among international Phuket visitors. Welcome Message, 549.

Dann, G., Nash, D., \& Pearce, P. (1988). Methodology in tourism research. Annals of Tourism Research, 15(1), 1-28.

Denzin, N. K., \& Lincoln, Y. S. (Eds.). (2011). The Sage handbook of qualitative research. Sage.

Derrett, R. (2003). Festivals \& regional destinations: How festivals demonstrate a sense of community \& place. Rural Society, 13(1), 35-53.

Dougoud, R. C. (2000). Souvenirs from Kambot (Papua New Guinea): the sacred search for authenticity. na.

Durko A. \& James, F. (2016). Owning a piece of paradise: How familiarity with location and intended recipient influence souvenir decisions. Paper presented 2012 TTRA International Conference, Taxas, n.d

Elomba, M. N., \& Yun, H. J. (2017). Souvenir Authenticity: The Perspectives of Local and Foreign Tourists. Tourism Planning and Development, 1-15.

Gordon, B. (1986). The souvenir: Messenger of the extraordinary. The Journal of Popular Culture, 20(3), 135-146.

Graburn, N. (1977). The museum and the visitor experience. Roundtable Reports, 1-5.

Greater Mekong Subregion [GMS] (2014). Project Administration Manual, GMS Tourism Infrastructure for Inclusive Growth Project in Lao PDR. Retrieved from http://www.tiigp laos.org/downloads/project_documents/gms-tourism-infrastructureinclusive-growth-project-pam.pdf

Guardian (2018). Where to go on holidays 2018. Retrieved from: https://www.theguardian.com/travel/nginteractive/2018/jan/06/where-to-go-on-holiday-in-2018-thehotlist\#Asia

Guba, E. G., \& Lincoln, Y. S. (1994). Competing paradigms in qualitative Research. Handbook of qualitative research, 2(163-194), 105.

Guba, E. G. (Ed.). (1990). The paradigm dialog. Sage publications.

Gupta, R. K., \& Awasthy, R. (Eds.). (2015). Qualitative research in management: Methods and experiences. SAGE Publications 
Hashimoto, A., \& Telfer, D. J. (2007). Geographical representations embedded within souvenirs in Niagara: The case of geographically displaced authenticity. Tourism Geographies, 9(2), 191-217.

Hashimoto, A., \& Telfer, D. J. (2013). Green tourism souvenirs in rural Japan: challenges and opportunities. Tourism and Souvenirs: Glocal Perspectives from the Margins, 33, 119.

Healy, R. G. (1994). Tourist merchandise'as a means of generating local benefits from ecotourism. Journal of sustainable tourism, 2(3), 137151.

Heitmann, S. (2011). Authenticity in tourism. Research themes for tourism, 45-58.

Hitchcock, M., \& Teague, K. (Eds.). (2000). Souvenirs: The material culture of tourism (p. 8). Aldershot: Ashgate.

Holiday Inn (2015). The value of souvenirs. Retreat from: http://3indubai.com/wp-content/uploads/2015/07/Value-SouvenirInfographic-AMEA-FINAL.pdf

Hume, D. (2009). The development of tourist art and souvenirs - the arc of the boomerang: From hunting, fighting and ceremony to tourist souvenir. International Journal of Tourism Research, 11(1), 55-70.

Hume, D. (2013). Tourism art and souvenirs: the material culture of tourism. Routledge.

International Trade Centre (2012). Liking the handicraft sector to tourism markets. Retrieved from: http://www.intracen.org/uploadedFiles/ intracenorg/Content/Exporters/Sectoral_Information/Service_Exports/ Tourism/Linking\%20the $\% 20$ Handicraft $\% 20$ Sector\%20reprint $\% 209 \%$ 2010\%202012\%20for\%20web.pdf

Idsala (2017). Promote Lao Handicraft products. Retrieved from: http://www.idsala.com. December 12

Jennings, G. (2010). Research Processes for Evaluating Quality Experiences: Reflections from the 'Experiences'. The tourism and leisure experience: Consumer and managerial perspectives, $44,81$.

Kim, H., \& Jamal, T. (2007). Touristic quest for existential authenticity. Annals of Tourism Research, 34(1), 181-201.

Kleine, R., \& Kernan, J. (1991). Contextual Influences on the Meanings Ascribed to Ordinary Consumption Objects. Journal of Consumer Research, 18(3), 311.

Kolar, T., \& Zabkar, V. (2010). A consumer-based model of authenticity: An oxymoron or the foundation of cultural heritage marketing?. Tourism Management, 31(5), 652-664.

Kong, W. H., \& Chang, T. Z. (2012). The role of souvenir shopping in a diversified Macau destination portfolio. Journal of Hospitality Marketing \& Management, 21(4), 357-373.

Kozak, N., \& Kozak. M. (2013). Tourism research: An interdisciplinary perspective / edited by Nazmi Kozak and Metin Kozak. Newcastle upon Tyne]: Cambridge Scholars Publishing.

Lacher, R., \& Nepal, S. (2011). The economic impact of souvenir sales in peripheral areas a case study from northern Thailand. Tourism Recreation Research,36(1), 27-37.

Lacher, R., \& Slocum, S. (2013). Souverin Development in 
Peripherial Areas: Local Constraints in a Global Market. Teoksessa J. Cave, L. Jolliffe \& T. Baum (toim.) Tourism and Souvenirs. Glocal Perspectives from the Margins (s. 147-160).

Laos Handicraft Association[LHA], (2016). 2016 annual report

Lao News Agency [KPL news] (2017). Visit Laos Year 2017 to be launched by this moth end. Retrieved by http://kpl.gov.la/En/Detail.aspx?id=28555

Laovoices (2013). World Best Tourist Destination for 2013 presented to Lao PDR. Retrieved from: http://laovoices.com/world-besttourist-destination-for-

Leavy, P. (2017). Research Design: Quantitative, Qualitative, Mixed Methods, Arts-Based, and Community-Based Participatory Research Approaches. Guilford Publications M.U.A.

Lee, J. S., Lee, C. K., \& Yoon, Y. (2009). Investigating differences in antecedents to value between first-time and repeat festivalgoers. Journal of Travel \& Tourism Marketing, 26(7), 688-702.

Lin, L., \& Mao, P.C. (2015). Food for memories and culture - A content analysis study of food specialties and souvenirs. Journal of Hospitality and Tourism Management, 22, 19-29.

Lin, C., \& Wang, W. (2012). Effects of Authenticity Perception, Hedonics, and Perceived Value on Ceramic SouvenirRepurchasing Intention. Journal of Travel \& Tourism Marketing, 29(8), 779-795.

Littrell, M. A., Anderson, L. F., \& Brown, P. J. (1993). What makes a craft souvenir authentic?. Annals of Tourism Research, 20(1), 197-215.

Littrell, M., Baizerman, S., Kean, R., \& Gahring, S. (1994). Souvenirs and tourism styles. Journal of Travel Research, 33(1), 3.

LNCCI (2010). SMEs in Laos. Retrieved from: http://laocci.com/index.php?option=com_content\&view=article \&id=62\&Itemid $=67 \&$ lang=en

Love, L., \& Sheldon, P. (1998). Souvenirs: Messengers of Meaning. Advances in Consumer Research, 25, 170.

Luang Prabang Department of Information Culture and Tourism [LPBDICT] (2017). 2017 annual report.

MacCannell, D. (1973). Staged authenticity: Arrangements of social space in tourist settings. American Journal of Sociology, 79(3), 589-603.

MacCannell, D. (1976). The tourist: A new theory of the leisure class / by Dean MacCannell. New York: Schocken Books.

Mackenzie, N., \& Knipe, S. (2006). Research dilemmas: Paradigms, methods and methodology. Issues in educational research, 16(2), 193-205.

MacLeod, N. (2006). Cultural tourism: Aspects of authenticity and commodification. Cultural tourism in a changing world: Politics, participation and (Re) presentation, 177-190.

Mekong Tourism (2015). 2015 Statistical report on tourism in Laos. Retreat from http://www.mekongtourism.org/wp-content/ uploads/Laos-2015-Statistics-Report-on-Tourism-in-EnglishVersion.pdf 
Ministry of Information Culture and Tourism [MICT, 2014]. 2014 Statistical report on tourism in Laos. Retreat from http://www.tourismlaos.org

Mkono, M. (2011). Authenticity does matter. Annals of Tourism Research, 39(1), 480.

Mkono, M. (2012). A netnographic examination of constructive authenticity in Victoria Falls tourist (restaurant) experiences. International Journal of Hospitality Management, 31(2), 387-394.

Morrison, M. (2012). Understanding methodology. Research methods in educational leadership and management, 14-28.

Moscardo, G. (2008). Building community capacity for tourism development. Wallingford, UK; Cambridge, Mass.: CABI.

Nazariadli, S., Morais, D., Barbieri, C., \& Smith, J. (2017). Does perception of authenticity attract visitors to agricultural settings? Tourism Recreation Research, 1-14.

O'Leary, K. D. (Ed.). (2013). Assessment of marital discord (psychology revivals): An integration for research and clinical practice. Routledge.

Parameswaran, P (2016). Laos in the ASEAN Spotlight: Opportunities and Challenges. Retrieved from: http://thediplomat.com/2016/07/laos-in-the-asean-spotlightopportunities-and-challenges/

Paraskevaidis, P., \& Andriotis, K. (2015). Values of souvenirs as Commodities. Tourism Management, 48, 1-10.

Patton, M. Q. (1990). Qualitative evaluation and research methods. SAGE Publications, inc.

Pearce, P. L., \& Moscardo, G. M. (1986). The concept of authenticity in tourist experiences. The Australian and New Zealand Journal of Sociology, 22(1), 121-132.

Pentol, A. (2013). Feeling at home: Creating a sense of place through airport store design and product offer can boost transaction spend and improve overall passenger experience, but are airports doing enough? (PROFILE: SENSE OF PLACE). Duty-Free News International,

Peters, K. (2011). Negotiating the 'place' and 'placement' of Banal tourist souvenirs in the home. Tourism Geographies, 13(2), 234256.

Pickard, A. J. (2013). Research methods in information. Facet publishing.

Poon, A. (1989). Competitive strategies for a'new tourism'. Progress in tourism, recreation and hospitality management, 1, 91-102.

Putachote, N. (2013). Thai consumer behaviour in night market in Luang Prabang Laos. International Journal of Sales \& Marketing Management Research and Development (IJSMMRD), 1(3), 1-6.

Ramkissoon, H., \& Uysal, M. (2011). The effects of perceived authenticity, information search behaviour, motivation and destination imagery on cultural behavioural intentions of tourists. Current Issues in Tourism, 14(6), 537-562.

Rogerson, C. M., \& Sithole, P. M. (2001). Rural handicraft production in Mpumalanga, South Africa: organization, problems and support needs. South African Geographical Journal, 83(2), 149-158. 
Saunders, M., Lewis, P., \& Thornhill, A. (2016). Research methods for business students / Mark Saunders, Philip Lewis, Adrian Thornhill. (Seventh Ed.).

Schmuck, R. (2006). Practical action research for change / Richard A. Schmuck; foreword by Eleanor Perry. (2nd Ed.). Thousand Oaks, Calif.: Corwin Press.

Scotland, J. (2012). Exploring the philosophical underpinnings of research: Relating ontology and epistemology to the methodology and methods of the scientific, interpretive, and critical research paradigms. English Language Teaching, 5(9), 9.

Seckelmann, A. (2002). Domestic tourism - a chance for regional development in Turkey? Tourism Management, 23(1), 85-92.

Sharpley, R. (1994). Tourists, tourism and society. Huntingdon: Elm.

Shen, M. J. (2011). The effects of globalized authenticity on souvenir. International Journal of Innovative Management, Information \& Production, 2(1), 68-76.

Silver, I. (1993). Marketing authenticity in third world countries. Annals of Tourism Research, 20(2), 302-318.

Smith, M., \& Duffy, R. (2003). The ethics of tourism development (Vol. 2). Psychology Press.

Smith, S. (2010). Practical tourism research / Stephen L.J. Smith. (CABI tourism texts). Wallingford, Oxfordshire, UK: Cambridge, MA: CAB International.

Steiner, C. J., \& Reisinger, Y. (2006). Understanding existential authenticity. Annals of Tourism Research, 33(2), 299-318.

Stewart, S. (1984). On longing: Narratives of the miniature, the gigantic, the souvenir, the collection. Duke University Press.

Swanson, K., \& Horridge, P. (2004). A Structural Model for Souvenir Consumption, Travel Activities, and Tourist Demographics. Journal of Travel Research, 42(4), 372-380.

Swanson, K. K., \& Horridge, P. E. (2006). Travel motivations as souvenir purchase indicators. Tourism management, 27(4), 671683.

Swanson, K. K., \& Timothy, D. J. (2012). Souvenirs: Icons of meaning, commercialization and commoditization. Tourism Management, 33(3), 489-499.

Taylor, H. (2005). A critical decision interview approach to capturing tacit knowledge: Principles and application. International Journal of Knowledge Management (IJKM), 1(3), 25-39.

Telfer, D. J., \& Sharpley, R. (2015). Tourism and development in the developing world. Routledge..

Thirumaran, K., Dam, M. X., \& Thirumaran, C. M. (2014). Integrating souvenirs with tourism development: Vietnam's challenges. Tourism Planning \& Development, 11(1), 57-67.

Thompson, C., \& Cutler, E. (1997). The effect of nationality on tourist arts: the case of the Gambia, West Africa. International Journal of Hospitality Management, 16(2), 225-229.

Timothy, D., \& Wall, G. (1997). Selling to tourists. Annals of Tourism Research, 24(2), 322-340.

Timothy, D. J. (2005). Shopping tourism, retailing and leisure. Channel View Publications.

Torabian, P., \& Arai, S. M. (2016). Tourist perceptions of souvenir 
authenticity: An exploration of selective tourist blogs. Current Issues in Tourism, 19(7), 697-712.

Tourism Development Department [TDD] (2016). Ministry of Information Culture and Tourism. Statistical report on tourism in Laos2016. Retreat from: http://www.tourismlaos.org/files/files/ 2016\% 20 Statistic \%20Report.pdf

Tourism Industry Association. (TIA, 2014). Domestic Tourism, the backbone of the country. Retrieved from: http://www.tourism2025.org.nz/tourism-2025-archive/domestictourism-the-backbone-of-the-industry/\#value-domestic-tourism

Trinh, T. T., Ryan, C., \& Cave, J. (2014). Souvenir sellers and perceptions of Authenticity:The retailers of Hội An, Vietnam. Tourism Management, 45, 275-283.

Tronvoll, B., Brown, S. W., Gremler, D. D., \& Edvardsson, B. (2011). Paradigms in service research. Journal of Service Management, 22(5), 560-585.

UNDP, 2013. Creative Economy Report 2013 Special Edition. Retrieved from http://www.unesco.org/culture/pdf/creativeeconomy-report-2013.pdf

UNWTO (2017). Southern and Mediterranean Europe, North Africa and the Middle East drive tourism growth through October 2017. Retrieved from: http://media.unwto.org/press-release/2017-12-14/southern-andmediterranean-europe-north-africa-and-middle-east-drive-touris

UNWTO (2012). Tourism and Intangible Culture Heritage. Retrieved from:https://www.immaterieelerfgoed.nl/nl/media/inline/2017/9/ 14/tourism_and_intangible_cultural_heritage_unwto.pdf

Vientiane Time, (2017). Opportunities abound for handmade Lao Souvenirs. February 7.

Waitt, G. (2000). Consuming heritage: Perceived historical authenticity. Annals of tourism research, 27(4), 835-862.

Wall, G. (2014). Tourism and souvenirs: Glocal perspectives from the margins. Anatolia, 1-2.

Walliman, N. (2010). Research methods: The basics. New York: Routledge.

Wang, N. (1999). Rethinking authenticity in tourism experience. Annals of Tourism Research, 26(2), 349-370.

Weathington, B., Cunningham, C., Pittenger, D., \& ProQuest. (2012). Understanding Business Research / Bart L. Weathington, Christopher J.L. Cunningham, David J. Pittenger.

Wei, L. Y., Zhan, L. N., \& Zhang, H. Y. (2010, November). Theoretical Exploration on Tourism Souvenir Development Based on Culture Regionalism. In E-Product E-Service and E-Entertainment (ICEEE), 2010 International Conference on (pp. 1-4). IEEE.

Wilkins, H. (2011). Souvenirs: What and why we buy? Journal of Travel Research, 50(3), 239.

Wilson, M. (2010). What can contemporary philosophy learn from our "scientific philosophy" heritage?.Noûs,44(3), 545-570.

Wu, M. Y., Wall, G., \& Pearce, P. L. (2014). Shopping experiences: International tourists in Beijing's silk market. Tourism Management, 41, 96-106.

Xie, P., Wu, T., \& Hsieh, H. (2012). Tourists' Perception of Authenticity in 
Indigenous Souvenirs in Taiwan. Journal of Travel \& Tourism Marketing, 29(5), 485-500.

Yamachi, S., \& Lee. (1999). Tourism development in the Lao People's Democratic Republic. Retrieved from:

http://www.un.org/esa/esa99dp9.pdf

Yeoman, I., Brass, D. \& McMahon-Beattie, U. (2007). Current issue in tourism: The authentic tourist. Tourism Management, 28(4), 1128-1138.

Yi, X., Lin, V. S., Jin, W., \& Luo, Q. (2016). The Authenticity of Heritage Sites, Tourists' Quest for Existential Authenticity, and Destination Loyalty. Journal of Travel Research, 0047287516675061. 


\section{Appendix A: Interview Section Guideline}

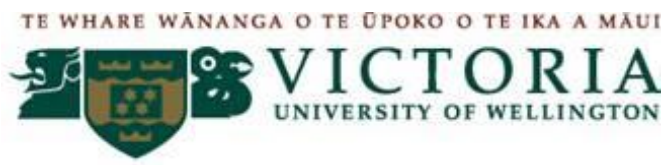

\section{Interview Section Guidelines}

\section{Suppliers' Perspectives of the Authenticity in Souvenir Products 'A case of Luang Prabang, Laos'}

Good morning/afternoon, thank you very much for your participation in this research. First, I would like to inform you that the main part of the interview today is to examine the souvenir suppliers' perceptions of, and attitudes toward, authentic souvenirs using Laos the case study, and in particular, Luang Prabang (LPB). Please feel free to share your information and you may ask questions for clarification if you feel it is unclear. This interview will take 45-60 minutes. There are five sections: You will be asked personal information in six questions, followed by at least fifteen discussion questions. Please inform me if you do not want to continue and would like to withdraw from this interview. You have the right to do so at any time.

\section{Section 1: Personal information}

1. How long have you worked in the souvenir industry?

(Please specify.

2. Which categories do you fit into? (Justify by researcher)

$\square$ Souvenir producers (SPs) $\square$ Souvenir vendors (SVs)

$\square$ Souvenir retailers (SRs) $\square$ Middleman

$\square$ Other (Please specify...........................)

3. Where do you reside?

LPB

Other provinces (Please

specify..... .)

$\square$ Overseas country (Please specify

4. Can you please tell us about your souvenir selling net profit per month?

$\square<1,000,000$ kips

2,000,000-3,000,000 kips

$\square>5,000,000 \mathrm{kips}$

ot comfortable sharing
1,000,000-2,000,000 kips

ㄱ $3,000,000-5,000,000$

Dot sure

O Other: 


\section{Section 2: Souvenir business in LPB from the suppliers' point of view}

1. Why have you been involved in the souvenir business? Can you compare your income before and after joining the souvenir business?

2. How do you feel about the souvenir market in LPB?

3. To what extent can the souvenir market in LPB provide good quality items at an appropriate price?

4. To what extent can the souvenir market in LPB provide locally produced souvenir products? Why or why not?

Sections 3: To identify the meaning of authentic souvenirs for suppliers

1. What does authentic souvenir mean to you?

2. Do you have criteria to identify authentic souvenirs? If yes, please elaborate why.

3. What criteria do you use when you select souvenir items to select/sell/make?

4. In your view, what are the authentic characteristics of LPB that tourists are looking for?

5. To producers: How do you select which souvenir products you should make?

6. To souvenir vendors, retailers, and middlemen: How do you select souvenir products?

Objective 3: To investigate the sources of souvenir supply through the suppliers' perspective in LPB

1. Who are the key stakeholders you need to maintain the relationship for the souvenir business in LPB?

2. Which stakeholder is the most important in your opinion, and why?

3. How and where do you get your items? (The local region? Laos? Overseas?)

4. To vendors and retailers: How do you choose your suppliers and obtain information about suppliers?

5. To middleman: How do you find out the main souvenir producers/makers and how do you find out the main customers and how is that information obtained?

6. To producers: And how do you obtain information about your potential customers?

And how do you choose what/which materials to use? Where do materials come from?

Objective 4: To explore and examine the most and least important values of souvenir products from the suppliers' perspectives

1. What are the most important values do you find from the souvenir sold in LPB? Would you address the value of souvenir products by categorising economic, social, environmental and cultural values?

2. What are the challenges of the souvenir being sold in LPB?

\section{Thank you very much for your participation!}




\section{Appendix B: Participant Consent Form}

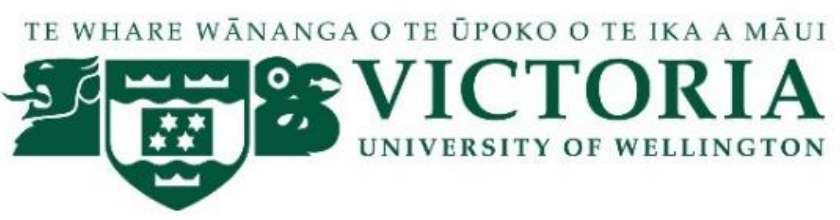

\section{PARTICIPANTS CONSENT FORM - INTERVIEWS}

Research title: Suppliers' Perspectives of Authentic Souvenir A case of Luang Prabang, Laos

Researcher: Bouavanh Soukhathammavong

Supervisor: Dr. Eerang Park

I have read and had explained to me, the Participant Consent Form. The researcher has also explained to me the purpose of this research and process of the interview. I understand that I can stop the interview at any time without any reason.

By signing below, I acknowledge that:

- My identity will be kept confidential, my real name will not be mentioned in any reports, unless otherwise agreed

- Confidentiality of information provided by the interviewee

- I may withdraw from this study four weeks after the interview, and any information that I have provided will be returned to me or destroyed

- The information I have provided will be destroyed three years after the research ends

- I permit any information I have provided to be interpreted, analysed, and published in student reports and in a thesis, as well as to be presented at conferences and to be available in other forms of publication such as journal articles and magazine or newspaper articles.

Please check/tick where is applied:

$\square$ I permit the researcher to make the audio/video recordings

$\square$ I permit the researcher to use my quotes in the research (without my identity)

$\square$ I request a summary of my interview

$\square$ I request to receive a summary of the report via my email address below.

I, agree and consent to the above statement.

Signature: Date:

Position: Suppliers' Types:

Mobile: E-mail: 


\section{Appendix C:Participant Information Sheet}

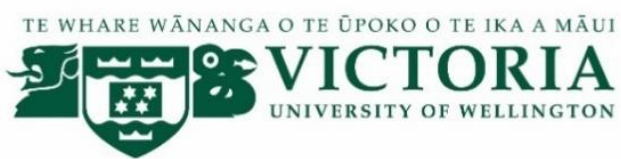

\section{INFORMATION SHEET FOR PARTICIPANTS \\ Research title: Suppliers' Perspectives of Authenticity in Souvenir Products.}

Thank you very much for your interest in this project. Please read this information before deciding whether or not you would like to take part in this survey.

My name is Bouavanh Soukhathammavong and I am a Masters' student in Tourism Management School at Victoria University of Wellington. This research project is part of my master completeness and I would love to welcome you to be part of this study. The study examines suppliers' perceptions of, and attitudes toward, authentic souvenirs with souvenir producers, souvenir retailers, souvenir producer, and middleman. You are invited to this research because you/your business belongs to one of the five groups of the supply system in Luang Prabang (LPB).

The outcome of this study will have both academic and practical benefit. For the academic contribution, this research will fill the existing gap in the area of tourism and souvenirs by providing/adding a platform of holistic understanding of souvenir suppliers' views on authentic souvenirs. As a practical contribution, key authorities could capitalise on the findings of this research due to the fact that these findings would not only benefit LPB souvenir businesses but also other provinces as it offers a business framework. Generally, this study can also be considered as ground-breaking in LPB, Laos, as well as in the context of developing countries.

The LPB Tourism Department and LPB souvenir businesses are aware that the research is taking place. Human ethics approval for this project has been obtained from Victoria University of Wellington (Approval number: 0000024730). The results of analyses will be presented in aggregated form and your quotes will be used in the report obtaining your consent to do so. Data will be stored for up to three years in a password-protected computer file.

If you agree to take part, I will interview you for 45 to 60 minutes. I will ask you questions about personal information, your motivation, perspective of authentic souvenirs, sources of souvenir supply, and souvenir market in LPB. The interview will be conducted using a voice recorder, and notes will be taken by the researcher to ensure that data is comprehensive.

Information you provided will be treated confidentially and used for research purposes only. You can withdraw from the interview at any time during the interview. In the case that you decide to discontinue, your incomplete interview record will be deleted.

If you have any questions about the project or would like to have further information, please contact me, Bouavanh Soukhathammavong (e-mail: soukhaboua @myvuw.ac.nz) or my supervisor, Dr. Eerang Park (e-mail: eerang.park@vuw.ac.nz or +64 4463 5726). You can also contact the the Victoria University HEC Convener: Associate Professor Susan Corbett. Email susan.corbett@ vuw.ac.nz or telephone +64-4-463 5480. 


\title{
12. Appendix D1: Research Approval Letter
}

\section{(English version)}

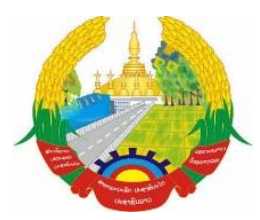

\author{
Lao People's Democratic Republic \\ Peace Independence Democracy Unity Prosperity
}

Luang Prabang Province

No: 019/ICT.LPB

LPB Department of Information Culture and Tourism Date9/5/2017

\section{Respond Letter/Approval Letter}

To: Head of the Institute of Mass Media Culture and Tourism, Ministry of Information Culture and tourism

Topic: Offering Approval Letter for conducting primary data in completeness of Master in the topic of Suppliers' perspectives on the authentic souvenir products, A case of Luang Prabang(LPB).

- According to the request letter of the institute of Mass Media Culture and Tourism, Ministry of Information Culture and tourism, number 230/, Vientiane capital, date 4/5/2017.

The department of Information Culture and Tourism of Luang Prabang province, respond to and inform to the institute of Mass Media Culture and Tourism, Ministry of Information Culture and tourism. With the request of supporting to Ms. Bouavanh Soukhathammavong, on her collecting data for her completeness of Master of Tourism Management and her thesis topic is 'Suppliers' perspectives on the authentic souvenir products in LPB'. The study uses LPB as the case study. We, the department of Information Culture and Tourism of LPB, are agreed with the request of using LPB as a research location and allow her to conduct data in this area. We will also support and assist her in further information that she requests and provide the convenience as much as we can do. This also includes the coordination with relevant parties/organisations to ensure her data collection is completely and successfully.

Thus, this letter is issued to confirm and inform the authorities

With due respect

Head of Department of Information Culture and Tourism

\section{Somok Phanthavong}

Note: This approval letter is written on behalf of researcher's working place (The Institute of Mass Media Culture and Tourism, Ministry of Information Culture and tourism) to request and seek approval for researcher in the LPB authorities (the original version in Lao language is shown in the next page) 


\title{
13. Appendix D2: Research Approval Letter \\ (Lao version)
}

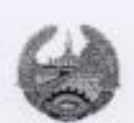

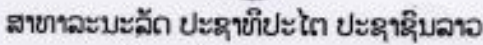

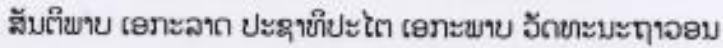

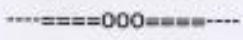 \\ แอองดูจอะะบา

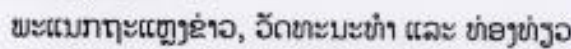

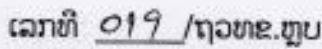 \\ ปะจ่าสเออง \\ วับชิ 9.5 .17$.

\section{ขับสิเเจ้วตยข}

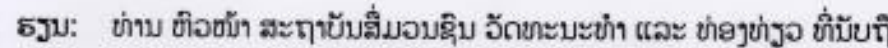

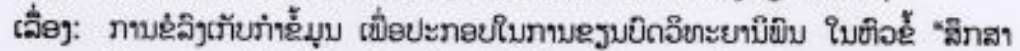

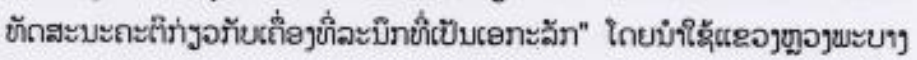 \\ เขับร่ละบิสึกสา
}

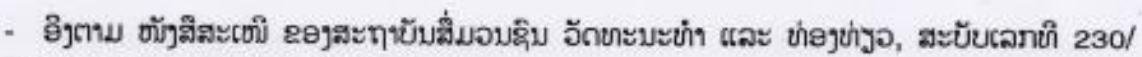

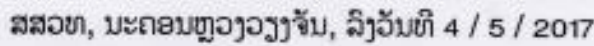

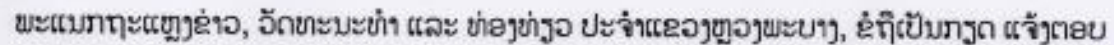

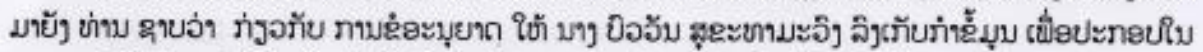

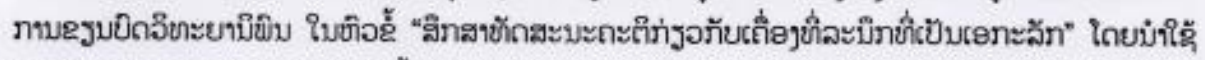

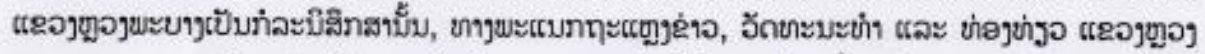

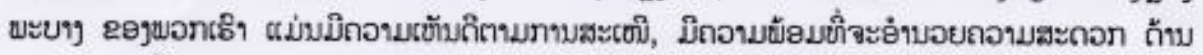

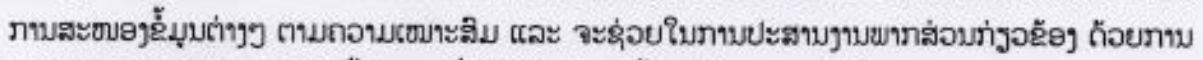

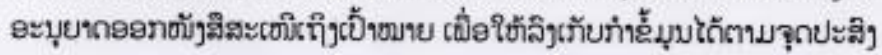

สะมั้ม, จึ่งอ่cเจ้วายบบบบัไย่าม เพื่อะาย

ธรมมาถ้อยถอนบบับฑึ

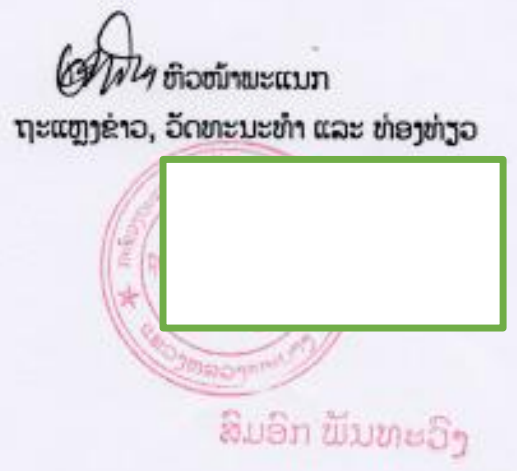

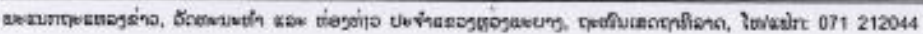

